\title{
PERCEPCIONES DE LA JUSTICIA EN ESPAÑA A \\ COMIENZOS DEL SIGLO XX: LOS ECOS DE LA CONSTITUCIÓN DE 1812
}

\section{PERCEPTIONS OF JUSTICE IN SPAIN IN THE EARLY TWENTIETH CENTURY: THE ECHOES OF THE CONSTITUTION OF 1812}

\author{
Miguel Ángel Morales Payán \\ Universidad de Almería
}

\begin{abstract}
SUMARIO: I.- INTRODUCCIÓN; II.- 1912; III.- EL CENTENARIO DE LA CONSTITUCIÓN DE 1812; IV.- EL ECO DE LOS POSTULADOS GADITANOS: 1. La estructuración territorial; 2. El orden judicial: 2.1. Trama orgánica: Partidos judiciales, Audiencias y Tribunal Supremo; 2.2. Textos normativos: 2.2.1. Los constitucionales: poder vs. administración; 2.2.2. Su desarrollo legislativo: 2.2.2.1. Primer tercio del XIX: los Reglamentos de Audiencias y Juzgados de Primera Instancia $y$ del Tribunal Supremo; 2.2.2.2. Segundo tercio del XIX: el Reglamento provisional para la administración de justicia; 2.2.2.3. Último tercio del XIX: La Ley Orgánica del Poder Judicial; 3. La herencia gaditana: 3.1. Los jueces: selección, inamovilidad y responsabilidad; 3.2.- La institución del jurado; 3.3.- La conciliación y el arbitraje; V.- OPINIONES CRÍTICAS; VI.- A MODO DE CONCLUSIÓN
\end{abstract}

Resumen: A lo largo del siglo XIX se configuró un modelo de organización de la justicia en España que supuso una ruptura con el anterior reinante desde la Edad Media. Aunque la Constitución de 1812 marcó las directrices, las circunstancias políticas provocaron que el proceso fuese muy largo y bastante ambiguo, no exento de constantes críticas. Este trabajo se sitúa justo cuando se celebra el primer centenario de aquélla tratando de determinar cuáles de sus planteamientos se hicieron realidad y cuáles no.

Abstract: Throughout the nineteenth century there was formed a model of organization of the justice in Spain who supposed a break with the previous rules valid from the Middle Ages. Although the Constitution of 1812 marked the directives, the political circumstances caused that the process was very long and ambiguous enough and with constant criticism. This work, rightly when the first centenary of Constitution of 1812 is celebrated, trying to determine which of his expositions made real and which not.

Palabras clave: Administración - Justicia - Constitución de 1812 - Centenario

Key Words: Administration - Justice - Constitution of 1812 - Centenary 


\section{INTRODUCCIÓN}

El 16 de septiembre de 1912 se celebraba el acto de solemne apertura de los tribunales en Madrid. Esta tradición, impuesta por exigencia legal, contaba en esta ocasión con la presencia de Diego Arias de Miranda y Goitia en cuanto Ministro de Gracia y Justicia. Tras el acostumbrado preámbulo en este tipo de eventos en el que el orador expresaba frente a su falta de merecimientos y modestia para dirigirse a los presentes su abnegado cumplimiento del deber ${ }^{1}$, pasó a rendir un breve homenaje a Jacobo López de Rueda ${ }^{2}$, juez de Sueca, que habia sido asesinado meses antes tras una revuelta popular ${ }^{3}$.

Una vez completado éste y transmitidos los saludos de la Corona, comenzó a desbrozar su discurso en el que destacaba la importancia de la justicia como cimiento de "toda sociedad bien organizada". En consecuencia, anunciaba la enésima reforma de la justicia: "está casi ultimado un proyecto de reforma de nuestra organización judicial”. Entre las previsiones sobresalian la necesidad de mudar los códigos penal ${ }^{4}$ y civil $^{5}$ y sus respectivas leyes de enjuiciamiento, el

1 El discurso, que lleva por título "La función judicial y las responsabilidades que su ejercicio impone como ponderación de la absoluta inamovilidad de los jueces y magistrados. Proyectos del Gobierno de S.M. sobre reformas legislativas", está publicado en la Revista General de Legislación y Jurisprudencia (en adelante RGLJ), no 121, 1912, pp. 193-226.

2 "La función judicial y las responsabilidades que su ejercicio impone como ponderación de la absoluta inamovilidad de los jueces y magistrados. Proyectos del Gobierno de S.M. sobre reformas legislativas", op. cit., p. 194: "Creo mi deber, ante todo, empezar mi modesto trabajo consignando el recuerdo doloroso de un hecho tristísimo acaecido en los comienzos del año judicial que acaba de terminar, que llenó de luto vuestro ánimo y el de todas las gentes honradas, que suscitó un sentimiento de general reprobación y que produjo la muerte de un dignísimo funcionario de la carrera judicial, que en los principios de ella hubo de dar su vida en holocausto al cumplimiento de su deber, dejando, a la vez que un imborrable recuerdo de su conducta, un ejemplo digno de imitación y una memoria honrada...".

3 Datos obtenidos en http://www.levante-emv.com/comunitat-valenciana/2011/09/18/cullera-1911levante-feliz/840774.html: “... En Cullera ocurrió que Jacobo López Rueda, juez de primera instancia del distrito judicial de Sueca, al enterarse de que el comité de huelga habia cortado los accesos a la ciudad e impedía la salida de reservistas, al igual que en otras poblaciones, enroló en un coche a su propio hijo, a sus ayudantes y a los hijos de uno de ellos y se fue a la población cullerense. En la entrada de Cullera se encontraron con un piquete huelguista y tras un enfrentamiento detuvo a dos de ellos y los subió al carruaje. Uno de ellos era un vecino muy conocido en la población: el Xato de Cuqueta, que posteriormente tendrá una destacada participación en los acontecimientos. La comitiva judicial se adentró con los detenidos en el pueblo. De inmediato, autoridad judicial y detenidos fueron reconocidos por los piquetes y la población, que estaba en la calle apoyando el movimiento contra la guerra. Numerosas personas rodearon el carruaje con el objeto de liberar a los detenidos. Y de la liberación se pasó a la ira. E1 secretario y el alguacil resultaron muertos en la refriega. Los demás pudieron refugiarse en el ayuntamiento. La Guardia Civil, movilizada por el gobernador militar para "sitiar" la ciudad de Valencia en previsión de manifestaciones, no pudo intervenir. No estaba. Pasó lo mismo en las demás poblaciones. Encerrados en el consistorio el juez y parte de la comitiva, la corporación municipal intentó apaciguar los enfurecidos ánimos de los huelguistas. En esta situación el juez sacó una pistola y disparó varias veces contra la población desde el balcón del ayuntamiento. Lejos de dispersarlos, como parecía que era su intención, embraveció aún más los ánimos populares, los cuales acabaron asaltando el ayuntamiento, dando muerte al juez y a su habilitado...".

${ }^{4}$ Así, por ejemplo para adecuarlo a las diversas leyes promulgadas con posterioridad como las relativas al descanso dominical, derecho de huelga, propiedades industrial e intelectual, bandolerismo... 
acometer una profunda transformación del modelo penitenciario ${ }^{6}$, el elevar las exigencias a los servidores de la justicia ${ }^{7} \mathrm{y}$, sobre todo, la creación de tribunales especiales para niños a los que dedicó una especial atención ${ }^{8}$.

Pero quizá, lo que más llame la atención de su larga alocución, en lugar de las novedades previstas, es que realzaba el buen hacer de una extensa nómina de disposiciones legislativas como la Ley Orgánica del Poder Judicial, el Código penal, la ley de Enjuiciamiento criminal o la del Jurado considerándolas exclusivamente fruto del espíritu revolucionario de 1868 olvidándose por completo, en un año tan emblemático como 1912, de la herencia gaditana, que, sin embargo, había sido pionera en el ordenamiento jurídico en exigencias tan básicas y elementales como la independencia, la inamovilidad o la responsabilidad judicial contenidas en la primera de las normas aludidas o las propias exigencias codificadoras o de participación popular en la administración de justicia que darían paso a las demás9.

5 Especialmente en lo tocante al 'arrendamiento de obras y servicios' que resulta insuficiente para las exigencias del momento.

6"La función judicial y las responsabilidades que su ejercicio impone como ponderación de la absoluta inamovilidad de los jueces y magistrados. Proyectos del Gobierno de S.M. sobre reformas legislativas”, op. cit., p. 216: “... asunto de la mayor importancia y trascendencia...".

7 Para tal fin se propone la creación de un 'Consejo judicial'. "La función judicial y las responsabilidades que su ejercicio impone como ponderación de la absoluta inamovilidad de los jueces y magistrados. Proyectos del Gobierno de S.M. sobre reformas legislativas”, op. cit., p. 198: que "como cuerpo consultivo del Ministro, entienda en todo lo relativo al nombramiento, traslación, reingreso, jubilación y destitución de Magistrados, Jueces y Fiscales....".

8 "La función judicial y las responsabilidades que su ejercicio impone como ponderación de la absoluta inamovilidad de los jueces y magistrados. Proyectos del Gobierno de S.M. sobre reformas legislativas", op. cit., p. 204: "Asunto por demás interesante y acerca del cual creo indispensable exponeros algunas consideraciones, es uno que fue recientemente objeto de iniciativa parlamentaria, en el acto recogido con gratitud y con entusiasmo por el Gobierno, y que éste se propone llevar inmediatamente a la práctica, siquiera sea bajo la forma de un modesto ensayo que pueda ser, como en otras naciones ha sido, germen y origen de instituciones altamente beneficiosas desde el punto de vista social y jurídico; me refiero a los Tribunales especiales para niños, que, originarios de América, se han extendido de pocos años a esta parte por la naciones europeas, constituyéndonos a nosotros en una dolorosa excepción que hay que hacer desaparecer a toda costa...".

9 "La función judicial y las responsabilidades que su ejercicio impone como ponderación de la absoluta inamovilidad de los jueces y magistrados. Proyectos del Gobierno de S.M. sobre reformas legislativas”, op. cit., p. 197: “... sin que ello implique que se desconozca lo merecedora que es de todos nuestros respetos la actual ley Orgánica, que constituye un verdadero monumento jurídico, en el cual se atiende con verdadero acierto todas las necesidades de la vida de los Tribunales, y que unido al Código penal, a la ley de Enjuiciamiento criminal, al establecimiento del Registro y Matrimonio civil, a la instalación del Jurado, a la ley para el ejercicio de la gracia y de indulto y a otras disposiciones no menos interesantes, constituyen, por decirlo así, la expresión jurídica de la revolución de Septiembre...". 


\title{
II. 1912
}

España inaugura ese año, el del centenario de La Pepa, regida por una 'monarquía parlamentaria' que recaía en la persona de Alfonso XIII. El nieto de la destronada Isabel II llevaba una década ciñendo la corona bajo la cobertura legal de un texto constitucional, el de 1876, que desde hacía más de treinta y cinco años cobijaba al comúnmente denominado 'sistema bipartidista' en el que conservadores y liberales se turnaban en el goce del poder. Un artificio político que dejaba al margen de las decisiones politicas a gran parte de la sociedad y que empezaba a mostrar algunos síntomas de agotamiento siendo, quizá, de los más llamativos, el que se produjo tres años antes, la denominada crisis de 1909, concretada, de un modo profundamente revelador, en la 'Semana trágica de Barcelona'. Para numerosos historiadores "el primer y muy serio aviso histórico sobre el resquebrajamiento del sistema canovista" 10 .

Desde ese aciago aldabonazo que supuso, entre otras cosas, la salida de Maura del gobierno bajaban especialmente revueltas las aguas y no sólo en politica interior sino también en el plano internacional, primordialmente, en cuanto a las relaciones diplomáticas con Francia y con la Roma papal. Respecto a la primera, la compleja cuestión marroquí enturbiaba los lazos vecinales desde hacía algún tiempo. De hecho, el diario ABC del día 19 de marzo, publicaba una nota en la que daba cuenta de la complejidad de las negociaciones:

\begin{abstract}
"Afirma un periódico que el Gobierno francés ha rechazado en su totalidad el contraproyecto español y que pide al Gobierno de Madrid que formule nuevas proposiciones. En los centros oficiales no se cree en una ruptura próxima de las negociaciones... España no ha dicho su última palabra y hay que esperar las nuevas proposiciones para saber si se camina hacia la conciliación o hacia la ruptura" 11 .
\end{abstract}

Unas relaciones que no se restauraron hasta casi final de año, concretamente el 27 de noviembre, con el Acuerdo hispano-francés sobre Marruecos en virtud del cual se creaba el Protectorado español en paralelo al francés ${ }^{12}$.

En cuanto a la sede pontificia la llegada a la presidencia del gobierno español del liberal Canalejas ${ }^{13}$, en febrero de 1910 , supuso un notable aumento de la tensión. Gallego, liberal militante, con un futuro prometedor aunque sin un partido fuerte detrás que lo respaldara, tenía una comprometida tarea por delante cuando asumió las riendas del ejecutivo. Con un talante netamente reformador fue capaz de, en apenas poco más de dos años, sacar adelante varios proyectos de modernización del país. Pero su labor también causó notable revuelo en los

10 Vid., entre otros, A. Bahamonde (Coord.), Historia de España. Siglo XX. 1875-1939, Madrid, 2000, especialmente pp. 376 y ss.

11 http://hemeroteca.abc.es/nav/Navigate.exe/hemeroteca/madrid/abc/1912/03/12.html.

12 A. Bahamonde, (Coord.), Historia de España. Siglo XX. 1875-1939, op. cit., pp. 392-396.

13 Vid. L. Antón del Olmet, y A. García Carraffa, Los grandes españoles. Canalejas, Madrid, 1913. 
sectores más reaccionarios de la sociedad que no le perdonaban sus decisiones en materia eclesiástica, especialmente, la publicación de la comúnmente denominada Ley del Candado. El papa Pío X, que resultará "decisivo en los destinos del catolicismo español contemporáneo"14, no aceptó de buen grado que el gobernante hispano hiciera del problema religioso "el punto axial de su política"15. Desde hacía varias décadas la cuestión clerical incidía de lleno en la politica nacional, especialmente en el seno del proyecto liberal, pero la publicación de dicha norma tensó la cuerda hasta el extremo de suspender las relaciones con la Santa Sede.

Un conjunto de decisiones tachadas de anticlericales, una notable inquina papal y una denodada labor integrista desde ciertas facciones católicas eran un cóctel demasiado explosivo que sólo podía traer consigo, como así fue, el acrecentamiento de la intransigencia entre diversos sectores de la sociedad hispana que se van configurando como enemigos irreconciliables. Máxime cuando la intervención del clero en la vida política era muy activa, al igual que lo había sido durante el curso de toda la centuria anterior, además, de modo prioritario, por una opción y unos principios políticos muy definidos ${ }^{16}$.

El fraccionamiento social, materializado con el propio asesinato de Canalejas ese azaroso año de 1912, venía gestándose desde tiempo atrás y se manifestaba en cualquier ocasión y por cualquier motivo. Muestra reveladora de ese enconamiento puede ser el propio hecho de la conmemoración del centenario de la Constitución de 1812. Pocos años antes, siete, nada más lanzar el alcalde gaditano Gómez de Aramburu ${ }^{17}$ la idea de rememorar la labor llevada a cabo en el siglo anterior por las Cortes reunidas en su ciudad y, de modo especial, su obra

14 J.M. Cuenca Toribio, "El Catolicismo español en la Restauración (1875-1931)", en AAVV, Historia de la Iglesia en España. V. La Iglesia en la España contemporánea, dirigida por R. Garcia Villoslada, Madrid, 1974, p. 305.

15 J.M. Cuenca Toribio, “El Catolicismo español en la Restauración (1875-1931)”, op. cit., p. 313 : “... de cuya favorable solución, sobre la base de la supremacia civil, dependia en gran parte la duración y viabilidad de su ministerio. En la prosecución de tal objetivo acometió sin tardanza unas prometedoras negociaciones con el Vaticano, que desembocarian poco después en un punto muerto, ante la irreductible defensa por Roma de su soberanía total en materia disciplinar".

16 J.M. Cuenca Toribio, “El Catolicismo español en la Restauración (1875-1931)”, op. cit., pp. 314-315: “La aspereza de la controversia religiosa levantada en torno a la 'Ley del Candado' dejó ver las débiles bases culturales sobre las que descansaba la cristiandad hispánica. Anclada en unos parámetros ideológicos superados por las corrientes dominantes en la Europa de la 'belle époque', sus esfuerzos por ser fiel a su tiempo fueron, en conjunto, dispersos y esporádicos. Quizá, como a fines del XIX, la raíz más honda de tal desfasamiento deba buscarse en la mediocridad de la formación del clero... En una España en la que, en contraste con su retraso socioeconómico, las letras conocían momentos cenitales -el 'siglo de la plata' de que hablaba Gregorio Marañón-, los tonos grisáceos de la cultura católica resaltaban aún más la brillantez de la labor de los hombres del 98 y de la generación de 1913". Casualmente, el ABC del día 19 de marzo de 1912 daba cuenta de la publicación por Juan Ramón Jiménez de su nuevo volumen Poemas mágicos y dolientes del que se decía que contenía poemas "tan finos, tan delicados, tan espirituales como los anteriores. Pocos períodos podrán citarse en nuestra historia literaria tan ricos de poesía lírica como el actual... No habría para demostrarlo que citar los nombres de Ramón Pérez de Ayala -exquisito prosista a más de delicado poeta-, Díez Canedo, Antonio y Manuel Machado, Villaespesa, Valle Inclán, Cristóbal y Miguel de Castro, Marquina, Carrere, Enrique de Mesa, Muñoz Sanromán... La lista podría alargarse todavía más...”.

17 Vid., al respecto, C. Mateos Alonso, "La conmemoración del primer centenario del sitio, las Cortes y la Constitución de 1812”, Cuadernos de Ilustración y Romanticismo, n 11, 2003 , p. 180. 
jurídica cumbre, la Constitución de 1812, se produjo un agrio debate sobre su conveniencia o no, sobre el cómo y el de qué manera. Al respecto apunta Moreno Luzón que "desde que comenzó a hablarse de las conmemoraciones, las derechas católicas se opusieron radicalmente a la idea"18. En esa línea, periódicos marcadamente confesionales como El Siglo Futuro o El Debate lanzaron fuertes diatribas contra lo que el texto constitucional significó y sobre la conveniencia de evocarlo.

\title{
III. EL CENTENARIO DE LA CONSTITUCIÓN DE 1812
}

Sin embargo, desde la orilla contraria, "para los liberales monárquicos, la Constitución de 1812 se hallaba en el origen del sistema político de la Restauración"19. En consecuencia, la conmemoración de fecha tan emblemática quedaba fuera de toda duda. Así pues, llegado el momento, un diario de marcada tendencia progresista, como El País, le dedicó notable atención. El mismo día que el texto cumplía cien años desde su promulgación esta gaceta abría su portada con el siguiente titular: "Centenario glorioso. Las Cortes de Cádiz.- La Constitución de 1812" ${ }^{20}$. De los varios artículos que incluye la edición merece la pena detenerse en dos. Uno firmado por Rafael M. de Labra, quien, sobre todo, honra el protagonismo que tuvo la sociedad de la época en su conjunto en la toma de decisiones para el cambio de rumbo del país:

\begin{abstract}
"Una de las notas más señaladas del gran movimiento renovador y fortificante de España de 1808 a 1814, consiste en la activa y calurosa participación que tuvieron en él todas las clases y las representaciones de la sociedad española, abandonada en aquella suprema crisis por todos sus viejos elementos directivos. Hombres y mujeres, eclesiásticos y seglares, pobres y ricos, ciudadanos y campesinos, jóvenes y viejos, sobresalientes y desconocidos... todos intervienen, actúan y aparecen en primera fila...".
\end{abstract}

Y el otro, a cargo de Rafael Salillas, que titulado 'Con las Cortes cerradas', opta por denunciar la paradoja que supone el estar celebrando la aprobación de un texto jurídico que supuso, entre otras cosas, la implantación de la libertad política, la limitación de poderes del estado, su separación y la participación ciudadana en el gobierno del país a través de una institución como las Cortes

18 J. Moreno Luzón, "Memoria de la nación liberal: el primer centenario de las Cortes de Cádiz", Ayer, no 52, 2003, pp. 209-210: “... Para los sectores antiliberales, mayoritarios en el catolicismo político español, las Cortes de Cádiz habian originado todos los males de la España contemporánea. Hijos del enciclopedismo y adscritos a la masonería internacional, los diputados reunidos en la isla de León, primero, y en el oratorio de San Felipe Neri, después, habian atacado con todas sus fuerzas a la Iglesia y a las auténticas tradiciones españolas...".

19 J. Moreno Luzón, "Memoria de la nación liberal: el primer centenario de las Cortes de Cádiz", op. cit., p. 213.

20 Pocos fueron los diarios que prestaron atención especial al día de la celebración del centenario. En este sentido, en la mayoria de los periódicos, ni siquiera en todos, se daba una vaga cuenta de los actos festivos celebrados en la ciudad de Cádiz únicamente, sin prestarle una dedicación diferenciada ni al texto constitucional ni a las propias Cortes (vid. al respecto http://www.bne.es/es/Catalogos/HemerotecaDigital/) 
cuando éstas, precisamente, en ese momento estaban cerradas por decisión del ejecutivo, personalizándola, paradójicamente, en la figura del liberal Canalejas, su presidente:

\begin{abstract}
"Estaba convenido que, para conmemorar modestamente el centenario de la promulgación de la Constitución de 1812, acordara el Congreso publicar en su Diario de Sesiones, el acta correspondiente a aquella fecha memorable. Ni este homenaje, por demás modesto, ha podido ser ¿Será significativo lo que ocurre? ¿Será simbólico? Si no es significativo ni simbólico, es verdaderamente singular, no por otra singularidad que la muy proporcionada y justa de los equivalentes, porque a una nación que ha tratado a sus Constituciones con irrespetuosas demasías y licencias, y que, como lo pidió en su tiempo el doceañista García Herreros, no ha sabido formar el alma civil del Estado, le tenía que corresponder, en el que de cualquier manera es gloriosísimo centenario, el papel mezquino de conmemorar la promulgación de la Constitución de 1812, con las Cortes cerradas”.
\end{abstract}

Otro de los periódicos que prestó especial atención al acontecimiento, el $\mathrm{ABC}^{21}$, ese día dedicaba su portada a Segismundo Moret. Con la declarada pretensión expuesta en el número que lo presentó en sociedad de "en política no seguir bandera alguna para no mermar su independencia"22, llevaba casi una década trabajando en el mundo de la información cuando ese martes 19 de marzo de 1912, el rotativo optó porque la fotografia de medio cuerpo del veterano politico gaditano, con un trasfondo en el que se atisbaba una efigie dedicada en Cádiz a su persona, ocupara toda la página. Al pié de la misma, un breve texto:

"El ilustre hombre público a quien los gaditanos tributaron ayer, ante su estatua $^{23}$, una entusiástica manifestación de simpatía, con motivo de su llegada para tomar parte de las solemnidades del Centenario de las Cortes de Cádiz".

Momentáneamente Moret $^{24}$ se habia apartado de la primera línea politica. Derrotado por el control del partido liberal y tras tres duros meses al frente de la

21 http:/ / hemeroteca.abc.es/nav/Navigate.exe/hemeroteca/madrid/abc/1912/03/12.html

22 Así lo afirma en su número del 1 de enero de 1903: "ABC es un periódico de información universal que nace para ser diario. Lo sería desde el presente número si la complicada maquinaria indispensable para editar una publicación de estas características estuviese ya montada en nuestros talleres... Pretende ABC no ser un periódico más, sino un periódico nuevo por su forma, por su precio, por los procedimientos mecánicos que empleará y por la índole de sus trabajos... ABC cultivará preferentemente la información gráfica, haciéndola objeto de especial cuidado para ofrecer en ella cuanto pueda interesar al público. En politica no seguirá bandera alguna para no mermar su independencia, dentro de la cual se propone vivir sin abdicar uno sólo de sus fueros...”.

23 La estatua era obra de Querol y se colocó en la plaza de Isabel II, siendo inaugurada el 29 de noviembre de 1909 según L. Antón del Olmet y A. García Carraffa, Los grandes españoles. Moret, Madrid, 1913, p. 21.

${ }^{24}$ L. Antón del Olmet y A. García Carraffa, Los grandes españoles. Moret, op. cit., p. 11: "Era el otoño de 1912. Aún no había sido asesinado D. José Canalejas. Don Segismundo Moret, un poco 
presidencia del Consejo de ministros vagaba en un voluntario paréntesis que rompió tras el asesinato de Canalejas para ocupar la presidencia del Congreso de los Diputados, cargo que desempeñaria hasta su muerte.

El impasse en que se encontraba no le privó, sin embargo, de tener un notable protagonismo en los actos que con motivo del centenario de La Pepa se habían de celebrar en la ciudad que le vio nacer. El noticiero se hacía eco de los planes de visita previstos para la semana que iba a pasar entre sus paisanos. Así, detallaba que entre sus propósitos se encontraban el fiscalizar las obras del muelle gaditano ${ }^{25}$, dar una vuelta por las cercanas localidades de Jerez y Sevilla para, finalmente, regresar a Madrid el lunes siguiente. Dejaba constancia de cómo se había negado a "hablar de política con los periodistas que, sobre tal materia, le han interrogado" matizando, únicamente, que mantenía un notable optimismo en relación con la negociación que se mantenía con Francia respecto al dominio de Marruecos $\mathrm{y}$, por supuesto, anunciaba que tenía previsto pronunciar un discurso que habría de versar sobre las 'Cortes de Cádiz y la Constitución'.

El rotativo daba cuenta en páginas interiores de otras noticias relacionadas con actos conmemorativos del primer centenario del célebre texto constitucional. Primero circunscritas a Madrid. Así, mientras que por una parte informaba a sus lectores de una serie de conferencias que en el Centro de Instrucción Comercial había organizado el catedrático de la Universidad Central Pío Zabala ${ }^{26}$, por otro, se hacía eco de la petición, liderada por el Ateneo madrileño y dirigida al ayuntamiento de la capital del reino, para que se cambiara el nombre de dos céntricas plazas de la localidad: la 'de los Ministerios' por el de 'Plaza de D. Ramón Lázaro Dou', en cuanto "primer presidente de las Cortes de 1810 a 1812 " y la del 'Senado' por 'Plaza de José Miguel Gordoa', "diputado mejicano, que fue el último presidente de aquellas Cortes”.

Junto a estas nuevas de la capital, el diario insiste en su particular homenaje al texto constitucional dando rendida cuenta de las celebraciones acontecidas en la ciudad de Cádiz. Con un expresivo 'Cádiz en fiestas. Centenario de la Constitución' daba paso a un extenso artículo en el que se loaba la egregia obra. Al par que honraba su nacimiento advertía que no se debía interpretar como una conmemoración puramente local sino genuinamente nacional, en la medida que significaba, por un lado, el cierre de "la época moderna" y, por otro, que se emprendiera "la narración de los Anales contemporáneos". Proseguía con un repaso de su devenir para concluir subrayando su trascendencia posterior, afirmando, de modo categórico:

distanciado de la mayoría liberal por haber votado contra el proyecto de Mancomunidades provinciales aprobado en el Congreso, vivía como en cierto retiro...".

25 Curiosamente, en una de sus reseñas, explicaba que ya había hecho la inspección a las obras del puerto y que había provocado que "el numeroso público allí congregado lo aclamara con entusiasmo".

26 "Habló en primer término el Sr. Oliveira Calheiros, distinguido joven portugués, quien hizo un concienzudo estudio de las Juntas provinciales, Central y de la Regencia, ilustrando su disertación con magníficas proyecciones. Después, el Sr. Zabala pronunció un interesantísimo discurso, en el cual, con cálida elocuencia y vigoroso concepto, analizó la génesis del espíritu constitucional y la transformación que implica el régimen representativo. Fue una conferencia de irreprochable forma y de sólido fondo; un trabajo de profunda huella. El auditorio aplaudió mucho y muy justamente al maestro y al alumno". 
"La conmemoración de hoy es bastante a suscitar no sólo estas ideas, sino el desfile de toda nuestra historia durante el siglo XIX. Ella se desenvuelve bajo la influencia de los discursos de Cádiz; las deliberaciones de las primeras Cortes tienen un amplio eco que resuena aún".

\section{EL ECO DE LOS POSTULADOS GADITANOS}

No iba muy desencaminado el autor del artículo pues buena parte del contenido del texto constitucional, de una manera $u$ otra, se había hecho realidad. A pesar de las criticas que desde sus origenes la norma jurídica había suscitado, era indudable que la Constitución de 1812 había sentado unas bases que cien años después seguian en pié y habian resultado harto beneficiosas para el país ${ }^{27}$.

Es cierto que hubo varios temas cuyo planteamiento fue imposible realizar a lo largo de todo el siglo y, simplemente, se abandonaron, bien por impedirlo las circunstancias, bien por ser objeto de rotundo rechazo, bien por otro tipo de considerandos (la unicameralidad, la confesionalidad excluyente...); otros fueron objeto de duras disputas, adoptándose una línea zigzagueante según quien tuviese las riendas del poder (la cuestión de la soberanía, el tema religioso, los derechos individuales...); finalmente, también hubo algunos que se aceptaron no sin cierto disenso (la corona -con muchos matices-, la participación de cierto modelo de partido político...). Pero de todos los frentes que se abrieron, quizá, los que mejor aguantaron a lo largo de toda una centuria fueron las propuestas de organización territorial y judicial que, por otra parte, tenían unos nexos ineludibles ${ }^{28}$.

\subsection{La estructuración territorial}

En este sentido, de manera muy simplificada, podíamos presentar los nuevos postulados organizadores doceañistas señalando que, desde el punto de vista gubernativo, frente al régimen polisinodial y los corregidores propios de los Austrias y su intento de superación por los primeros Borbones con los Secretarios de Estado y los intendentes, se aspiraba a conseguir una administración local próxima al ciudadano y residenciada en el municipio; una administración intermedia o territorial representada por la provincia que habia de coordinar los intereses supramunicipales y una administración central como escalón supremo en defensa de los intereses generales. Dicho en términos institucionales, frente al súbdito, ahora, al ciudadano, le debian gestionar sus asuntos los alcaldes, que dirigian el ayuntamiento, los jefes politicos en cuanto presidian las diputaciones y, finalmente, el gobierno titular del poder ejecutivo.

27 El mismo hecho de que la clase politica exigiera fijar el modelo de sociedad que quería imponer en un texto constitucional (bien fuese el propio del 12 o los de 1834, 1837, 1845 y 1869 , amén de otro sinfin de proyectos), independientemente de que después se cumplieran o no en la práctica, era prueba palpable de cómo habían cuajado ciertas exigencias de los doceañistas.

28 Vid. al respecto C. Garriga; M. Lorente, Cádiz, 1812. La Constitución jurisdiccional, Madrid, 2007, especialmente pp. 373 y ss. 
Desde la perspectiva jurisdiccional, se trataba de organizar un modelo piramidal paralelo muy simple: un juez cercano al ciudadano, el de partido o primera instancia, un tribunal intermedio que revisase la actuación de éstos, las audiencias, y en la cúspide, el Tribunal Supremo, que había de vigilar la labor de los anteriores ${ }^{29}$.

La necesaria separación de poderes, especialmente entre ejecutivo y judicial, la forzosa distinción entre jueces y magistrados, por una parte, y alcaldes, jefes políticos y demás jerarquía, por otra, no fue óbice para que la Constitución de 1812 y las normas que la desarrollaron establecieran la necesidad de compartir, a efectos organizativos, la misma base territorial, el mismo bien común: la provincia. Una concepción provincial percibida bajo un nuevo prisma, muy distinto de como se concebía en la tradición institucional castellana heredada de la Edad Moderna ${ }^{30}$. Ahora debía encarnar una división del territorio "con vistas a facilitar la acción del poder central encaminada al bienestar de los individuos que componen la nación"31. Comúnmente indica la doctrina que el nuevo modelo de

29 J. Escriche, Diccionario razonado de legislación y jurisprudencia, I, Madrid, 1847, p. 111, definía la administración pública como "La parte de la autoridad pública que cuida de las personas y bienes en su relación con el Estado, haciéndolos concurrir al bien común y ejecutando las leyes de interés general, a diferencia de la justicia que tiene por objeto los individuos y bienes en sus relaciones particulares de individuo a individuo, aplicando las leyes de interés privado. La administración considera a los hombres como miembros del Estado y la justicia como individuos: ésta se ejerce por los jueces, audiencias, tribunales supremos; y aquélla por los alcaldes y ayuntamientos y los jefes públicos, etc.".

30 E. Garrigós Picó, Las Autonomias: historia de su configuración territorial, Madrid, 1995, p. 23: "En el siglo XVI, la 'provincia' estaba ligada a las ciudades con voto en Cortes. Cada una de las dieciocho provincias que, con Navarra y Vascongadas, configuraban el territorio castellano, tenían por capital una ciudad con voto en Cortes, cuyo origen debe buscarse varios siglos atrás. Hasta el siglo XIV, muchas ciudades realengas castellanas participaban con voz y voto en las Cortes que convocaba el rey. Generalmente, estas convocatorias a Cortes obedecían a la necesidad de la Corona de recaudar fondos mediante nuevos impuestos, y éstos debian ser aprobados en las Cortes. La cantidad aprobada era repartida para recaudar entre todas las ciudades con voto en Cortes que, a su vez, la redistribuían, asignando cupos a los núcleos de población que representaban".

31 Vid., entre otros, F. Caballero, "Proyecto de división territorial de España para todos los ramos del servicio”, RGLJ, n 39, 1871, pp. 143-195; J. Gascón y Marín, La administración provincial española. Sus problemas, Madrid, 1942; J. Beneyto, Historia de la Administración española e iberoamericana, Madrid, 1958; J. del Moral, La provincia y el gobernador civil (el movimiento y la configuración de la vida local), Madrid, 1961; M.A. Pérez de la Canal, Notas sobre la evolución del régimen legal de los gobernadores civiles (1812-1958), Madrid, 1964; VVAA, Dimensión politica de la provincia, Barcelona, 1965; S. Martín Retortillo et alii, Descentralización administrativa $y$ organización politica. I. Aproximación histórica (1812-1931), Madrid, 1973; A. Guaita, "La división provincial y sus modificaciones" en VVAA, Actas del III Symposium de historia de la Administración, Madrid, 1974, pp. 309-352; G. Martínez Diez, “Génesis histórica de las provincias españolas” en Anuario de Historia del Derecho Español, $n^{\circ}$ 51, 1981, pp. 523-593; E. Garrigós Picó, “Organización territorial a fines del Antiguo Régimen” en M. ARTOLA (dir.), La economía española al final del Antiguo Régimen, Madrid, 1982, pp. 1-105; E. Baraja; A. Cifuentes, La provincia. Pasado, presente y futuro, Cádiz, 1985; A.M. Calero Amor, La división provincial de 1833. Bases y antecedentes, Madrid, 1987; F. Bermejo Martín y J.M. Delgado Idarreta, La administración provincial española: la Diputación Provincial de la Rioja, Logroño, 1989; J. Lalinde Abadía, "El orto de la provincial constitucional en España” en VVAA, La provincia en el sistema constitucional, Madrid, 1991, pp. 493-511; J. Burgueño, Geografía politica de la España constitucional. La división provincial, Madrid, 1996; A.L. Cortés Peña y J. Marina Barba, Proyectos de división territorial en la crisis del Antiguo Régimen. Granada, de reino a provincia, Granada, 1997; E. Orduña Rebollo, "El municipio y la organización territorial del Estado constitucional” en VVAA., El municipio constitucional. II Seminario de Historia de la Administración, Madrid, 2003, pp. 77-120; del mismo 
provincias no sólo perseguian modificar la organización territorial existente tratando de fijar unos límites y proporciones más racionales, sino que todas las actividades administrativas, gubernativas y judiciales vinieran a coincidir en unas mismas unidades territoriales básicas que cubriesen uniformemente todo el territorio de la Monarquía.

No hay que perder de vista que España había iniciado su andadura decimonónica con treinta y seis provincias cuya conformación no respondía a criterios lógicos. En perjuicio de la racionalidad predomina una amalgama de circunstancias históricas, entre las que la guerra contra los musulmanes había tenido un protagonismo extremo. En las estructuraciones territoriales resultantes primaba un incontestable axioma fiscal, especialmente en su vertiente recaudadora, que había ido otorgando preponderancia a las ciudades de rancio abolengo, con voz y voto en Cortes, en torno a las que se aglutinaban las demás poblaciones menores. Tanto Carlos III como Carlos IV dieron algunos pasos para transformar la situación. Pero tan insustanciales que José I, revestido del aura reformadora de los Bonaparte, en su malogrado proyecto de gobierno, decidió acometer una profunda reforma que racionalizase este arquetipo de administración territorial. Como no podía ser de otra manera, siguió el modelo francés de división prefectural, partiendo de una serie de demarcaciones básicas con una superficie más o menos homogénea, donde se tenían en cuenta principalmente los criterios geográficos (esencialmente la orografia y la hidrografia), junto con algunas variantes politicas minorando la importancia de los criterios históricos. No tuvo, sin embargo, efectividad práctica pero sirvió para concienciar a los liberales opuestos al dominio galo de la urgencia en la modificación de la estructuración territorial. De ahí que, en esa "otra España", la no ocupada por los franceses, los constituyentes gaditanos plasmasen ese deseo en el conocido art. 11 de la Constitución de 1812: "Se hará una división más conveniente del territorio español por una ley constitucional". Pero dada la situación de guerra y ocupación por la que atravesaba el país añadieron: "luego que las circunstancias politicas de la Nación lo permitan".

Esas circunstancias abocaron, entre otras cosas, a la promulgación de un Decreto de las Cortes, el CLXIV con fecha de 23 de mayo de 1812, con el que se pretendía el "Establecimiento de las Diputaciones provinciales en la Península y Ultramar". Según se explicita en el mismo:

"las Cortes generales y extraordinarias, con el objeto de facilitar la execución (sic) del artículo 325 de la Constitución, y de que pueda verificarse, luego que se publique, el útil establecimiento de las Diputaciones provinciales, decretan: I. Que mientras no llega el caso de hacerse la conveniente división del territorio español, de que trata el artículo 11, habrá Diputaciones provinciales en la Península e Islas adyacentes, en Aragón, Asturias, Ávila, Burgos, Cataluña, Córdoba, Cuenca, Extremadura, Galicia, Granada, Guadalaxara (sic) con Molina, Jaén, León, Madrid, Mancha, Murcia, Navarra, Palencia, en cada una

autor, Municipios y provincias. Historia de la Organización Territorial Española, Madrid, 2003; J.A. Pérez Juan, Centralismo y descentralización. Organización y modelos territoriales en Alicante (18121874), Madrid, 2005; E. Orduña Rebollo; L. Cosculluela Montaner, Historia de la Legislación de Régimen Local, Madrid, 2008; R. Polo Martín, Centralización, descentralización y autonomía en la España constitucional, Madrid, 2014. 
de las provincias Vascongadas, en Salamanca, Segovia, Sevilla, Soria, Toledo, Valencia, Valladolid, Zamora, Islas Baleares, e Islas Canarias...”.

Esta normativa traía consigo un plantel de 31 demarcaciones territoriales al frente de las cuales, como órgano de gobierno, aparecía un elemento ciertamente novedoso en el contexto institucional castellano: la Diputación provincial ${ }^{32}$.

Enorme expectativa generó el nuevo órgano administrativo que pronto acabaria en frustración dado el corto margen de actuación que tuvo por el abrupto proceder de Fernando VII que con el R.D. de 4 de mayo de 1814 abolió la obra liberal en general y por el de 15 de junio de 1814 las diputaciones provinciales en particular. Apenas poco más de un año de vida en los que estas neófitas corporaciones debian afrontar retos tan titánicos como los de promover la prosperidad provincial, intervenir y aprobar el repartimiento de las contribuciones entre los pueblos de la provincia, velar por la buena inversión de los fondos públicos, proponer al gobierno obras de utilidad, impulsar la agricultura, la industria, el comercio y la educación de la juventud ${ }^{33}$. Grandes propósitos que, en su parco caminar, quedaron reducidos, en general, a la búsqueda de una sede digna, la intervención en materia de contribuciones dada la precariedad económica en la que se encontraba el país y el acometimiento de los primeros estudios para proceder a la reestructuración de los órganos de justicia.

$\mathrm{Al}$ anterior decreto relativo a las Diputaciones provinciales hay que vincular el de 9 de octubre de 1812 (CCI), que aprobaba el Reglamento de las Audiencias $y$ Juzgados de Primera Instancia, y que ordenaba que aquéllas acordasen con las Audiencias la división en partidos judiciales de sus respectivas provincias con la obligación de que en cada uno de ellos hubiera un juez letrado de primera instancia ${ }^{34}$.

32 Vid., entre otros, J. Lladonosa Pujol, Historia de la Diputación de Lérida, Lérida, 1974; P. González Mariñas, Las Diputaciones Provinciales en Galicia: del Antiguo Régimen al Constitucionalismo, La Coruña, 1978; R. Piña Homs, La Diputación Provincial de las Baleares (1812-1979), Palma de Mallorca, 1979; X. Fariña Jamardo y M. Pereira Figueroa, La Diputación de Pontevedra, 1836-1986, Pontevedra, 1986; J.J. Martínez Marín, "Los origenes de la diputación almeriense" en VVAA, I Encuentro de Cultura del Mediterráneo, Almeria, 1986; J.A González Casanovas, Las Diputaciones provinciales en España. Historia politica de las Diputaciones desde 1812 hasta 1985, Madrid, 1986; L. Moreno Nieto, Historia de la Diputación provincial de Toledo, Toledo, 1986; B. de RIQUER (Coor.), Historia de la Diputación de Barcelona, Barcelona, $1987 ;$ P. Martín Bobillo, Origen de la Diputación Provincial de Zamora, Zamora, 1988; M. Santana Molina, La Diputación provincial en la España decimonónica, Madrid, 1989; del mismo autor, "La Diputación provincial en la legislación gaditana”, VVAA, Materiales para el estudio de la Constitución de 1812, Sevilla, 1989, pp. 703-718; P. Ortego Gil, Evolución legislativa de la Diputación Provincial en España 1812-1845. La Diputación Provincial de Guadalajara, Madrid, 1990; E. Orduña Rebollo, Evolución histórica de la Diputación provincial de Segovia 1833-1990, Segovia, 1991; M. Requena Gallego, Historia de la Diputación de Albacete, Albacete, 1993; F. Carantoña y G. Puente (Dtors.), Historia de la Diputación de León, León, 1995; A. Chust Calero (Dtor.), Historia de la Diputación de Valencia, Valencia, 1995; R. Villena Espinosa, Revolución democrática y administración provincial. La Diputación de Ciudad Real 1868-1874, Ciudad Real, 1995; E. Galván, Rodríguez, El origen de la Autonomía Canaria. Historia de una Diputación Provincial (1813-1925), Madrid, 1995; H. Pastrana Morilla, La Diputación Provincial de Valladolid, 1875-1930: Politica y gestión, Valladolid, 1997.

33 Art. 335 de la Constitución de 1812.

34 Cap. II, art. I: "Las diputaciones provinciales, o las juntas donde no estuviesen establecidas las diputaciones, harán de acuerdo con la Audiencia la distribución provisional de partidos en sus respectivas provincias, para que en cada uno de ellos haya un Juez letrado de primera instancia conforme el artículo 273 de la Constitución". 
El prototipo liberal comenzaba a dar unos inseguros primeros pasos que, sin embargo, fueron bruscamente interrumpidos tras la llegada de Fernando VII a la Península como hemos advertido anteriormente. La normativa regeneradora fue marginada durante seis años hasta que el golpe de estado del general Riego en 1820 puso nuevamente en vigor el texto gaditano y permitió proseguir los designios constitucionales.

La tarea ordenadora liberal insistía en que la provincia fuese el eje de la estructuración político-administrativa, económica y judicial. Durante los tres años que estuvo vigente de nuevo la constitución gaditana dio tiempo a recuperar las diputaciones y a ensayar una división del territorio peninsular esta vez en 52 provincias según el Decreto de 27 de enero de 1822. Paralelamente, otro Decreto, el de 3 de febrero de 1823 sobre gobierno económico y politico de las provincias, marcará las directrices a seguir tanto en el gobierno local como en el provincial: las funciones económicas debían ser tarea prioritaria de los ayuntamientos y las diputaciones, en los ámbitos local y provincial respectivamente, mientras que las cuestiones politicas debían reservarse para los alcaldes y los jefes políticos dependientes jerárquicamente del gobierno central.

La llegada de los cien mil hijos de San Luis y la consiguiente restauración absolutista trajeron consigo la derogación del texto constitucional, de toda la legislación derivada y, por consiguiente, el abandono de la flamante división territorial. Diez años debieron transcurrir para que renaciese y, esta vez sí, con vocación de permanencia. A los dos meses del fallecimiento del ínclito Fernando VII ve la luz, a instancias del reformador Javier de Burgos ${ }^{35}$, el Real Decreto de 30 de noviembre de 1833 sobre la división civil del territorio español en la Península e islas adyacentes en virtud del que se formaliza una partición de España, ahora en 49 provincias $^{36}$. Igualmente, las diputaciones provinciales serán restablecidas y renovadas en virtud de un Real Decreto de 21 de septiembre de 1835.

Curiosamente, sin reanudarse la vigencia del texto gaditano, uno de sus proyectos estelares, el previsto en el artículo 11 , se iba a hacer realidad. Se ha de entender que a la altura del primer tercio del siglo XIX "las circunstancias políticas de la Nación" eran favorables, por fin lo permitian. Y bastantes años después, cuando se celebran los festejos conmemorativos del centenario de la Constitución del 12, provincias y diputaciones seguían plenamente vigentes, con tan sólo algunos leves retoques respecto a su concepción originaria. La herencia gaditana no dejaba lugar a dudas ${ }^{37}$.

35 A. Mesa Segura, Labor administrativa de Javier de Burgos, Madrid, 1946.

36 A. Nieto, Los primeros pasos del estado constitucional. Historia administrativa de la regencia de Maria Cristina, Barcelona, 2006, especialmente, pp. 238 y ss.

37 Un breve resumen sobre su evolución en esta etapa puede verse en J. Sánchez-Arcilla, Materiales didácticos para el estudio de las Instituciones politico-administrativas. Siglos XV-XIX, II, pp. 190-194. 


\subsection{El orden judicial}

\subsubsection{Trama orgánica: Partidos judiciales, Audiencias y Tribunal Supremo.}

Un legado centenario que también se dejaba sentir, y sobre todo, en el mundo de los tribunales. Precisamente, la división provincial debía ser la base para la reordenación de la administración de justicia. Los constitucionalistas de Cádiz habian previsto un modelo de justicia que tendría que sustituir al caduco y complejo sistema de Corregimientos, Alcaldias mayores, Audiencias, Chancillerias, Consejos..., heredado de la Edad Media. De modo parecido al croquis planeado respecto de las tareas gubernativas, para las labores judiciales se quiso implantar un modelo en el que el juez de primera instancia hiciera las veces del alcalde, esto es, donde la proximidad e inmediatez con la ciudadanía se convertian en un referente inexcusable ${ }^{38}$. Como escalón intermedio, habrian de implantarse unos órganos compuestos por un reducido número de magistrados y que, aunque debian recibir el conocido nombre, en la tradición institucional castellana, de audiencias, implicaba una concepción totalmente diferente de la hasta entonces gastada. Finalmente, en la cúspide, una institución novedosa, el Tribunal Supremo con jurisdicción sobre todo el país y con un notable paralelismo (con indudables matices) con el gobierno de la nación en el ámbito del poder ejecutivo.

Justamente el alcance de la jurisdicción de cada uno de estos órganos era uno de los problemas prioritarios a solucionar. Al optar como referente diferenciador por el territorio, resultaba imprescindible fijar una unidad territorial básica de actuación de cada órgano judicial. Aprovechando la flamante división en provincias, esto es, la aparición de nuevas entidades aglutinadoras de la acción ejecutiva y judicial del Estado, sólo había que, por un lado, subdividirlas en un número variado de unidades territoriales menores para acercarlas a la ciudadanía, lo que se llamaria el 'partido judicial', y asignárselas a un juez de primera instancia o de partido y, por otro, agruparlas en unidades más amplias, para marcar el límite de la jurisdicción de la segunda instancia.

Como hemos dicho anteriormente, las circunstancias politicas de la nación, como indicaba el artículo 11 de la Constitución de 1812, permitieron poner en práctica toda esta compleja operación tras la muerte de Fernando VII, en concreto a través de disposiciones como el Real Decreto de 26 de enero de 1834 y el de 21 de abril de 1834. Aquel ensayo provisional ejecutado en 1812 bajo el amparo normativo del Reglamento de las Audiencias y Juzgados de Primera Instancia, que ordenaba a las diputaciones ponerse de acuerdo con las audiencias para dividir el territorio en partidos judiciales, tenía continuidad veintitantos años después aunque, ahora, con vocación de permanencia. De nuevo sin que la norma constitucional estuviera vigente y de modo similar a lo que ocurriría a comienzos del siglo XX, cuando este diseño organizativo persistía en sus líneas maestras a pesar de regir otras disposiciones normativas.

38 Vid. al respecto M.A. Morales Payán, "Los alcaldes al servicio de la justicia decimonónica: una propuesta discutida” en I. Czegühn; A. Sánchez Aranda (Hg.), Vom Diener des Fürsten zum Diener des Rechts, Regensburg, 2011, pp. 43-60. 


\subsubsection{Textos normativos:}

\subsubsection{Los constitucionales: poder vs. administración.}

El sinfin de normas sancionadas en el ámbito judicial a lo largo de todo el XIX tratará de ir moldeando un modelo de organización de justicia casi siempre sobre la base del esquema imaginado a principios del siglo. Afirmación que hay, no obstante, que matizar pues, como subraya Varela Suanzes-Carpegna ${ }^{39}$, no hay que perder de vista que frente al modelo constitucional doceañista que impone una indudable supremacia de las Cortes, durante el resto del siglo XIX y comienzos del XX, a grandes rasgos, imperó un canon constitucional donde la hegemonía estaba en la Corona.

Indiscutiblemente esta diferencia de perspectiva se dejó sentir en el ámbito de la justicia. El modo en que los respectivos textos fundacionales del nuevo orden afrontaban esta delicada cuestión resulta harto significativo. Así, frente a los 66 artículos de la Constitución de 1812 a los exiguos 8 artículos de la de 1876, que es la que estará vigente a la altura de la celebración de los fastos de aquélla; frente al revelador título: "De los tribunales y de la administración de justicia en lo civil y en lo criminal", a la expresión: "De la administración de justicia”. El cambio en el enfoque es radical ${ }^{40}$.

39 J. Varela Suanzes-Carpegna, Politica y Constitución en España (1808-1978), Madrid, 2007, especialmente, pp. 9 y ss.

40 Vid., entre otros, A. De Chavarría y Montoya, Reflexiones sobre los vicios de la administración de justicia, abusos de algunos curiales y necesidad de una pronta y eficaz reforma de nuestros códigos, Madrid, Imp. M. de Burgos, 1840; M. Torres Campos, Cómo se administra justicia, Madrid, Librería Universal, 1881; E. Bravo Moltó, Organización Judicial vigente, Madrid, Establecimiento Tipográfico de Pedro Núñez, 1890; A. García Gallo, "Jueces populares y jueces técnicos en la historia del derecho español” en VVAA, La justicia municipal en sus aspectos histórico y científico, Madrid, 1946; A. Carretero Pérez, "La administración de justicia desde 1808 a 1833 y de 1833 a 1868", Revista de Derecho Judicial, no 21 y 22, 1965, pp. 159 y ss. y 117 y ss. respectivamente; A. Agúndez, Historia del poder judicial en España, Madrid, 1974; J.I. González Escribano, "El poder judicial a través de las constituciones españolas hasta el año 1870", Revista de Derecho Judicial, 1970, pp. 42-59; B. González Alonso, "La justicia” en M. Artola (dir.), Enciclopedia de Historia de España, II, Madrid, 1988, pp. 407 y ss.; R. Roldán Verdejo, Los jueces de la monarquía absoluta. Su estatuto y actividad judicial. Corona de Castilla, siglos XIV-XVIII, Universidad de La Laguna, 1989; F. Tomás y Valiente, "De la Administración de Justicia al Poder Judicial" en VVAA, Jornadas sobre el poder judicial en el Bicentenario de la Revolución Francesa, Madrid, 1990; J. Montero Aroca, Independencia y responsabilidad del juez, Madrid, 1990 ; J. Paredes, La organización de la justicia en la España liberal. Los orígenes de la carrera judicial 18341870, Madrid, 1991; J.L de las Heras Santos, La justicia penal de los Austrias en la Corona de Castilla, Salamanca, 1991; J. Sáinz Guerra, La administración de justicia en España (1810-11870), Madrid, 1992; A. Serrano González, "Chocolate a la española: formación y afección de jueces en el siglo XIX" en A. Mazzacane y C. Vano, Università e profesión giuridiche in Europa nell'età liberale, Napoli, 1994, pp. 423-462; MA. Aparicio, El status del poder judicial en el constitucionalismo español (1808-1936), Barcelona, 1995; J.F. Lasso Gaite, Crónica de la codificación española, I, Madrid, 1999; M.A. Morales Payán, La justicia penal en la Almería de la primera mitad del siglo XIX, Almeria, 1998; F. Martínez Pérez, Entre confianza y responsabilidad. La justicia del primer constitucionalismo español (1810-1823), Madrid, 1999; S. Villas Tinoco e I. Gómez González, "Instituciones y poderes: gobierno, justicia y régimen municipal” en F. Andújar Castillo (ed.), Historia del Reino de Granada, III, Del siglo de la crisis al fin del Antiguo Régimen (1630-1833), Granada, 2000; E. Álvarez Cora, La arquitectura de la justicia burguesa. Una introducción al enjuiciamiento civil en el siglo XIX, Madrid, 2002; R. Gómez Rivero, Los jueces del Trienio Liberal, Madrid, 2006 ; J. Moya Morales; E. Quesada Dorador; D. Torres Ibáñez (eds.), Real Chancillería de Granada. V Centenario 1505-2005, Granada, 2006; J.I. Marcuello Benedicto, La Constitución de 1845, Madrid, 
Es conveniente recordar que la Constitución de 1812 partía de la premisa de la separación de poderes ${ }^{41}$. Así en los arts. 15, 16 y 17 se proclamaba la existencia de tres potestades diferentes: para "hacer las leyes", para "hacer ejecutar las leyes" y para "aplicar las leyes en las causas civiles y criminales". En cada una de ellas se residenciaban tres pilares institucionales diferenciados: "Cortes con el Rey", "Rey" y "Tribunales establecidos por la ley".

Precisamente, para desarrollar el contenido del art. 17 se incluía un título, el V, que se rotulaba: "De los tribunales y de la administración de justicia en lo civil y criminal" 42 . Aunque expresamente no hablaba de 'poder judicial' se sobreentendia. No era necesario pues ya se había definido con anterioridad, al igual que pasaba con el legislativo y el ejecutivo cuyo desarrollo aparecía en apartados que no incluian el término 'poder' sino que se nominaban "Del gobierno", "De las Cortes" y "Del Rey".

Panorama completamente diferenciado presentaba el Estatuto Real de 1834, el pseudo texto constitucional que, tras la muerte de Fernando VII, debía, en teoría, establecer las nuevas reglas del juego politico. Tan pretendidamente elemental que simplemente ignoraba la cuestión. El giro de los acontecimientos durante la mitad de la cuarta década desencadenó la irrupción de un modelo constitucional, el de 1837, que podía haberse convertido en la necesitada vía intermedia que hubiese puesto paz y sosiego en el convulso devenir de la lucha politica diaria española 43 . De haberlo conseguido, el carácter plenamente independiente de la magistratura española pudiera haberse consolidado ${ }^{44}$. Pero la clase politica de la etapa no estaba por la labor. De sobra es conocido que los textos constitucionales de 1837 y de 1845 difieren, teóricamente, bastante poco. En realidad, el último se suele tener por una copia modificada del primero cuyas contadas variantes sólo pretenden mostrar el giro conservador que quiere imprimir la élite gobernante. Entre las escasas alteraciones que se producen en aspectos constitucionales muy sensibles aparece uno que afecta de lleno al mundo de los tribunales. Dejan de ser considerados como un poder independiente. El título que le dedica el texto constitucional, prácticamente igual

2007; M. Artola; R. Flaquer Montequi, La Constitución de 1812, Madrid, 2008; J. Varela SuanzesCarpegna, La Constitución de 1876, Madrid, 2009; J. Pro Ruiz, El Estatuto Real y la Constitución de 1837, Madrid, 2010; M. Pérez Ledesma, La Constitución de 1869, Madrid, 2010.

${ }^{41}$ Sin ánimo de ser exhaustivo y sólo destacando algunas lecturas que pueden ser útiles para este trabajo se recomienda acudir, además de los ya citados anteriormente, a D. Sevilla Andrés, Constituciones y otras leyes o proyectos politicos de España, I, Madrid, 1969; J. Bravo Murillo, Politica y administración en la España isabelina, Madrid, 1972; J.M. Romero Moreno, Proceso y derechos fundamentales en la España del siglo XIX, Madrid, 1983; J. Tomás Villarroya., Breve historia del constitucionalismo español, Madrid, 1990; F. Puy Muñoz (Coord.), Los derechos en el constitucionalismo histórico español, Santiago de Compostela, 2002; I. Fernández Sarasola, "La división de poderes en la historia constitucional española”, Fundamentos: Cuadernos monográficos de teoría del estado, derecho público e historia constitucional, $\mathrm{n}^{\circ}$ 5, 2009, pp. 167-202; J. Varela Suanzes-Carpegna, "Las Cortes de Cádiz y la Constitución de 1812: una visión de conjunto", Corts: Anuario de Derecho Parlamentario, n 26, 2012, pp. 191-208, especialmente pp. 200-202.

42 Con un total de 67 artículos.

43 Vid. al respecto J. Varela Suanzes-Carpegna, "La Constitución española de 1837: una constitución transaccional”, Revista de Derecho Politico, n 20, 1983-84, pp. 95-106.

44 Título X con 6 artículos. 
en su contenido al de su predecesor del 37, sin embargo, lleva por título De la administración de justicia. Toda una declaración de intenciones.

Cuando las circunstancias politicas lo permitieron, los sectores más progresistas de la sociedad, exigieron que a la justicia se la tuviera por un auténtico poder. Y esa consideración debía quedar reflejada en el texto de referencia que regulara la convivencia social. De ahí que la Constitución de 1869 recuperara la fórmula de la del 37: Del Poder Judicial ${ }^{45}$. Finalmente, un nuevo giro conservador con una nueva fórmula constitucional, la de 1876, rescatará la rúbrica de la del 45: De la administración de justicia ${ }^{46}$. Y este referente en el orden judicial será el dominante cuando se celebren los actos del centenario constitucional.

\subsubsection{Su desarrollo legislativo}

Estos complejos vaivenes no impidieron que cuajara un modelo de justicia donde la figura del juez profesional era la piedra angular del edificio. Inherente a esta profesionalización eran, entre otras cosas, el establecimiento de un proceso de selección con garantías, la preservación de su independencia en el ejercicio de su tarea, circunstancia ineludiblemente vinculada a su inamovilidad, o las correspondientes exigencias de responsabilidad. Todo ello acompañado de una serie de necesarios complementos para el buen desarrollo de su tarea como la unificación de jurisdicciones o la de códigos. Requerimientos todos ellos contenidos en el texto gaditano. Así, respecto al proceso de selección hay que remitirse al art. 25147. En relación a la independencia, a los arts. 242, 243 y $245^{48}$. La inamovilidad está comprendida en el art. $252^{49}$ mientras que la responsabilidad en los arts. 253 y 25450. La unificación de jurisdicciones se consigna en los arts. 248, 249 y $250^{51}$ y la de códigos en el art. 25852. Cien años

45 Título VII con 8 artículos.

46 Título IX con 8 artículos.

47 Constitución de 1812: “Art. 251. Para ser nombrado magistrado o juez se requiere haber nacido en el territorio español y ser mayor de veinticinco años. Las demás calidades que respectivamente deban éstos tener serán determinadas por las leyes”.

48 Constitución de 1812: “Art. 242. La potestad de aplicar las leyes en las causas civiles y criminales, pertenece exclusivamente a los tribunales. Art. 243. Ni las Cortes ni el Rey podrán ejercer en ningún caso las funciones judiciales, avocar causas pendientes, ni mandar abrir los juicios fenecidos. Art. 245. Los tribunales no podrán ejercer otras funciones que las de juzgar y hacer ejecutar lo juzgado".

49 Constitución de 1812: “Art. 252. Los magistrados y jueces no podrán ser depuestos de sus destinos, sean temporales o perpetuos, sino por causa legalmente probada y sentenciada; ni suspendidos, sino por acusación legalmente intentada".

50 Constitución de 1812: “Art. 253. Si al Rey llegaren quejas contra algún magistrado, y formado expediente, parecieren fundadas, podrá, oído el consejo de Estado, suspenderle, haciendo pasar inmediatamente el expediente al supremo tribunal de Justicia, para juzgue con arreglo a las leyes. Art. 254. Toda falta de observancia de las leyes que arreglan el proceso en lo civil y criminal, hace responsables personalmente a los jueces que la cometieran"

51 Constitución de 1812: “Art. 248. En los negocios comunes, civiles y criminales no habrá más que un solo fuero para toda clase de personas. Art. 249. Los eclesiásticos continuarán gozando del fuero de su estado, en los términos que prescriben las leyes o que en adelante se 
después todos estos mandatos constitucionales, de una manera u otra, habían cuajado y eran una realidad evidente ${ }^{53}$. El camino no había sido fácil. El batallar fue largo y duro durante toda la centuria. Y las quejas, constantes. Pero, al final, estos preceptos doceañistas se habían llevado a la práctica.

\subsection{Primer tercio del XIX: los Reglamentos de Audiencias y Juzgados de Primera Instancia y del Tribunal Supremo.}

Del primer tercio decimonónico, ocupado en buena parte por el reinado de Fernando VII, cabe subrayar la escasa vigencia del texto de 1812. Durante el mismo apenas rigió durante cinco años y de manera intermitente. En tan corto espacio de tiempo si bien se promulgaron distintas disposiciones que pretendian desarrollar los mandatos constitucionales, apenas tuvieron recorrido. Así, baste apelar a cómo el Decreto de 9 de octubre de 1812 (Reglamento de Audiencias y Juzgados de Primera Instancia), la Instrucción para dirimir las competencias de jurisdicción en toda la Monarquía de 19 de abril de 1813 o el Decreto de 13 de marzo de 1814 (Reglamento del Tribunal Supremo) promulgados en el ámbito de la estructuración de los tribunales quedaron prácticamente inéditos tras ser derogados a la vuelta del Borbón de su cautiverio y su decisión de borrar toda la obra liberal (Decreto de 4 de mayo de 1814). Bien es verdad que se restablecieron durante el trienio pero tampoco tuvieron el tiempo suficiente para calar entre la sociedad y conseguir sus objetivos de renovación. Igual ocurrió en la esfera de la división territorial que en el primer período de vigencia de la norma gaditana quedó frustrada (proyecto Bauzá) viendo la luz en el segundo (Decreto de 27 de enero de 1822) pero por un espacio temporal muy exiguo (Decreto de 1 de octubre de 1823). Habrá que esperar a que el monarca felón desaparezca de la escena politica para que los nuevos dirigentes retomen el frustrado proyecto liberal de justicia y traten de hacerlo realidad.

\subsection{Segundo tercio del XIX: el Reglamento provisional para la administración de justicia.}

En este sentido, iniciado ya el reinado de Isabel II, todavía menor de edad bajo la Regencia de su madre $\mathrm{M}^{\mathrm{a}}$ Cristina, la división provincial auspiciada por Javier de Burgos, marca un punto de inflexión para el acomodo del vetusto aparataje institucional a la nueva planta judicial de la que hoy somos herederos directos. Con su decreto de división provincial (Real Decreto de 30 de noviembre de 1833 ya citado), habilita otra parcelación primordial para la organización judicial: los partidos judiciales (Real Decreto de 21 de abril de 1834 ya citado). Con esta base, definido el marco espacial, el siguiente paso consiste en colocar al

prescribieren. Art. 250. Los militares gozarán también de fuero particular, en los términos que previene la ordenanza o en adelante previniere”.

52 Constitución de 1812: “Art. 258. El código civil y criminal y el de comercio serán unos mismos para toda la Monarquía, sin perjuicio de las variaciones, que por particulares circunstancias podrán hacer las Cortes".

53 Vid al respecto A. Fiestas Loza, "Codificación procesal y estado de la administración de justicia, 1875-1915” en J.L. García Delgado, La España de la Restauración. Política, economía, legislación y cultura, Madrid, 1985, pp. 413-436. 
frente de cada división a un juez, a ese aplicador de disposiciones procedentes del legislativo o del ejecutivo que demandaban los auspiciadores de la Constitución de 1812. Y esto lo hilvanan el Reglamento provisional para la administración de justicia de 26 de septiembre de 1835, el Reglamento del Tribunal Supremo de España e Indias de 17 de octubre de 1835 y las Ordenanzas para todas las Audiencias de la peninsula e islas adyacentes de 19 de diciembre de $1835^{54}$.

No obstante, es la primera de éstas la más sobresaliente ${ }^{55}$. Como virtud cardinal se pueda destacar, ante todo, que supone el primer paso efectivo para reformar o suplantar el modelo de justicia heredado del Antiguo Régimen. En palabras de Sáinz Guerra se trataba de "una extensa norma que venía a sustituir la compleja y contradictoria legislación vigente sobre administración de justicia"56. Por fin, iniciaba el camino la añeja idea constitucional de una administración piramidal con unos jueces próximos al ciudadano al frente de sus correspondientes partidos judiciales, revisados en su actuación por unos cuerpos colegiados intermedios que, a su vez, debían rendir cuentas ante un supremo tribunal que se situaba en la cúspide. La condicionada interinidad del modelo constitucional del 12, agravada por las oleadas restauradoras fernandinas con su sesgo purificador, parecía poder remediarse con este Reglamento.

Pero como su nombre indica, como sus propios forjadores lo tildaron, la nominación de 'provisional' era consecuencia directa de la toma de conciencia de que sólo se trataba de un primer paso en el largo camino que quedaba por recorrer. A pesar de este condicionante, este novel diseño arrinconaría de manera definitiva el arcaico y confuso modelo de Alcaldias mayores, Corregimientos, Chancillerias, Audiencias y Consejo Real ${ }^{57}$. La propuesta, al menos globalmente y de inicio ${ }^{58}$, tuvo una valoración bastante positiva. A título de ejemplo cabe traer a colación a Bravo Murillo59, futuro presidente del Consejo de Ministros, quien, poco después de la promulgación del texto reglamentario, publicará un artículo en el que rompería una lanza a su favor:

54 La nómina de disposiciones no se detiene en éstas tres citadas. Vid. al respecto M. Lorente Sariñena; F. Martínez Pérez; M.J. Solla Sastre, Historia legal de la justicia en España (1810-1978), Madrid, 2012, especialmente pp. 195-273.

$55 \mathrm{Su}$ determinación es reconocida por P. Gómez de la Serna, "Administración de justicia en lo criminal", RGLJ n ${ }^{\circ} 28,1866$, pp. 80-89, con las siguientes palabras: "Rindiendo un tributo a la justicia, no podemos menos de decir que en el actual reinado se han hecho importantísimas reformas para la más pronta y mejor aplicación de las leyes penales. Al Reglamento provisional para la administración de justicia debe principalmente este progreso...". Vid. también el placet que le otorga J. Vicente y Caravantes, Tratado histórico, crítico filosófico de los procedimientos judiciales en materia civil, según la nueva ley de enjuiciamiento, con sus correspondientes formularios, Madrid, Imp. de Gaspar y Roig, I, 1856, especialmente, pp. 91 y ss.

56 J. Sáinz Guerra, La administración de justicia en España (1810-11870), op.cit., p. 83.

$57 \mathrm{Y}$ esto sólo en cuanto a los tribunales del fuero común. Para un estudio más profundo de esta cuestión puede ser muy útil el apartado de Orientación bibliográfica incluido en J. Moya Morales; E. Quesada Dorador; D. Torres Ibáñez (eds.), Real Chancilleria de Granada. V Centenario 1505-2005, op. cit., pp. 259-264.

58 J. Sáinz Guerra, La administración de justicia en España (1810-11870), op. cit., pp. 83-84: "Sus criterios fueron bien recibidos, sin que faltaran las lógicas objeciones de los magistrados y la critica, en ocasiones severa, de parte de la doctrina".

59 J. Bravo Murillo, "Observaciones sobre el Reglamento provisional para la administración de justicia en lo respectivo a la Real jurisdicción ordinaria”, Boletín de Jurisprudencia y Legislación $\mathrm{n}^{\circ}$ I, 1836, p. 12 . 
“... acaso sea la parte más interesante de nuestra actual jurisprudencia. Por él se han derogado muchas disposiciones de nuestro derecho, por él se ha creado un derecho nuevo en la importante materia de los procedimientos judiciales... Con el reglamento se ha tratado de remediar una necesidad urjente (sic): tal era la de reformar nuestra legislación, en sumo grado viciosa, sobre el orden de enjuiciar, y desterrar al menos los principales de los muchos abusos introducidos en el foro... Nosotros hallamos en él disposiciones utilísimas, respecto de las cuales no seremos escasos en tributarles el elogio debido".

Este regocijo, sin embargo, será breve. La disposición normativa pronto da claras muestras de insuficiencia. Una norma de estas características no podia resolver los graves problemas que atosigaban al mundo de los tribunales ${ }^{60}$. Una autoridad en el tema, Gómez Becerra, recién abandonado el cargo de ministro de Gracia y Justicia, advierte, en una publicación en la que monográficamente aborda el estado del poder judicial en España, que a pesar del buen hacer del reglamento el rumbo de la justicia no termina de enderezarse ${ }^{61}$. Y de las diversas objeciones que realiza sobresale, por encima de las demás, la no consideración de la justicia como un verdadero poder independiente. Desde su sólido punto de vista, la norma reglamentaria se muestra bastante vulnerable al respecto y ni siquiera el refuerzo de la Constitución de 1837, por entonces en vigor, es suficiente:

\begin{abstract}
"No es este Poder judicial el que quiere la Constitución, porque no es independiente, y porque careciendo de esta cualidad esencial, no es un verdadero Poder político. Tener al Poder judicial despojado de los caracteres esenciales, que le da la Constitución, es un quebrantamiento continuo y permanente de la propia Constitución, y de la promesa de guardarla y hacerla guardar, que se ha hecho y repetido, con el sello de la religión del Juramento. Resulta de esto una usurpación notoria, por parte del Poder ejecutivo y si no son absolutamente dos los Poderes que restan, en vez de tres, que establece la Constitución, a lo menos, ha crecido el uno, con mengua del otro, y se han destruido el nivel y las lineas divisorias" 62 .
\end{abstract}

Si con el marco legislativo propicio no se había conseguido, la promulgación de la Constitución de 1845, en sustitución de la del 37, iba a suponer un nuevo giro en las directrices que sobre la justicia y su modelo de organización dictaba la

60 Vid. al respecto J.A. Alejandre, "La crítica de los Ilustrados a la Administración de Justicia del Antiguo Régimen", Separata del Anuario Jurídico y Económico Escurialense N ${ }^{\circ}$ XXVI, vol. II, S.L.E., 1993, pp. 427-451.

61 En la misma senda, A. De Chavarría y Montoya, Reflexiones sobre los vicios de la administración de justicia, abusos de algunos curiales y necesidad de una pronta y eficaz reforma de nuestros códigos, op. cit., especialmente pp. LI y ss.

62 A. Gómez Becerra, Observaciones sobre el estado del poder judicial en España, Madrid, Imprenta del Colegio nacional de sordo-mudos, 1839, pp. 58-59: “... Hemos dibujado un cuadro, triste y opaco, por cierto, pero, por desgracia, sencillo y verdadero del estado que tiene el Poder Judicial en España...”. 
clase política63. La corriente negacionista, con todas las consecuencias que aparejaba, resultó ser la triunfante en estas décadas centrales del siglo ${ }^{64}$.

Y eso a pesar de que no cejaron los empeños en revertir la situación. Así, a título de ejemplo, cabe mencionar los esfuerzos de un jurista como Hernández de la Rúa que aprovechará la coyuntura política en la que se debatía un nuevo texto constitucional que sustituyera al vigente de 1845, para publicar en el Boletín de Jurisprudencia y Administración un artículo netamente reivindicativo en el que plantea que la expresión 'orden judicial' supone no reconocer que los tribunales de justicia son un poder distinto del poder ejecutivo. Y eso, según su punto de vista, resulta muy grave pues:

“... la administración de justicia es el más poderoso elemento que conduce al cumplimiento del objeto de la asociación del hombre, porque si bien las sociedades pueden subsistir un tiempo dado sin Gobierno, cuando por un instante falte la administración de justicia, se desmorona el edificio social..."65

El eco del artículo fue tal que provocó que los directores de la Revista General de Legislación y Jurisprudencia lo reprodujeran integramente en uno de sus números con el título de 'El poder judicial'.

El rotundo fracaso en la configuración de la justicia como poder independiente cuando el XIX estaba a punto de finiquitar su primera mitad, se compensaba en parte con el intento de renovar buena parte del armazón legislativo que debian aplicar los tribunales. La creación de la Comisión General de Codificación o la introducción en el escenario normativo del país de un código penal, como el de $1848^{66}$, resultaron ser pasos especialmente sugestivos. La

63 Algunos tratan de encuadrar la justicia en su justo lugar soslayando incluso la cuestión semántica como el caso de E. Bravo, De la administración de justicia, Madrid, 1864, pp. 126-127: “... todo esto significa que la administración de justicia es un poder, y que para llamarlo así no hay que salirse del terreno de la legalidad existente, pues si bien es cierto que la Constitución vigente no le da el nombre de poder judicial, es indudable que no ha menoscabado en lo más mínimo las atribuciones que la de 1812 le concedía, y poco importa el nombre en verdad cuando en la esencia es el mismo".

64 A. Alcántara y Pérez; J. Morales y Serrano, Tratado de las competencias y de la autorización para procesar a los empleados administrativos, I, Madrid, Imprenta a cargo de J.E. Morete, 1866, pp. 33-34, tratarán de explicar que: "Partiendo de la idea del Estado como el orden de derecho, y separando el ejercicio del poder necesario para establecer y conservar este orden, hallamos dos poderes distintos que han de ser independientes en su acción, si bien dependientes en el fondo, puesto que el uno dicta la ley y el otro la hace cumplir: poder legislativo, poder ejecutivo. Según que éste mira a los intereses generales o a los particulares, según ejecuta leyes politicas y administrativas, o leyes civiles y penales, recibe el nombre de poder ejecutivo o poder judicial: el primero lleva a efecto las reglas que dicta el legislador sobre el gobierno y administración del país; el segundo aplica la regla de acción individual al caso que se le presenta y decide la contienda sobre derechos privados".

65 Concretamente en el número 6 (1855). Vid., además, sus Lecciones de Derecho español, I, Madrid, Imprenta de Salvador Albert, 1838 y Lecciones de práctica forense, III, Madrid, Imprenta de Salvador Albert, 1841.

66 Tampoco había supuesto una mejora extraordinaria la aprobación de normas como los Reales Decretos de 29 de diciembre de 1838 (Reglas para mejorar la condición de magistrados y jueces) o de 1 de mayo 1844 (Reglamento de juzgados de primera instancia). En este sentido se 
aplicación de éste debía traer consigo ciertos avances y mejoras en la justicia y su administración ${ }^{67}$, al menos, en el mundo del crimen y su persecución, aunque tampoco serian suficientes. Así se manifestaba, por ejemplo, la Junta de Gobierno del Colegio de Abogados de Madrid en una exposición dirigida al Ministerio de Justicia:

\begin{abstract}
"Nada, absolutamente nada se ha conseguido con el código y nada valen tampoco todos esos esfuerzos individuales para aplicarle, que la Junta reconoce y aplaude porque se estrellan forzosamente contra diligencias innecesarias, trámites redundantes, dilaciones injustificables, métodos de prueba defectuosos, conflictos con jurisdicciones especiales que debieran estar relegadas a la historia y otros cien obstáculos que se levantan para producir el triste resultado de que la pena bien calculada en el código, se evada en algunos casos por el delincuente o se aplique al procesado en tales momentos y condiciones, que el castigo aparezca tardío las más veces, desproporcionado otras y casi siempre falto de ejemplaridad y por tanto desautorizado. El código penal, preciso es reconocerlo, sin una buena ley de enjuiciamiento, sin una organización judicial vigorosa, es tan infecundo como un centro industrial sin vias de comunicación; tan inerte y tan inútil como un buque perfectamente construido, pero falto de aparato impulsor"68.
\end{abstract}

Es indudable que la situación a mediados de la centuria decimonónica había cambiado respecto de la de comienzos de siglo, aunque, también es verdad que de un modo parcial y precario ${ }^{69}$. Había dejado de ser "incierta, errante y sin guía"70 pero aún le quedaba un largo camino por recorrer.

expresa J. Vicente y Caravantes, Tratado histórico, crítico filosófico de los procedimientos judiciales en materia civil, según la nueva ley de enjuiciamiento, con sus correspondientes formularios, op. cit., p. 95: “A pesar de todas estas reformas, la administración de justicia experimentaba entorpecimientos y obstáculos a causa de la multitud de disposiciones que regian sobre la materia...".

67 J. De Castro y Orozco; M. Ortiz de Zúñiga, Código penal explicado, para la común inteligencia y fácil aplicación, I, Granada, Imprenta y Librería de D. Manuel Sanz, 1848, p. V: "La publicación de un código penal, es un acontecimiento de la mayor trascendencia en el orden moral, social y politicos... El código penal es, según se ha dicho, una verdadera revolución”; P. Carrilo y Sánchez, Código penal de España, Madrid, Imprenta y fundición de D. Eusebio Aguado, 1850, p. 3: "Sancionado por S.M. el 19 de marzo de 1848 el Código penal de España, calmóse (sic) la ansiedad que esperimentaba (sic) el pueblo por esta ley; ansiedad nacida de la confusión en que estaba nuestra legislación criminal..."; J.N. Villoslada y Ruiz, Clave del Código penal, con arreglo a sus reformas y aclaraciones, Imprenta y Librería de D. Miguel de Benavides, números 5 y 7, p. 4: "Como hija de tan diversas épocas y circunstancias, nuestra antigua legislación penal era incoherente, desordenada y monstruosa... Era pues una necesidad urgentísima, imprescindible y por todos reconocida la formación de un Código penal acomodado a nuestras nuevas costumbres e instituciones y a los adelantos del siglo...".

68 "Esposición (sic) que la Junta de Gobierno del Colegio de Abogados de Madrid, asociada a los ex decanos del mismo, ha elevado al Excmo. Sr. Ministro de Gracia y Justicia solicitando se lleven a pronto y feliz término las reformas iniciadas sobre organización de tribunales y ordenación del enjuiciamiento criminal”, RGLJ, n² 22, 1863, pp. 64-77.

69 M. Ortiz de Zúñiga, “De la responsabilidad judicial”, RGLJ, no 25, 1864, pp. 99-115 y 145163: "El espíritu reformador del siglo indudablemente nos ha conducido a mejorar los principales aspectos de nuestra administración pública y nuestro poder... Mas por una falta inconcebible, la administración de justicia, la institución eminentemente conservadora de la sociedad, la más sublime entre todas las humanas, y por consiguiente la que más atención demanda siempre de 
Urgía, ante todo, como demandaba un jurisconsulto de la época, Gonzalo de las Casas ${ }^{71}$, "desentrañar ese caos, ese multorum camellorum onus de nuestras leyes civiles", además de ser "apremiante corregir los errores, suplir los vacíos y armonizar las contradicciones de nuestro código penal" y "dar otra forma a la organización de nuestros tribunales". Era necesario, en fin, "simplificar el procedimiento para que las ruedas de tan complicada máquina marchen todas movidas por un mismo resorte y dirigidas a un mismo fin"72.

El propio ministro de Gracia y Justicia, José de Castro y Orozco, con motivo de la promulgación de la Instrucción del procedimiento civil con respecto a la Real jurisdicción ordinaria de 30 de septiembre de $1853^{73}$, reconocía el negro panorama reinante en su conocida Exposición de Motivos, donde, entre otras cosas, acusaba a "los litigios y reclamaciones jurídicas" de ser "el espanto y la ruina de muchas familias", un "manantial perenne de escándalos" y la "muerte de la justicia"74.

los gobiernos y de los legisladores, la vemos estacionaria y como rezagada desde las importantes novedades introducidas en 1834 y $1835 \ldots .$.

70 M.L. De Azcutia, Derecho criminal. Sustanciación de los procesos, $2^{\mathrm{a}}$ ed., Madrid, 1862, p. 7 : "Todo afortunadamente ha cambiado de algunos años a esta parte. No se oyen ya, como tiempo atrás se oían, los lastimeros ayes de los reos martirizados en el tormento, confesando por miedo a los dolores que sufrian, culpas que no habian cometido; ni se ven tampoco, como entonces se veían, las penas discrecionales... ni anda, en fin, la justicia como antes andaba. Incierta, errante y sin guía...".

$71 \mathrm{~J}$. Gonzalo de las Casas, "Reforma del procedimiento civil con respecto a la real jurisdicción ordinaria”, RGLJ, n 2, 1853, pp. 168-190.

72 En esa línea I. Miquel y Rubert, "Observaciones al Real Decreto de 9 de octubre sobre abono de la prisión en las condenas", RGLJ, $\mathrm{n}^{\circ} 2$, 1853, pp. 191-211. Así, en el ámbito de la esfera criminal subrayaba: “... Si al Código penal, que echó por tierra aquella jurisprudencia, hubiese acompañado la conveniente organización de los tribunales; si se hubiera publicado un buen código de procedimientos, en los que se viera hermanada la celeridad compatible con la legitima defensa, entonces cabría establecer en principio y aplicar en la práctica la doctrina de que las penas deben ser irremisibles...".

73 Precisamente, y al hilo de esta norma, J. Gonzalo de las Casas, "Reforma del procedimiento civil con respecto a la real jurisdicción ordinaria”, op. cit., p. 168, dejará constancia tanto del eco que ha tenido en la sociedad su introducción en el panorama legislativo como la repercusión que se intuye pueda tener en el futuro: “... Cúmplenos hoy hacernos cargo de la Instrucción sobre el procedimiento civil, que ha tenido el privilegio de absorber por completo la atención pública, deteniendo por algunos días el curso de la política palpitante para dar cabida al examen de un documento, que indudablemente formará época en la historia de nuestras instituciones judiciales...". No será el único artículo que este autor brinde a la Instrucción de 30 de septiembre de 1853 en la Revista General de Legislación y Jurisprudencia. En el mismo número y en la sección Bibliográfica (pp. 439-458), al hilo de la monografia que a la misma le dedicó José María Manresa y Navarro, hace otra incursión aunque ahora su enfoque cambia, pues se centra más en la visión que de la misma ofrece éste último: "No es nuestro ánimo entrar ahora en el examen analítico de la Instrucción de 30 de setiembre último... Hoy nos concretaremos a dar una idea de la obra del señor Manresa, nuestro ilustre colaborador, cuya primera entrega acaba de publicarse. Y sentimos no estar conformes con todas sus apreciaciones...".

${ }^{74}$ L. Prieto Castro, "La instrucción del Marqués de Gerona 'para arreglar el procedimiento de los negocios civiles con respecto a la real jurisdicción ordinaria”, RGLJ, $\mathrm{n}^{\circ}$ 193, 1955, pp. 114-133. Las consecuencias nefastas del estado de la administración de justicia llega numerosas veces a extremos dantescos como denuncian los editores de la Revista General de Legislación y Jurisprudencia en un artículo que lleva por título "Reforma de la Ley provisional sobre la prisión de los procesados", en RGLJ, $\mathrm{n}^{\circ}$ 1, 1853, pp. 665-668: "Es de tal importancia el real decreto de 30 de setiembre sobre la prisión de los procesados, publicado en la Gaceta de $1^{\circ}$ de octubre; son de tal trascendencia las reformas que introduce en la ley provisional para la aplicación del Código penal, 
Aguirre 75 , reputado jurista, daba con la tecla al advertir que todos los fracasos en los intentos de mejora del orden judicial derivaban de la propia indefinición que guiaba el proceso reformador, de la confusión que tenía el legislador que degeneraba en constantes traspiés:

\begin{abstract}
"Sin advertirlo me separaba del objeto principal de mi discurso, llevado de una idea dominante que hace mucho tiempo me ocupa en discurrir sobre reformas sociales y legales, indispensables al mejoramiento de la condición de nuestro pueblo, y principalmente a la recta administración de justicia, entorpecida por la conservación de ciertas instituciones judiciarias, hijas unas de la preocupación del fanatismo y del amor escesivo (sic) a los intereses materiales, otras del pretesto (sic) de la necesidad de defensa de los derechos de la sociedad, y otras, en fin, consecuencia natural y necesaria de la mezcla que ha querido hacerse, y se está haciendo, de lo antiguo y lo moderno, de las formas absolutas y las constitucionales, de la justicia estrictamente tomada con la justicia malamente llamada administrativa, con las restricciones puestas a los tribunales en el libre ejercicio de sus funciones, con la impunidad de los que delinquen obrando a nombre de la autoridad, y otros abusos que deben desaparecer...”.
\end{abstract}

Y vaticinaba la solución. Una salida airosa que pasaba por una ruptura radical con el pasado. Auguraba el remedio:

"el día en que la buena reforma, la saludable reforma, la necesaria reforma corte de raíz infinitos males que afligen al Estado".

Pero ésta, por unas causas u otras, no llegaba. Y las críticas se cebaron en la clase politica. Dura denuncia de la manifiesta apatía de los representantes politicos fueron las palabras de Miquel y Rubert, uno de los directores de la Revista General de Legislación y Jurisprudencia en sus primeros años de andadura:

que a pesar de tener compuesta y casi concluida la presente entrega, no hemos titubeado un retirar algunos materiales de interés para darle cabida desde luego en nuestra REVISTA. Deseamos que por nuestra parte tenga la mayor publicidad posible, no solo para que llegue cuanto antes el consuelo a mil y mil familias que gimen desoladas por el infortunio y abatidas por la prisión, sino para que no se demore ni por un momento el parabién que damos de todo corazón al digno ministro que ha sabido aconsejar a S.M... Todo el mundo sabe que los partidos politicos, en medio de su general desbordamiento, apelan a medios los más reprobados para conseguir sus fines. Nada más común en vísperas de elecciones o con ocasión de ellas, ver formar unas cuantas causas con falsas imputaciones por lo general, pero que apoyadas en un principio con las declaraciones de algunos testigos, dan lugar a auto de prisión, en la que va envuelta la suspensión de ejercer cargos públicos y derechos politicos...”.

75 "De las reformas para la recta administración de la justicia ¿Conviene la abolición de todos los fueros privilegiados? ¿Conviene la supresión de las autorizaciones para procesar a los empleados de la Administración?”, RGLJ, n 19, 1861, pp. 285-301. 
"Sensible es decirlo, pero en la cuarta parte de siglo que lleva el actual reinado no debia quedar nada por hacer, y por desgracia muy poco es lo que se ha hecho..."76.

Joaquín María De Paz ${ }^{77}$ era otro de los incontables ensayistas decimonónicos que insistía en la misma cuestión:

"La administración de la justicia, que es siempre la norma para juzgar y calificar a los gobiernos, ha estado casi constantemente en España en completo abandono, en el más indisculpable olvido... La política, por desgracia, todo lo absorbe en nuestra patria, donde los ánimos, continuamente escitados (sic) por las pasiones e intereses de partido, prefieren lo transitorio a lo perpetuo, lo falaz a lo cierto, la luz fosfórica de la imaginación a la radiante del raciocinio".

Y para más escarnio, en las escasas ocasiones en que se elogiaba el inicio de cierto interés político, el cumplido venía acompañado de una crítica vehemente a que la actuación legislativa tuviera un carácter meramente provisional. En ese sentido, De La Tejera se quejará de que:

"... las reformas y variaciones continuas que esperimenta (sic) la administración de justicia, está muy lejos de la paridad que debe buscarse entre las necesidades públicas y los adelantos de la civilización..."78.

En este contexto era lógico que una iniciativa, como por ejemplo el proyecto de ley constitutiva de tribunales del fuero común de $1854^{79}$, fuese objeto de una dura contestación en el foro. Y no tanto por su contenido sino porque el modelo de organización judicial que se proponía por parte del gobierno reconocía expresamente su carácter de "provisionalidad". Resultaba inconcebible que, después de tantos años de trabajo, de tantos estudios realizados, de tanto esfuerzo, la propia iniciativa legislativa admitiese su condición de interinidad:

"Y al dar principio a estas consideraciones, no podemos dejar de lamentarnos por las palabras del decreto: 'con las reformas que, oyendo a la comisión de códigos, considere conveniente introducir en él'; porque en verdad, nos parece sensible, que después de largos años de estéril ansiedad, al llegar el instante deseado de ver organizados los tribunales de justicia, todavía las disposiciones de ese arreglo se nos presentan sin fijeza, con ese carácter de transitorio y provisional, cuando nosotros, y con nosotros todos los que intervienen en los

76 "De la inamovilidad y responsabilidad de los magistrados y jueces", en RGLJ, n 9, 1857, pp. 7-16.

77 J.M. De Paz, "Reformas en la administración de justicia", RGLJ, nº 8, 1856, pp. 73-76.

78 "Reflexiones acerca del establecimiento de los tribunales de distrito", RGLJ, n 4, 1854, pp. $145-147$.

79 Sobre esta cuestión vid. J.F. Lasso Gaite, Crónica de la codificación española, op. cit., pp. 6871. 
asuntos forenses, hubieran querido verle limpio de esa mancha, libre de ese anatema que desde algún tiempo parece una triste necesidad de nuestras disposiciones legislativas..." 80 .

La desesperación de numerosos juristas con la clase política ante una situación que consideraban insostenible era notable:

"Léanse nuestros periódicos políticos y se verá que los que son ministeriales, todo lo encuentran bueno, y pintan siempre la administración de justicia como el bello ideal apetecible, al mismo tiempo que los que son oposición, nada consideran aceptable y suponen que el país está abandonado a todas las pasiones criminales, y que por todas partes el delito levanta su osada frente con imprudencia. Pero hay una crisis ministerial; se cambian los papeles: la oposición pasa a ser gobierno, y éste a ser oposición, y los que la víspera lo veían todo con mal ojo, en el día siguiente lo consideran inmejorable, y se duermen en el ansiado triunfo como los que les precedieron, y tal vez no vuelvan a acordarse de los que antes decian y no reparan que las cosas siguen poco más o menos como estaban antes, ni caen en la cuenta de que en su mano tienen grandes medios para adquirir una reputación y buen nombre muy superiores al que pueden esperar de esas luchas estériles en que se agitan los partidos..." 81 .

Máxime cuando los responsables de la cartera de justicia solían ser juristas y magistrados, profundos conocedores de los problemas que la acuciaban ${ }^{82}$. Así, Pareja de Alarcón clamaba porque:

\begin{abstract}
"En el departamento de la Justicia... hemos visto ya en los ocho años que lleva de existencia nuestro periódico, respetables jurisconsultos, magistrados y legisladores, que subieron a este puesto precedidos de una reputación honrosa como hombres de rectitud y de ciencia... Y ¿cuáles han sido los resultados, de tan fervientes deseos, de tan laudables propósitos, de manifestaciones y protestas tan enérgicas? Los abusos continúan los mismos, los males de la administración de justicia se perpetúan, agravándose como las enfermedades crónicas, la suprema autoridad va perdiendo su prestigio..." 83 .
\end{abstract}

80 P.M., "Observaciones al proyecto de ley constitutiva sobre organización de tribunales de fuero común, leido por el Excmo. Sr. Ministro de Gracia y Justicia en la sesión del Congreso de señores Diputados del día 21 de noviembre de 1853" en RGLJ, n² 2, 1853, p. 459.

${ }^{81}$ P. Gómez de la Serna, "Administración de justicia en lo criminal”, op. cit., pp. 80-89.

82 Resulta significativo el dato aportado por J. Paredes, La organización de la justicia en la España liberal. Los orígenes de la carrera judicial 1834-1870, op. cit., p. 16, que: “... durante el reinado de Isabel II, la media de permanencia de los titulares de Gracia y Justicia no superase los seis meses".

83 "Nuevos desengaños en los asuntos de la administración de justicia", El Faro Nacional, Revista de Jurisprudencia, ${ }^{\circ}$ VIII, sábado 9 de enero de 1858, p. 37. 


\subsubsection{3. Último tercio del XIX: La Ley Orgánica del Poder Judicial}

Gonzalo de las Casas fue un jurista coetáneo del Marqués de Gerona. Cuando el ministro decidió promulgar la Instrucción del procedimiento civil con respecto a la Real jurisdicción ordinaria, de 30 de septiembre de 1853, le auguró un fracaso inmediato. Se congratuló de que, al fin, desde las correspondientes instancias de responsabilidad política hubiera una decidida actuación en una materia tan necesitada como el orden procesal:

"Después de algunos años de marasmo y de inacción, el departamento de Gracia y Justicia ha inaugurado una actividad desconocida hasta ahora. A los pocos días de haber tomado posesión el actual señor ministro del ramo, hemos visto aparecer en el periódico oficial decretos de la mayor importancia, no tanto por las consideraciones que les preceden, cuanto por las reformas que introducen..." 84 .

Pero la principal objeción por la que clamaba era el propio proceder del ministro 85 . En un doble sentido. Por un lado, por el individualismo que había presidido su actuación ${ }^{86}$ y, por otro, por la gratuidad de las críticas vertidas sobre

84 J. Gonzalo de las Casas, "Reforma del procedimiento civil con respecto a la real jurisdicción ordinaria", op. cit., pp. 168-190. No le duelen prendas en admitir algunas de sus ventajas ("reconocemos desde luego que con la Instrucción se han removido algunos abusos, se han cortado algunas dilaciones, y se han introducido algunas mejoras de importancia"), pero también subraya sus desventajas (“... pero hay también innovaciones peligrosas, cuyas consecuencias aún no pueden preverse; hay supresiones, tal vez perjudiciales para la buena defensa de los litigantes, y hay en fin otras disposiciones que necesariamente han de crear conflictos de mayor trascendencia..."), advirtiendo que no era una disposición adecuada para resolver los problemas a los que se había de enfrentar ("Si solo hubiéramos de guiarnos por el espíritu que ha dominado en la prensa periódica, creeríamos desde luego que la Instrucción del 30 de septiembre había resuelto el gran problema de toda institución judicial: la brevedad y sencillez de los juicios sin perjudicar la legítima defensa. Pero si desentrañamos esos mismos artículos, que tanto ensalzan aquel notable documento, ¿qué otra cosa encontramos en ellos que la justa apología del pensamiento del consejero de la corona? Nosotros también aplaudimos los buenos deseos, las grandes miras que se ha propuesto el Sr. Castro y Orozco... Pero así como somos los primeros en reconocer y aceptar la gran idea que ha servido de base a la Instrucción, también estamos firmemente persuadidos que en la práctica no ha de ofrecer los resultados que se esperan..."). No fue el único. Para J. Vicente y Caravantes, Tratado histórico, critico filosófico de los procedimientos judiciales en materia civil, según la nueva ley de enjuiciamiento, con sus correspondientes formularios, op. cit., p. 96, esta norma "no supo conciliar la brevedad tan conveniente a las partes en la administración de justicia con la conservación de los trámites que reclamaban los fueros de la defensa, las garantías del acierto y las necesidades de la justicia".

$85 \mathrm{~J}$. Gonzalo de las Casas, "Reforma del procedimiento civil con respecto a la real jurisdicción ordinaria”, op. cit., p. 169: “... Ahora bien: si tales son nuestros principios y nuestros deseos, si a ellos pretendemos que se ajusten todas nuestras apreciaciones ¿debemos cantar el hossana por la publicación de la Instrucción del 30 de setiembre, o deberemos por el contrario combatirla en todas sus partes? Estamos muy lejos de aceptar ninguna de esos dos estremos (sic). Ni nos ciega un espíritu sistemático de oposición a la reforma, ni pretendemos quemar incienso en el altar de la adulación..."

$86 \mathrm{~J}$. Gonzalo de las Casas, "Reforma del procedimiento civil con respecto a la real jurisdicción ordinaria”, op. cit., p. 169: “... reformas de tal importancia y magnitud deben meditarse mucho, antes de que adquieran fuerza de ley; no creemos que sea dado a un hombre solo abarcar cuantos conocimientos se necesitan para organizar un sistema tan vasto y complicado. Y aun cuando esto fuera dable, todavía debería reconocerse la necesidad de que se oyera a los hombres más eminentes encanecidos en la práctica de los negocios judiciales, y a las corporaciones que siempre $\mathrm{y}$ en todos casos se han tenido como competentes para informar en las materias de su 
abogados, jueces, fiscales y demás personal subalterno ${ }^{87}$. Entrados ya en el último tercio de siglo y conscientes del paso de los años sin la imprescindible mejora de la delicada situación existente, hay juristas ${ }^{88}$, como Emilio Bravo, que incluso añoran a esa personalidad tan cuestionada ${ }^{89}$ como la del Marqués de Gerona:

"Aquí la gloria que hay que adquirir es la del hombre de Estado que entrase en el Ministerio de Gracia y Justicia, decidido a trabajar, a organizar, a remover obstáculos de todos los géneros"90.

Qué grado de desesperanza había para que éste fuera el piloto añorado cuando en su momento había resultado tan controvertido.

Se han gastado casi dos tercios del siglo y sigue pendiente la "buena, saludable y necesaria reforma' que arregle el problema de la justicia. Son muchos los años trascurridos con promesas, trabajos malogrados y vanos esfuerzos que no han dado los frutos esperados ${ }^{91}$. Coinciden los profesionales en que de

incumbencia... porque legislar no es teorizar una ciencia, no es escribir un libro, no es fundar una escuela filosófica, no es explicar un pensamiento, no es en fin hacer alarde de los más sanos principios, ni de las más puras intenciones...”.

87 J. Gonzalo de las Casas, "Reforma del procedimiento civil con respecto a la real jurisdicción ordinaria”, op. cit., p. 170: “... Estamos muy lejos de creer que haya habido intención de denigrar a clases tan respetables como las de la magistratura y la abogacía; porque si alguna mancha quedaba esculpida en sus frentes, también se vería grabada en la de quien, antes llegar a ser consejero de la corona, había vestido con tanta honra como probidad esa misma toga que con tan negros colores se dibuja. No creemos en la intención; pero creemos en la influencia de esas calificaciones, que arrojadas desde la cumbre del poder han causado una profunda sensación en todas las clases de la sociedad... Duélenos en el alma el haber leído en un documento oficial éstas $\mathrm{y}$ otras palabras tan inconvenientes como innecesarias; porque si se cometian abusos y se trataban de remediar ¿para qué exagerarlos? Y si eran tan deformes y tan execrables ¿por qué no se han corregido antes?...".

88 Coincidía en esta época también M. Torres Campos, Cómo se administra justicia, op. cit., p. 6, en focalizar el rompecabezas de España en la clase política y su desinterés por los verdaderos problemas del país: "El verdadero cáncer de España es la empleomanía, la existencia de los políticos de oficio, que llegan a los principales puestos del país, a veces sin capacidad y sin títulos, sin verdaderas condiciones, antes, por el contrario, con falta de ellas... El objeto es cobrar y vivir sin trabajar, o con el menor trabajo posible. Bastaría esto sólo para explicar el desconcierto administrativo. No se establece una organización adecuada a las necesidades públicas: se trata tan solo de crear destinos con que obsequiar a amigos y paniaguados".

89 En las “Observaciones sobre la Instrucción del procedimiento civil de 30 de setiembre de 1853”, RGLJ n ${ }^{\circ}$ 3, 1854, pp. 13-92, se coloca una nota en la que, además de dejar constancia de sus autores, "los Colegiales D. José Maria Monreal, D. Juan Manuel González Acevedo, D. Luis Díaz Pérez, D. Pedro Gómez de la Serna y D. Manuel Silvela”, se pone de manifiesto el revuelo que ocasionó su entrada en vigor, especialmente por el modo en que se desarrolló todo el proceso de su gestación. Y, de modo particular, por las afirmaciones un tanto ofensivas para el corporativismo del mundo judicial. La dirección de la revista cree necesario publicar un artículo para justificar la oportunidad de la norma, salvando el modo de proceder ministerial: porque contribuye "al mejoramiento de nuestras leyes de actuaciones civiles, e impulsa la reforma en el sentido que la ciencia y las necesidades públicas reclaman urgentemente...".

90 E. Bravo, De la administración de justicia, op. cit., pp. 475.

91 "Esposición (sic) que la Junta de Gobierno del Colegio de Abogados de Madrid, asociada a los ex decanos del mismo, ha elevado al Excmo. Sr. Ministro de Gracia y Justicia solicitando se lleven a 
manera inminente se ha de actuar en, al menos, varios puntos cardinales: la mejora de la parcheada organización de los tribunales ${ }^{92}$, la promulgación de un código de derecho civil, de procedimientos y la reforma del penal ${ }^{93}$, la unificación de las diversas jurisdicciones ${ }^{94} \mathrm{y}$, como culmen de la pirámide, la consideración de la justicia como poder independiente ${ }^{95}$.

pronto y feliz término las reformas iniciadas sobre organización de tribunales y ordenación del enjuiciamiento criminal", op. cit., pp. 64-77: "La opinión pública, que aprecia en todo lo que vale la recta y pronta administración de justicia, preciosa conquista de los pueblos civilizados, base cardinal de la paz, el orden y la prosperidad interior de los Estados, ha empezado a preocuparse de los defectos de que adolece la legislación española y a alarmarse en vista de los tristes resultados que produce una organización de tribunales conocidamente viciosa y un sistema de enjuiciar confuso, regido por leyes anticuadas unas, impremeditadas y provisionales otras y en completo desacuerdo todas, con los adelantos y las necesidades de la época”.

92 M. Ortiz de Zúñiga, "De la responsabilidad judicial”, op.cit., pp. 99-115: "Preciso es, además, establecer acertadamente la ley constitutiva de nuestros tribunales, que fije sus propias atribuciones, estendiéndolas (sic) a donde en buenos principios debe alcanzar la jurisdicción común, y haciendo dificiles, si no imposibles, las eternas cuestiones sobre competencia de conocimiento, que son hoy una mengua de nuestra época..." . Para otros como E. Bravo, De la administración de justicia, op. cit., p. 172, incluso es necesaria la reforma del Ministerio de Gracia y Justicia: "No sería lógico que antes de hablar de la organización de los Tribunales nos olvidásemos de la del Ministerio de Gracia y Justicia, de quien depende en el orden administrativo...".

93 "Pensamiento de la Revista", La Escuela del Derecho. Revista jurídica, nº I, 2a ed., Madrid, 1863, p. 5: "Nos hallamos en una época de elaboración científica y de renovación legislativa. Nuevos tiempos traen consigo nuevas necesidades: nuevas necesidades reclaman nuevas leyes... España está a punto de sufrir una profunda transformación legislativa. En materia civil estamos envueltos en el caos de los antiguos códigos. Hoy existe uno en proyecto, que aún no sabemos si algún día llegará a ser ley. Tenemos un Código criminal que habrá de reformarse en muchas de sus partes... La organización judicial habrá de asentarse muy en breve sobre nuevas y más sólidas bases...". De otra parte, M. Ortiz de Zúñiga, "Sobre los trabajos de la Sala primera del Tribunal Supremo de Justicia”, RGLJ, $\mathrm{n}^{\circ}$ 18, 1861, pp. 629-647, señala que somos “... un país donde falta un Código civil y la legislación es un caos, donde no se ha reformado la antigua organización de los tribunales...”. Igualmente, E. Bravo, De la administración de justicia, op. cit., p. 193: "La reforma de los procedimientos judiciales es una de las necesidades más imperiosas de nuestra Administración de justicia...".

94 Aguirre, "De las reformas para la recta administración de la justicia ¿Conviene la abolición de todos los fueros privilegiados? ¿Conviene la supresión de las autorizaciones para procesar a los empleados de la Administración?”, op. cit., pp. 285-301: “... En vano se intentaría una reforma saludable para que la justicia sea una verdad si las bases fundamentales del sistema no fueran la unidad en la administración de justicia, la remoción de los recursos y dilaciones que hacen interminables los juicios, la libre acción de los tribunales y la separación absoluta e independiente de las facultades de la administración en general de la justicia. Y como ninguno de estos fundamentos forma parte del sistema que rigen en España para la administración de justicia, he aquí por qué no puede administrarse pronta y rectamente...”. En la misma línea, J.M. Manresa y Navarro; J. Reus y Garcia, Ley de Enjuiciamiento civil, comentada y esplicada (sic). Apéndice a los cinco tomos de esta obra, Madrid, 1869, p. VI: "De las reformas indicadas, la más importante... es la que se refiere a la unidad de fueros. Reclamada esta reforma por la ciencia y por la opinión pública, venía preparándose hace tiempo, hasta que por la ley de 11 de abril de 1868 se autorizó al Gobierno para llevarla a efecto en lo relativo a los negocios civiles... el Gobierno provisional ha realizado la reforma por su Decreto de 6 de diciembre de 1868".

95 Que no se consigue ni aún con mandatos constitucionales expresos como denuncia A. Gómez Becerra, Observaciones sobre el estado del poder judicial en España, op. cit., p. 27: "Sentimos el amargo dolor de tener que decir, que no es independiente, y que vivimos con respecto a esta parte de la Constitución de 1837, en un estado de infracción permanente y continua... Nada importa, que el Poder judicial deba ser independiente...". 
Respecto a la unificación de las jurisdicciones surgida del texto de 1812, en un plano estrictamente constitucional, tuvo eco tanto en la Constitución del $37^{96}$ como en las de $1869^{97}$ y $1876^{98}$. Ignorada en el Estatuto Real llama la atención el expreso silencio que mantiene la de $1845^{99}$ que, aunque copió el artículo 4 de su predecesora, suprimió este apartado ${ }^{100}$. Su concreción a nivel práctico vino de la mano del Decreto de 6 de diciembre de 1868 estableciendo la unidad de fueros ${ }^{101}$. Advierte este texto de forma contundente que "la diversidad de fueros embaraza la administración de justicia". Partiendo, pues, de que "la unidad de miras en hombres de todos los partidos, revela de una manera indudable que la diversidad de fueros, por razón de las personas que litigan, no tiene razón de ser; que no hay motivos justos que la abonen", acaba con diversas herencias gaditanas laxas en esta cuestión, como la jurisdicción de Hacienda y de Comercio; aunque, por peculiares circunstancias, consiente como fueros privilegiados el eclesiástico ${ }^{102} \mathrm{y}$ el militar ${ }^{103}$, singularidades que persistirán al comienzo del siglo XX.

De la mano de la unificación de fueros camina la de códigos que también tiene su hueco en los distintos ejemplares constitucionales ${ }^{104}$. Proceso lento y

96 Art. 4: "Unos mismo códigos regirán en toda la Monarquía y en ellos no se establecerá más que un solo fuero para todos los españoles en los juicios comunes, civiles y criminales”.

97 Art. 91: “A los Tribunales corresponde exclusivamente la potestad de aplicar las leyes en los juicios civiles y criminales. La justicia se administra en nombre del Rey. Unos mismos Códigos regirán en toda la Monarquía, sin perjuicio de las variaciones que por particulares circunstancias determinen las leyes. En ellos no se establecerá más que un solo fuero para todos los españoles en los juicios comunes, civiles y criminales".

98 Art. 75: "Unos mismos Códigos regirán en toda la Monarquía, sin perjuicio de las variaciones que por particulares circunstancias determinen las leyes. En ellos no se establecerá más que un solo fuero para todos los españoles en los juicios comunes, civiles y criminales".

99 Art. 4: "Unos mismos códigos regirán en toda la Monarquía".

100 Cuestión que se justifica en el preámbulo del Decreto de 6 de diciembre de 1868 estableciendo la unidad de fueros diciendo que "no fue porque el Gobierno y la Comisión que entendió en ella no abrigasen el mismo convencimiento, sino porque no consideraron la declaración propia de la ley constitutiva del Estado".

101 Un breve resumen de su devenir puede verse en E. Álvarez Cora, La arquitectura de la justicia burguesa. Una introducción al enjuiciamiento civil en el siglo XIX, op. cit., pp. 49-56; J.M. Romero Moreno, Proceso y derechos fundamentales en la España del siglo XIX, op. cit., especialmente, p. 295; M. Lorente Sariñena; F. Martínez Pérez; M.J. Solla Sastre, Historia legal de la justicia en España (1810-1978), op. cit., pp. 282 y ss., especialmente la nota 17.

${ }^{102}$ Decreto de 6 de diciembre de 1868 estableciendo la unidad de fueros: “... Esta jurisdicción santa no puede ser menoscabada ni restringida. La Iglesia, fiel depositaria de ella, continuará ejerciéndola, tal como la recibió de manos de su fundador... estendiéndose (sic) únicamente el desafuero a las personas eclesiásticas por razón de los negocios comunes, civiles y criminales”.

103 Decreto de 6 de diciembre de 1868 estableciendo la unidad de fueros: “... el ejemplo de las demás naciones y la experiencia que demuestra los inconvenientes que traeria consigo tan inmoderada estensión (sic), cuando se trata de materia criminal, de delitos cometidos por aquellos que tienen las armas en la mano, y por cuya razón es menester, o castigar más severamente o con la mayor urgencia, para que venga la reparación justa que contenga a todos en el limite de sus deberes...".

104 Vid., entre otros, J.M. Antequera, La codificación moderna en España, Madrid, 1886; F. Sánchez Román, La codificación civil en España, en sus dos periodos de preparación y consumación, Madrid, 1890; A. González Miranda, Historia de la codificación penal española y ligera critica al código vigente, Madrid, 1907; M. Peset, "La primera codificación liberal en España (1808-1823)", Revista crítica de derecho inmobiliario, $\mathrm{n}^{\circ}$ 48, 1972; del mismo autor, "Una 
farragoso como es conocido que si bien comienza con prontitud, especialmente en el ámbito penal, se embarra apresuradamente en el civil. Cuando Fernando VII en el año 1820 declara su famoso 'Marchemos francamente, y yo el primero, por la senda constitucional' a la Constitución de 1812, que apenas había estado en vigor dos años y dos meses, se le abre una nueva oportunidad para hacer realidad sus dictados. Así pues, aunque las dificultades fueron incontables, los legisladores del trienio dieron unos primeros pasos codificadores en sintonía con lo exigido por el art. 258 y tan sólo un bienio después, en 1822, ya habían preparado un código penal. Norma sobre la que hay serias dudas de que llegara a entrar en vigor pero que puso de manifiesto la necesidad existente de renovación de la legislación criminal. Una mudanza que se produjo varias décadas después, en 1848, cuando ya regía un nuevo texto constitucional. Esta flamante disposición criminal sentó las bases de la posterior codificación penal. Retocada dos años después de su aprobación fue derogada tras la promulgación de un nuevo código, el de 1870, vigente cuando se celebraban los fastos del centenario constitucional. A principios del siglo XX no hay duda de la renovación en materia de legislación criminal aunque éstas, las mudanzas, siempre resulten insuficientes.

Menos problemas hubo en la esfera mercantil. En 1829, reinando todavía el reacio a cualquier novedad Fernando VII, se promulga el primer código de comercio de nuestra historia que permanecería vigente hasta que, fruto de nuevas exigencias mercantiles, sea sustituido por otro, el de 1885, que conservará su fuerza legal durante todo el siglo $\mathrm{XX}^{105}$. Hacer realidad el mandato constitucional del doce había costado diez años en el ámbito penal y diecisiete en el mercantil mientras que para el civil habrán de esperarse setenta y siete. El Código civil verá la luz, tras sortear múltiples dificultades, en 1889.

En la esfera procesal, a pesar de contar con numerosas disposiciones, La Pepa no exigía la promulgación de un código como tal. Y la tradición se mantuvo. A lo largo del XIX y primeras décadas del XX son innumerables las disposiciones que afrontan y tratan de resolver la problemática del mundo de los jueces y tribunales y del proceso. Unas, la mayor parte, intentan solventar cuestiones puntuales mientras otras, en cambio, tienen un carácter más genérico. Pero a ninguna, se le da el nombre de código, si bien, como recalca Tomás y Valiente, varias de ellas por su contenido y por su estructura se lo merecian, en especial el Reglamento para la administración de justicia en lo respectivo a la jurisdicción ordinaria de 26 de septiembre de 1835 y la Ley provisional Orgánica del Poder Judicial de 15 de septiembre de 1870, disposición que, cuando la Constitución de 1812 cumple cien años, era el armazón jurídico que hacía viables buena parte de sus exigencias en cuanto a la selección de jueces y magistrados y a la garantía de su independencia, responsabilidad e inamovilidad.

interpretación de la codificación española” en J.L. Soberanes Fernández (Coor.), Memoria del II Congreso de historia del derecho mejicano, Méjico, 1980; E. Gacto, "El código de comercio de 1885" en J.L. García Delgado (Coor.), La España de la Restauración. Politica, economía, legislación y cultura, Madrid, 1985; F. Tomás y Valiente, Códigos y Constituciones, Madrid, 1989; J. Baró Pazos, La codificación del derecho civil en España (1808-1889), Santander, 1993.

$105 \mathrm{Al}$ poco de ver la luz se le acompañó de una ley, con fecha de 24 de julio de 1830, relativa al 'Enjuiciamiento sobre los negocios y causas de comercio', disposición derogada por el Decreto de Unificación de fueros que como ya se ha señalado acabó con las peculiaridades de los tribunales de comercio. 
Dos grandes virtudes se le reconocen a esta controvertida disposición que sienta las bases de nuestra organización actual ${ }^{106}$. Frente a la anterior regulación reglamentaria y decretista, dispersa y fragmentada, el dotar "de rango de ley al orden judicial". En segundo lugar, el que lo haga con un texto completo, en el sentido de que contiene "en una misma disposición toda la organización de la estructura judicial y de su personal"107. En cambio, se le reprocha su carácter contradictorio ${ }^{108}$. Aunque será precisamente esta singularidad, la inclusión de principios contrapuestos, la que, desde su perspectiva, garantizará su supervivencia, en la medida en que según la tendencia política gobernante se acentuarán unos u otros. De ahí que durante más de cien años sobreviva y,

$106 \mathrm{Su}$ puesta en vigor trajo consigo una extensa nómina tanto de fervientes partidarios como de acérrimos contradictores. Respecto a estos últimos véanse, por ejemplo, las exposiciones elevadas por las Juntas de gobierno de distintos colegios de abogados del país. Entre los más vehementes destaca, quizá, el de Madrid, que se negó a asistir al acto de solemne apertura de los tribunales. El de Barcelona, más moderado, en una Exposición elevada al Excmo. Sr. Ministro de Gracia y Justicia en 26 de Noviembre de 1870, subraya que "abriga la fundada esperanza de que el carácter interino de la misma permitirá mejorarla con todas las reformas de que sea susceptible para adquirir la fijeza y estabilidad que debe tener una ley de tanta importancia" mientras que el de Burgos prefiere centrarse en "llamar respetuosamente la atención a V.E. acerca de lo coartado que en la novísima organización del poder judicial queda, sin razones bastantes en su concepto, el ejercicio de la abogacía (Exposición elevada al Excmo. Sr. Ministro de Gracia y Justicia en 2 de Abril de 1871). Este mismo colegio, en un informe que emite meses después (Informe que, en cumplimiento de la Real Orden de 17 de julio de 1871, emite la Junta de Gobierno del Ilustre Colegio de Abogados de Burgos sobre la Ley provisional de organización del poder judicial, Burgos, Imprenta de D. Timoteo Arnaiz, 1871, p. 5) insiste en que “... las mejores leyes, entre las cuales contamos la que es objeto de estos renglones, se convierten en malas, cuando los espíritus no están preparados para recibirlas".

107 B. Clavero, "La gran innovación: Justicia de Estado y Derecho de Constitución” en J.M. Scholz, El tercer poder. Hacia una comprensión histórica de la justicia contemporánea en España, Frankfurt am Main, 1992, p. 179.

108 Subraya M.A. Aparicio, El status del poder judicial en el constitucionalismo español (18081936), op. cit., p. 113, que el ejemplo más revelador de su paradójica contradicción aparece pronto: en su artículo segundo, en el que tratando de delimitar la función jurisdiccional a la tradicional afirmación de que le corresponde "la potestad de aplicar las leyes en los juicios civiles y criminales" le añade, como ruidosa novedad, "juzgando y haciendo ejecutar lo juzgado". Esto significa, en su opinión, un elemento de soberanía que en realidad resulta ser una "ficción" pues los tribunales por definición no ejecutan sino que ordenan la ejecución. Para J.E. Sobremonte Martínez, Indultos y amnistía, Valencia, 1980, pp. 241-242, la propia configuración de los tribunales que establece esta ley de 1870, consiente en su actividad de aplicación de la ley, al menos en supuestos concretos, que lo que no le esté permitido hacer a los tribunales le sea concedido al poder ejecutivo. Y toma como ejemplo el caso de los indultos: "Para comprender la función judicial, que, aunque atenuada ejerce el poder ejecutivo, hay que tener en cuenta la configuración de los Tribunales españoles en su actividad de aplicación de la Ley; pues ésta es heredera de la concepción de Montesquieu, según la cual el Juez es la 'Bouche que prononce les paroles de la loi', o, 'etres inanimes qui no prevent moderer ni la forcé ni la rigueur de la loi', que se corresponde a la definición de la Ley Orgánica del Poder Judicial, dictada en el mismo año de 1870 e inspirada en los mismos principios. Según esta concesión, lo que no está permitido hacer a los Tribunales le es concedido al poder ejecutivo que en definitiva aplica 'derecho' o más concretamente un 'principio de justicia' que debe definirse como el de la convivencia de que la estricta aplicación del derecho positivo no traiga como consecuencia -la calificación social- de perjuicios mayores que los que se ocasionarian si la condena no fuera cumplida o atenuada. Se reserva de este modo el poder ejecutivo una de las funciones más excelsas del Poder, como es de la de hacer justicia, hacer lo justo, lo más conveniente en cada caso concreto". 
además, lo haga bajo regímenes y tendencias politicas muy diversas a pesar de haberse intentado su derogación en numerosas ocasiones ${ }^{109}$.

No hay que perder de vista que nació al amparo de una Constitución, la de 1869, que traía consigo un giro copernicano en el orden judicial. De inicio, la justicia pasaba de administración a poder ${ }^{110}$. Muy sugestivas resultan al respecto las palabras de Pedro Gómez de La Serna que, en su condición de presidente del Tribunal Supremo, se verá obligado, por exigencias legales, a pronunciar un solemne discurso con motivo de la inauguración del año judicial celebrado el 15 de septiembre de 1869 ("la apertura de los tribunales"). Aprovecha la ocasión para disertar sobre el beneficio de apostar por la independencia del poder judicial. Bajo la premisa de que se propone conferenciar sobre "lo que fuimos, de lo que somos, $\mathrm{y}$ de las obligaciones que nos impone la sublime potestad de que estamos investidos"111 hace un repaso de lo que ha sido el devenir de la magistratura en la historia de España partiendo del lugar privilegiado que ha ocupado el Rey en cuanto "Juez Supremo" y "fuente única de la Justicia" con "unos tribunales que eran delegación suya" hasta llegar a los momentos presentes en los que tanto para gobiernos republicanos como monárquico-constitucionales la judicatura debe tener "vida propia, funciones fijas escritas en la ley, libertad para juzgar, independencia en todo lo que concierne al ejercicio de su potestad, e inamovilidad cuando no son temporales las funciones que se ejercen".

No se olvida de aquellos publicistas que defienden que "el orden judicial es sólo una desmembración del poder ejecutivo para auxiliar su acción en casos determinados", que proclaman que "no es verdadero poder", que defienden que "no tiene vida ni acción propia" y que "obra siempre provocado por la sociedad o por los particulares, y declarados el hecho y el derecho, ha cumplido su misión dejando al poder ejecutivo que lleve a efecto lo juzgado". Entiende que no es el lugar ni el momento adecuado para combatir dichas posiciones desde un plano doctrinal aunque sí quiere dejar por sentado que por fin no tienen cabida, siquiera sea desde el punto de vista meramente legal, pues el texto constitucional vigente había proclamado al orden judicial como "un verdadero poder del Estado y no meramente un orden de funcionarios públicos para aplicar leyes determinadas"112.

109 M. Lorente Sariñena; F. Martínez Pérez; M.J. Solla Sastre, Historia legal de la justicia en España (1810-1978), op. cit., p. 278: "A pesar de la distancia contextual y temporal, en cambio, la LOPJ compendiaba los elementos básicos por los que identificamos a nuestra justicia actual. Formalmente porque se trataba de una ley elaborada por Gracia y Justicia, pero una ley orgánica al fin y al cabo, lo cual nos aproxima al poder judicial como un orden cuyo diseño es disponible dentro del marco constitucional, clausurando la concepción de la justicia como infraestructura, indisponible, de todo el orden constitucional. Materialmente, porque el aparato judicial y el diseño del juez eran ya los de la administración de justicia que conocemos...”.

110 Así, en su Título VII Del poder judicial.

111 Discurso leido por el Excmo. E Ilmo. Sr. D. Pedro Gómez de la Serna, presidente del Tribunal Supremo de Justicia en la solemne apertura de los tribunales celebrada el 15 de setiembre de 1869 , Madrid, Imprenta del Ministerio de Gracia y Justicia, 1869, pp. 7 y ss.

112 La cuestión no era baladí, pues no sólo había que lidiar contra quienes negaban fervientemente la condición de poder al judicial, del que algunos textos constitucionales daban fe como ya hemos dejado constancia, sino que también estaban los que, por el contrario, defendian la necesidad de la existencia de cuatro poderes. A la tradicional división tripartita le sumaban un cuarto: el moderador, que habia de estar por encima de todos y encargarse de poner fin a las desavenencias entre los otros tres. En este sentido, un autor como Miguel Moya en su obra 
En ese sentido, defiende que la justicia siempre tiene que estar vigilante ante posibles, y más que probables, intromisiones de otros poderes, especialmente del gobierno. De ahí que no renuncie, a lo largo de su exposición, a ir marcando diferencias, a desmenuzar singularidades que fortifiquen su emancipación respecto de las demás potestades. Así, señala que no puede el poder judicial "admitir ciegamente todos los actos que provienen del ejecutivo" pues si "lo hiciera, permitiria la invasión de otro poder en las funciones que la ley confia sola y exclusivamente a la institución judicial, abdicaría de sus funciones, se haria responsable ante el país, y ante la historia por la deserción del más sagrado de sus deberes, rebajaría su carácter de poder, reduciéndolo a la esfera subalterna de una dependencia de la Administración, bastando que el Gobierno pidiera su concurso para que se convirtiese alguna vez en instrumento mecánico de errores, de malas apreciaciones, y quizá de iras y rigores de gobernantes, que echaran un velo sobre la estatua de la ley e introdujeran graves perturbaciones en el libre ejercicio de los demás poderes". En consecuencia se pregunta:

“... ¿Qué sería de la libertad, qué de la propiedad, qué de la seguridad individual de los ciudadanos? ¿De qué serviría la salvaguardia de estos derechos, confiada por la ley a los Tribunales, si estos humillaran su cabeza a las invasiones de un poder usurpador?...".

No obstante este posicionamiento, es consciente, y admite, que un poder judicial descontrolado, como cualquier otro en sus mismas circunstancias, acabaría generando violencia y convirtiéndose en temible para el Estado. Pero esa posibilidad en modo alguno justifica su menosprecio. Todo lo contrario. De hecho, desde su perspectiva hay resortes suficientes para impedir aquel escenario y convertirlo, como de hecho es, en un poder neutral. El judicial:

\footnotetext{
“... nunca obra activamente, nunca adopta medidas de carácter general. A diferencia del ejecutivo, que establece en gran parte las reglas por que ha de regirse y las aplica después, aquél nunca juzga según reglas que él ha establecido, sino conforme a las leyes, en cuya formación no ha tenido participación alguna; puede decirse que no es él quien juzga, sino la ley, de que es órgano; ante ella dobla su cabeza; nunca puede alterarla ni modificarla, viene a ser un intermediario entre la ley y los que comparecen para ser juzgados...."113.
}

\footnotetext{
Conflictos entre los poderes del Estado. Estudio Politico, Gaspar editores, Madrid, $2^{\mathrm{a}}$ edición, 1881, pp. 63-74, intentará identificar y enumerar todos los posibles conflictos entre poderes. No obstante, al reconocer que su pretensión es inviable en la práctica opta por presentar una clasificación genérica de los mismos dividiéndolos en varios grupos, encuadrando al judicial entre aquellos que lo enfrentan, de modo especial, con el ejecutivo advirtiendo del extremo peligro que supone: "pues se traducen en cuestiones positivas o negativas de competencia, o dan origen a la sumisión y dependencia de la administración de justicia".

113 P. Gómez de la Serna, Discurso leído por el Excmo. E Ilmo. Sr. D. Pedro Gómez de la Serna, presidente del Tribunal Supremo de Justicia en la solemne apertura de los tribunales celebrada el 15 de setiembre de 1869, op. cit., p. 15.
} 
Prosigue su razonamiento destacando dos cuestiones que podrian inducir a confusión en cuanto a la dependencia o no judicial respecto del ejecutivo. Se trata del hecho ya mencionado anteriormente de que los textos constitucionales afirman que la justicia se administra en nombre del rey y que es a éste a quien corresponde el nombramiento de jueces y magistrados ${ }^{114}$. Este cordón umbilical podría marcar, a juicio de quienes defienden la no independencia del poder judicial, el sutil punto de sometimiento. Enérgicamente lo rechaza pues, a su juicio, el rey, además de ser el jefe del gobierno, ejerce funciones moderadoras entre poderes lo que significa que no tiene por qué identificarse con ninguno en concreto. Además, entre otras cosas, es simbolo de la unidad nacional y personificación del estado lo que implica que se pueda impartir justicia en su nombre, que es lo mismo que decir en nombre de todos, del estado en su conjunto. En cuanto a lo de los nombramientos de jueces y magistrados también lo refuta bajo la premisa esencial de que el monarca no tiene libertad absoluta para nombrar a quien quiera. Todo lo contrario. Culmina un proceso en el que hay una participación de todos los poderes del estado de modo que el legislativo establece el marco normativo genérico (donde fija la manera y forma de elección) que es, a su vez, desarrollado por el ejecutivo con la supervisión final del judicial al examinar la capacidad legal de los elegidos.

Finalmente, quiere romper una lanza a favor de dos principios irrenunciables: la 'santidad' de la cosa juzgada y la inamovilidad judicial. En cuanto a la primera cuestión no se detiene mucho pues entiende que es un asunto indiscutible: "los pueblos cultos colocarian entre los no civilizados al que consignara en sus leyes que el poder ejecutivo pudiera anular, corregir o reformar los fallos de los Tribunales". En cuanto a la segunda advierte que ya no es posible retrasar más su implantación: "Sí, Señores, el poder judicial será inamovible de hecho, como lo es de derecho; ya ha sonado la hora en que lo sea..."115. Si se retrasara más -señala- “...continuaría la hipocresía de aparentar vivir bajo otra forma de gobierno que en la que en realidad rigiera los destinos de este gran pueblo, que bien merece llegar al término de sus conquistas políticas...".

Ahora bien, admite que la inamovilidad, al igual que debe ser una garantía para el desarrollo de un trabajo exigente imprescindible para la sociedad, podría convertirse en un privilegio odioso a cuya sombra podría cobijarse "la importunidad y el nepotismo". Consciente del peligro que representa recuerda que se mitiga con un adecuado sistema de elección de los futuros profesionales, como puede ser la vía de la oposición, completada con un oportuno sistema de ascensos y de exigencia de responsabilidad. La satisfactoria combinación de todos estos condicionantes debe dar como resultado la selección de unos jueces con un talento innato, un profundo conocimiento del derecho y un buen sentido a la hora de impartir la justicia. Virtudes que deben completarse, entre otras ${ }^{116}$,

114 Esta cuestión fue recurrente para aquéllos que negaban la independencia al poder judicial a pesar de que se pudiera recoger expresamente en un texto constitucional. Posición que solía ser combatida con nutridos argumentos. Vid., v. gr., R. Sánchez Ocaña, "Inamovilidad judicial”, RGLJ, $\mathrm{n}^{\circ}$ 65, 1884, pp. 115-121.

115 P. Gómez de la Serna, Discurso leido por el Excmo. E Ilmo. Sr. D. Pedro Gómez de la Serna, presidente del Tribunal Supremo de Justicia en la solemne apertura de los tribunales celebrada el 15 de setiembre de 1869, op. cit., p. 20.

116 P. Gómez de la Serna, Discurso leido por el Excmo. E Ilmo. Sr. D. Pedro Gómez de la Serna, presidente del Tribunal Supremo de Justicia en la solemne apertura de los tribunales celebrada el 15 
con la exigencia de "una conducta inmaculada en el orden público y en el hogar doméstico" y cierta "templanza en la manifestación de las pasiones políticas". Y, todo al objeto de no perder de vista que "no basta para tranquilizar la conciencia pública que la justicia esté bien administrada, sino que es necesario que todos comprendan que es recta y que es imparcial".

Al principal impulsor de la Ley Orgánica del Poder Judicial, Eugenio Montero Ríos, lo veremos el mismo día de su promulgación, el 15 de septiembre de 1870, pronunciando el tradicional discurso de apertura de tribunales del que también se pueden extraer jugosas conclusiones tanto por la profundidad de lo proclamado como por la condición del que las pronuncia, a la sazón Ministro de Gracia y Justicia. En este sentido, relata cómo, con anterioridad a la revolución septembrina del año 1868, existían numerosas voces que denunciaban la mala organización de los tribunales de justicia al par que reclamaban garantías para que jueces y magistrados pudieran desempeñar su labor con total independencia. Ahondando en esa línea argumental recalca cómo, a pesar de los grandes pasos dados en tal sentido, gracias entre otras a disposiciones como el Reglamento de 1835, a esas alturas del siglo subsistian anomalias como el supuesto de los alcaldes que aún conservaban la consideración de funcionarios judiciales, situación a todas luces inadmisible ${ }^{117}$. Advierte que esta incoherencia, como otras tantas, entre las que recordaba el hecho de que los tribunales de primera instancia fuesen unipersonales o que las salas de las audiencias hubiesen venido conociendo indistintamente de asuntos civiles y criminales ${ }^{118}$, eran unánimemente rechazadas. De forma resignada reconoce que no existía acuerdo respecto a su forma de proceder para corregirlas ${ }^{119}$. Pero preconiza que una posible vía de corrección, y quizá la mejor, fuese la promulgación de una norma

de setiembre de 1869, op. cit., p. 23. Enumera además los siguientes requerimientos: “... Debe estar y aparecer contento con su situación, ageno (sic) a esa inmoderada sed de engrandecimiento, a esas miras desordenadas de medro que, en tiempos anormales se apoderan de algunos, modesto en su vida pública, sencillo en la privada, austero respecto a sí, benigno con los demás, justo siempre, imbuido en el sentimiento de sus deberes, estudioso como lo han de ser todos los que conocen la gran extensión de las ciencias jurídicas, discutidor sin presunción y sin espíritu de predominar sobre sus colegas, animoso para sostener sus ideas antes de que una mayoría adopte opinión diferente, pero dócil y respetuoso al fallo que prevalezca...".

117 E. Montero Ríos, Discurso leído por el Excmo. Sr. D..., Ministro de Gracia y Justicia en la solemne apertura de los tribunales celebrada en 15 de setiembre de 1870, Madrid, Imprenta del Ministerio de Gracia y Justicia, 1870, p 12: "Antes del profundo cambio politico efectuado en Setiembre de 1868, existía ya en el país una opinión muy autorizada que se había pronunciado enérgicamente en frecuentes ocasiones, condenando la organización que tenían y han conservado hasta ahora nuestros Tribunales de justicia y Ministerio fiscal, y reclamando para los Jueces y Magistrados y funcionarios de aquel orden las garantias que son condición necesaria para el recto desempeño de sus funciones. A pesar de las grandes novedades introducidas desde 1835, con el fin de separar la justicia de la administración, todavía hasta hoy han conservado los Alcaldes su carácter de funcionarios judiciales...".

118 E. Montero Ríos, Discurso leido por el Excmo. Sr. D..., Ministro de Gracia y Justicia en la solemne apertura de los tribunales celebrada en 15 de setiembre de 1870, op. cit., p. 12: "Nuestros Tribunales de primera instancia tienen aún también la forma unipersonal, a pesar de que la ciencia viene proclamando como más perfecta la forma colegiada; y las Salas de justicia de nuestras Audiencias conocian en esta última época indistintamente de lo civil y de lo criminal".

119 E. Montero Ríos, Discurso leido por el Excmo. Sr. D..., Ministro de Gracia y Justicia en la solemne apertura de los tribunales celebrada en 15 de setiembre de 1870, op. cit., pp. 12-13: "Pero si los vicios de nuestra organización judicial eran unánimemente reconocidos, no así lo era el medio más conveniente de corregirlos...". 
específica para el mundo de los tribunales: precisamente la Ley Orgánica del Poder Judicial. Como parte activa en su génesis, reconoce que la disposición recién alumbrada no es la solución más sublime que se hubiera podido concebir pero sí alega que es la propuesta más adecuada en atención a los medios y circunstancias en los que se halla el país en esos momentos para enderezar ese rumbo erróneo que seguía el orden judicial ${ }^{120}$. Resaltando, además, que contiene una prolija regulación, demandada por lo demás de forma unánime, de "los dos grandes principios que son un elemento esencial de vida para el poder judicial: la inamovilidad y la responsabilidad". Coincide con el presidente del Tribunal Supremo en su disertación del curso anterior en ser éstos los basamentos clave para apuntalar la independencia judicial.

Admite sin ambages que ambos principios han sido recogidos por las distintas constituciones que se han ido sucediendo a lo largo del siglo XIX. Pero asume también que hasta ese momento no se ha "sentido su eficacia"121. Y esta ausencia se debe, según su punto de vista, no "única ni siquiera principalmente a la arbitrariedad de los Gobiernos" sino por la ausencia de un marco legislativo adecuado $^{122}$. Insuficiencia que viene a cubrir su apadrinada Ley Orgánica.

Solemnemente declara que "la inamovilidad sin la responsabilidad es la tiranía del poder judicial" mientras que, por el contrario, "la responsabilidad sin inamovilidad es la arbitrariedad de los Gobiernos". Como parte de la base de que son premisas irrebatibles se tornaba indispensable que, en la nueva norma aprobada, se convirtieran en máximas tangibles. De ahí que pregone que:

“... desde hoy los Magistrados y Jueces tienen la seguridad de no ser arbitraria o injustamente suspendidos en sus funciones, trasladados ni depuestos. Desde hoy también los funcionarios del Ministerio fiscal estarán a salvo de la ciega y caprichosa arbitrariedad. Pero desde hoy también empiezan a responder de todos sus actos, de manera eficaz y severa, como hasta lo presente no ha sucedido. Grandes son las garantias que se les otorgan; grandes son también los deberes que contraen, y de cuyo cumplimiento se les habrá de exigir estrecha cuenta"123.

Todo ello, junto al pormenorizado tratamiento de otras cuestiones propias del mundo de los tribunales, le lleva a confiar ciegamente en que la novedosa ley judiciaria, a pesar incluso de tener la condición de provisional, vaya a colocar al

120 E. Montero Ríos, Discurso leído por el Excmo. Sr. D..., Ministro de Gracia y Justicia en la solemne apertura de los tribunales celebrada en 15 de setiembre de 1870, op. cit., p. 13: "En la ley orgánica se ha aceptado la forma de organización judicial, que si no es la más perfecta que la inteligencia puede concebir, es siquiera la menos defectuosa, dados el actual estado y recursos del país".

121 E. Montero Ríos, Discurso leído por el Excmo. Sr. D..., Ministro de Gracia y Justicia en la solemne apertura de los tribunales celebrada en 15 de setiembre de 1870, op. cit., p. 13.

122 E. Montero Ríos, Discurso leído por el Excmo. Sr. D..., Ministro de Gracia y Justicia en la solemne apertura de los tribunales celebrada en 15 de setiembre de 1870, op. cit., p. 13: "La inamovilidad y la responsabilidad judicial no se conciben sin la existencia de leyes especiales que, desarrollando estos dos grandes principios, los armonicen y hagan viables en la práctica".

123 E. Montero Ríos, Discurso leido por el Excmo. Sr. D..., Ministro de Gracia y Justicia en la solemne apertura de los tribunales celebrada en 15 de setiembre de 1870, op. cit., pp. 13-14. 
poder judicial, por primera vez, en un lugar que hasta entonces no había alcanzado:

\begin{abstract}
"Hasta ahora había sufrido éste constantemente los vaivenes de la política. Había estado privado de las condiciones de vida que son indispensables para desempeñar su altísima misión. No había sido en fin un verdadero poder en el Estado a pesar de la honrosa declaración de los ilustres legisladores de 1812. De hoy más, tendrá una estabilidad completa. Gozará de una inamovilidad bastante para permitirle funcionar libremente. Será, en fin, un verdadero poder en el Estado, que llevará en sí mismo la razón y los medios de su existencia. Tendrá, pues, todas las prerrogativas y poseerá todas las garantías a que tenía derecho y que hasta ahora habian sido nada más que un bello ensueño y una lisonjera aspiración siempre halagada y sostenida, pero nunca satisfecha" 124 .
\end{abstract}

En suma, con esta ardorosamente defendida Ley provisional sobre organización del poder judicial de 15 de septiembre de 1870 se trataba de poner fin a treinta y cinco años de numerosas tentativas zigzagueantes ${ }^{125}$ que habian tratado de pergeñar una "ordenada administración de justicia" en término legales ${ }^{126} \mathrm{o}$, en palabras de Clavero, “... una justicia gubernativa $\mathrm{y}$, administrativamente, políticamente, dependiente"127.

124 Y prosigue en p. 15: "No es eso todo. El poder judicial hasta ahora se había limitado a la noble, pero modesta, misión de regular por medio de la justicia las relaciones comunes de la vida del ciudadano y a la averiguación y castigo de los delitos. La nueva Constitución del Estado le ha colocado en las más altas esferas, haciendo de él la piedra angular del grandioso edificio que en aquella ley fundamental se ha principiado a levantar, la base de las nuevas instituciones politicas, el protector celoso de la libertad y el sostén finísimo del orden. El poder judicial en un pueblo libre, a diferencia de los Tribunales de justicia en aquel que todavia no se ha hecho cargo del cumplimiento de sus propios destinos, está llamado a vivir en medio del movimiento general y a dejar sentir su influencia, siempre benéfica, sobre las pasiones agitadas e inconstantes de la política, no para tomar parte apasionada en la lucha de los partidos y de los individuos, sino para moderar, tranquilo y sereno siempre, la acción de aquellos conforme a la ley y contenerles en el cumplimiento de sus respectivos deberes. Debe ser, en fin, como la inmóvil roca en medio del mar siempre agitado, a la cual se acojen (sic) los que, combatidos por la tempestad, buscan en ella su salvación, y contra cuya base se estrellan siempre las embravecidas olas sin conmoverla".

125 Incluida la creación de un órgano especializado como la Comisión General de Codificación. Sobre todas estas cuestiones vid. J.F. Lasso Gaite, Crónica de la codificación española, op. cit., especialmente, pp. 25 y ss.

126 Como así rezaba el Real Decreto de 22 de marzo de 1834, Gaceta de Madrid, núm. 36.

127 B. Clavero, "La gran innovación: Justicia de Estado y Derecho de Constitución", op. cit., p. 179. 


\subsection{La herencia gaditana}

\subsubsection{Los jueces: selección, inamovilidad y responsabilidad}

Cuando hacia la mitad de siglo Lorenzo Arrazola128 detalle el catálogo de contenidos que propone para que se discutan en la Academia Matritense de Jurisprudencia y Legislación centrará su atención preferentemente en la figura del juez, con cuestiones tan candentes como los requisitos que debian reunir para su selección además de las ineludibles demandas de su independencia, inamovilidad y responsabilidad.

Asuntos tratados legalmente pero no bien resueltos. Entre la propia doctrina dio origen a profundos debates a lo largo de todo el siglo. Así, a título ilustrativo se podrian citar a autores como Gómez de la Serna, a quien le gustaba subrayar que las exigencias de ingreso debían ser tales que inspirasen, ante todo, seguridad: "la seguridad de que los elegidos tienen toda la ciencia, toda la probidad, todas las dificiles prendas que requiere el alto cargo de juzgar"129. Miquel y Rubert, por el contrario, era más concreto. Tres, según su punto de vista, debían ser los requerimientos para ser juez: ciencia, probidad y celo. La primera entendida no como "una vana erudición, sino un estudio bastante profundo de la ciencia de lo justo y del derecho patrio..."130. Con la segunda, consustancial a la condición de juez, hacía alusión al compendio de virtudes que habian sido exigidas desde épocas remotas ${ }^{131}$. Y, finalmente, como guinda,

128 Catálogo de temas que deberán discutirse en las sesiones teóricas de la Academia Matritense de Jurisprudencia y Legislación, en el año 1845, formado por su presidente..., Madrid, 1845, pp. 315 .

129 P. Gómez de la Serna, "Sobre la manera de proveer los cargos judiciales", RGLJ, n” 24, 1864, pp. 97-108 y 257-262.

130 Para Antonio De Casas y Moral, "Indicaciones sobre el personal de la administración de justicia”, RGLJ, n⿳ 8, 1856, pp. 475-481, los títulos universitarios no eran garantía suficiente en la formación de un juez: “... parece imposible que los encargados de la administración del Estado no la hayan tenido muy presente para no estimar estos títulos en su valor aparente, para no reputarlos como garantía de suficiencia y para exigir otras circunstancias menos engañosas...”. Parecida opinión expresa P. Gómez de la Serna, "Del ingreso y ascensos en la carrera judicial", RGLJ, no 19, 1861, pp. 342-352 y 388-396: "No creemos que los exámenes de los cursos y grados académicos sean suficiente prueba de aptitud para las funciones judiciales" pues eso trae consigo que se pueda ser juez con 22 o 23 años y no tiene "la solidez de juicio necesaria para dominar todas las materias que son objeto de las tareas del juez". En la misma senda, E. Bravo, De la administración de justicia, op. cit., p. 228: "Nosotros creemos que no basta el título de abogado para el desempeño de los cargos judiciales...".

131 Sobre éstas vid., entre otros, J. Castillo De Bobadilla, Politica para Corregidores y Señores de vasallos, en tiempos de paz, y de guerra, y para Ivezes Eclesiásticos, y Seglares, y de Sacas, Aduanas, $y$ de Residencias, y sus Oficiales, y para Regidores, y Abogados y del valor de los Corregimientos, y Goviernos Realengos, y de las Órdenes. Autor el Licenciado... del Consejo del Rey Don Felipe Tercero nuestro Señor, y su fiscal en la Chancilleria de Valladolid, Madrid, $1649\left(1^{\mathrm{a}}\right.$ ed. Madrid, 1597); L. Santayana Bustillo, Gobierno politico de los pueblos de España, y el Corregidor, Alcalde y Juez en ellos, Zaragoza, 1742; L. Guardiola y Saéz, El corregidor perfecto y juez dotado de la calidades necesarias y convenientes para la recta administración de justicia y buen gobierno politico y económico de los pueblos, Madrid, 1785; V. Vizcaíno Pérez, Tratado de la jurisdicción ordinaria, para dirección, y guía de los alcaldes de los pueblos de España. Trata de sus elecciones, su gobierno, y de los exentos de su Fuero, conforme a las Leyes, Pragmáticas, y Ordenanzas Militares, publicadas hasta este año. Le escribió..., Madrid, 1781. Ya metidos en el siglo XIX un 
acentuaba la obediencia, inmediatez y abnegación que debían mostrar quienes se dedicasen a prestar este servicio, esto es, "el pronto y exacto cumplimiento de sus deberes". Emilio Bravo, en cambio, enumeraba un catálogo más amplio de pretensiones de entre las que sobresalian no sólo el ser buenos y dignos sino que era "también indispensable el parecerlo"132.

Descendiendo de forma más concreta al modo de seleccionar el personal las opiniones también eran muy diversas. Pacheco ${ }^{133}$, en su momento, se preguntó si había de ser más útil seguir el tradicional sistema de presentación de ternas, sustituyendo a la Cámara de Castilla por el Consejo de Estado o el Tribunal Supremo o "continuar nuestra práctica del día, dejándolo plenamente al arbitrio y bajo la responsabilidad ministerial". Tras considerar los pros y los contras de ambas opciones se inclinaba por un sistema híbrido, proponiendo que para los juzgados de primera instancia fuera obligatorio el sistema de las ternas mientras que para los tribunales superiores la posibilidad de solicitar éstas fuese potestativa del gobierno. La atribución de grandes prerrogativas al ejecutivo horrorizaba, sin embargo, a Gómez de la Serna pues "la absoluta discreción del Gobierno que no solo puede no elegir a los mejores, sino frecuentemente hace nombramientos en personas incapaces o indignas del cargo que se les confia". Se sitúa en la orilla contraria y se convierte en un acendrado defensor del sistema de los concursos ${ }^{134}$ para seleccionar a los jueces. Emilio Bravo compartía esa aversión a la discrecionalidad interventora del ejecutivo pero se inclinaba más que por el sistema concursal por la creación de "una escuela especial de aspirantes"135.

autor como G. Setti acentúa la necesidad de no descuidar las posibles influencias externas a las que está sometido el juez, reclamando actuaciones al respecto como así expone en su artículo "Las recomendaciones a los jueces", La Escuela del Derecho, Revista Jurídica, nº I, pp. 83 y ss.: “¿Dónde iríamos a parar si fuera dable una época, en que la administración de justicia fuese inmoral juego de suerte y azar, donde triunfara de la razón la malicia, de la legalidad la astucia, y de la más sana intención el fraude y la codicia?”.

132 E. Bravo, De la administración de justicia, op. cit., pp. 419 y ss.: "E1 administrar justicia, ya lo hemos indicado, no es un destino ni cargo como cualquiera otro de los más o menos interesantes en la causa pública; es un sacerdocio. La casa donde este importantísimo objeto se cumple, no es una oficina, es un templo... Todas las carreras del Estado, desde la más encumbrada hasta la más humilde, requieren ciertamente virtudes y sacrificios... Pero nosotros tenemos todavía obligaciones más altas... Porque debemos prescindir de la amistad más cara, del parentesco más querido, de la afección más tierna y pura... Porque nosotros, inaccesibles a todo sentimiento de vanidad e impureza, debemos serlo también a las seducciones del poder, y aún al terror de la muerte... Aquél que no se sienta bastante imparcial, bastante fuerte de cuerpo y de alma para su ejercicio, que busque otro camino... Pero no basta el ser buenos y dignos; es también indispensable el parecerlo...”.

133 J.F. Pacheco, Estudios de Lejislación (sic) y de Jurisprudencia, Madrid, 1843, p. 220.

134 P. Gómez de la Serna, “Del ingreso y ascensos en la carrera judicial”, RGLJ, n 19, 1861, pp. 342-352 y 388-396: “... no hay, a nuestro modo de entender, otro medio más que el de los concursos. A su anuncio acudiria nuestra brillante juventud no siempre bien juzgada y calumniada frecuentemente, a disputar en campo abierto, en noble lucha y a la luz del dia, la entrada en las funciones judiciales que ganarian mucho en dignidad y prestigio desde que fueran el premio reservado al saber y la señal de un triunfo debido al mérito y la capacidad. Tribunales de concurso compuestos de altas y caracterizadas personas deberían calificar ese mérito; la publicidad de los ejercicios sería una prenda más de la justicia y de la imparcialidad con que se preferiria a los más dignos...". También defiende el mismo sistema en su artículo "Sobre la manera de proveer los cargos judiciales", op. cit.

135 E. Bravo, De la administración de justicia, op. cit., p. 475. 
Ahora bien si éstos eran algunos de los posibles requerimientos que debía demandar la sociedad de quien se dedicaba a administrar justicia la doctrina también defendía que los jueces tenían derecho a reclamar, como contrapartida, otras contraprestaciones irrenunciables como eran, sobre todo, la inamovilidad. Sin duda, la cuestión más reivindicada a lo largo de todo el siglo y que más se hizo esperar"136. Al respecto Pacheco ${ }^{137}$ dirá que "la inamovilidad judicial ha sido y es una máxima del liberalismo... Nada es menos extraño que la uniformidad sobre esa idea..."138. En esta misma senda Miquel y Rubert afirmará que

136 R. Mosquera y Montes, “De la inamovilidad judicial”, RGLJ, n 24, 1864, pp. 30-38:"E1 principio consignado en el Código fundamental de la Monarquía sobre la inamovilidad judicial, es la más bella etapa de nuestros días, consecuencia de las ilustradas aspiraciones de la sociedad en que vivimos; garantía cierta y segura para espurgar (sic) abusos de todo género de los hombres encargados de la alta pero espinosa misión de interpretar las leyes y administrar la justicia en el orden en que existimos".

137 J.F. Pacheco, Estudios de Lejislación (sic) y de Jurisprudencia, op. cit, pp. 222-235: "XII. La inamovilidad judicial... Por nuestra parte, sin aprobar aquel nombre de poder, sin ocultarnos los inconvenientes que esa inamovilidad encierra, y sobre los que por lo común se han cerrado los ojos, todavía somos sus partidarios, como de una institución provechosa en el mayor número de los casos y las circunstancias. Todavía es nuestra doctrina y como tal la proclamamos...”.

138 I. Miquel y Rubert, "De la inamovilidad y responsabilidad de los magistrados y jueces”, op. cit., p. 7: “... La inamovilidad y la responsabilidad judicial han sido temas favoritos de la tribuna y de la prensa. El Gobierno frecuentemente ha dado a entender que pensaba en estos asuntos, harto más graves, harto más trascendentales que tantos otros que llaman preferentemente la atención de los que gobiernan y de los que tratan de las cosas públicas..."; P. Gómez de la Serna, "Modo único de hacer inamovible el poder judicial", RGLJ, no 9, 1857, pp. 369-377: "Achaque común es de los que quieren hacer una magistratura a su gusto, tratar de paliar la irregularidad de su conducta pretestando (sic) el interés público. Para ello tienen que dar tormento a las palabras, y esforzarse para hacerlas significar lo contrario de lo que realmente significan. Llaman hacer un arreglo en la carrera judicial, a destituir, y frecuentemente casi en masa a los jueces y magistrados, a tenerlos a todos en la más cruel incertidumbre respecto de su porvenir, a separar funcionarios dignísimos sin más motivos que el capricho o el deseo de dejar puestos vacantes con el fin de colocar a otros que dan bastante idea de su indignidad para ocuparlos, en el hecho de ser tan poco escrupulosos para admitirlos. Y cada vez que se agitan revoluciones, y cada vez que vienen las reacciones, alternativas por desgracia tan frecuentes en nuestra patria, y siempre que a un ministro le place, se hace nuevo arreglo...". De nuevo volverá a la carga P. Gómez de la Serna en otros artículos como "Sobre la inamovilidad judicial y oportunidad de declararla", RGLJ, n 18 , 1861, pp. 145-153: "Nunca nos cansaremos de alzar nuestra débil voz a favor de la inamovilidad judicial. La hemos alzado siempre que se nos ha presentado ocasión en la prensa, en la cátedra y en la tribuna. No abandonaremos, pues, esta idea en los momentos más oportunos para su triunfo, triunfo que debe ser definitivo y completo" o "Del ingreso y ascensos en la carrera judicial" op. cit., pp. 342-352 y 388-396: “... Lo peor es que por esta dificultad ni aún la jurisdicción ordinaria se reforma, y que semejante estado contribuye principalísimamente a la suerte triste de los jueces y magistrados que, a pesar de la Constitución que declara su inamovilidad, son de hecho amovibles..."; M. Ortiz de Zúñiga, "De la responsabilidad judicial”, op. cit., pp. 99-115: "Paralela con esta disposición debe ser la de hacer efectiva la inamovilidad judicial, no absoluta e indeterminada, sino bien definida, susceptible de aplicación y establecida de modo que conduzca sin graves dificultades a su importante fin..."; A. Gómez Becerra, Observaciones sobre el estado del poder judicial en España, op. cit., p. 10: “¿De qué servirá, que Magistrados de carácter recto y firme, lo desplieguen con toda su energía, para contrarrestar el influjo y las invasiones de otro Poder, si el Gobierno puede separarlos y conferir sus plazas a otros más dóciles, más condescendientes, y aún dispuestos a prostituir su respetable y delicado ministerio?”; E. Bravo, De la administración de justicia, op. cit., p. 222: "No se comprende la Administración de Justicia sin la independencia bastante para su ejercicio, y ésta no puede obtenerse sino por medio de la inamovilidad. Esta es una verdad de sentido común que proclaman en España todas las clases y partidos politicos, y que sostienen todas las naciones; unas habiéndolo establecido como derecho, y otra practicándolo como hecho". 
"magistratura e inamovilidad son dos palabras tan intimamente enlazadas, que no se concibe la una sin la otra en el estado actual de nuestra sociedad..."139. A lo que Montero Ríos sumaba la correspondiente responsabilidad ${ }^{140}$.

A estas cuestiones tan controvertidas, inamovilidad, responsabilidad o selección del personal, el texto de 1870, la Ley Orgánica, les dedicó notable atención ${ }^{141}$. Desde una perspectiva puramente teórica el asunto, a partir del último tercio del siglo XIX, podía pensarse que quedaba solventado. Y se dice teóricamente pues si bien la cuestión de la selección de jueces y magistrados y su responsabilidad dieron lugar a menos quejas no ocurrió así con la inamovilidad que provocó constantes diatribas.

Mientras que la responsabilidad se zanjó, sobre todo, dándole protagonismo al Tribunal Supremo para exigirla disciplinaria y jurídicamente, la elección se solventó adoptando unas medidas con carácter inmediato junto a otras de futuro. Entre las de carácter perentorio estaban las que permitian permanecer dentro de la carrera judicial a quienes ya venian desempeñando estas tareas siempre y cuando superasen una serie de cautelas ${ }^{142}$. Mientras que, como inversión para el porvenir ${ }^{143}$, se establecía un mecanismo de selección mediante el sistema de oposición ${ }^{144}$. Este debería garantizar a medio y largo plazo tanto la adecuada

139 I. Miquel y Rubert, "De la inamovilidad y responsabilidad de los magistrados y jueces", op. cit., p. 8. Igualmente, en la "Esposición (sic) que la Junta de Gobierno del Colegio de Abogados de Madrid, asociada a los ex decanos del mismo, ha elevado al Excmo. Sr. Ministro de Gracia y Justicia solicitando se lleven a pronto y feliz término las reformas iniciadas sobre organización de tribunales y ordenación del enjuiciamiento criminal", op. cit., pp. 64-77 se recordará que: "Origen ha sido también de gravísimos males la amovilidad de los funcionarios del orden judicial, que, sometidos a la saña de los partidos o a los caprichos y al favor de los gobernantes, han visto perdido su prestigio por remociones en masa y destituciones aisladas y frecuentes...”.

140 E. Álvarez Cora, La arquitectura de la justicia burguesa. Una introducción al enjuiciamiento civil en el siglo XIX, op. cit., pp. 56 y ss.

141 Cfr. Título II 'De las condiciones necesarias para ingresar y ascender en la carrera judicial' (arts. 80-146); Título IV 'De la inamovilidad judicial' (arts. 221-244) y V 'De la responsabilidad judicial' (arts. 245-266).

142 Fundamentalmente superar una valoración de su trayectoria profesional. El Consejo de Ministros decidía con plena libertad aunque teniendo presente el informe elaborado por una 'Junta de clasificación' creada ex profeso compuesta por el Presidente del Tribunal Supremo, un Consejero de Estado de la Sección de Gracia y Justicia, el Fiscal del Tribunal Supremo, dos diputados nombrados por el Gobierno, un magistrado del Tribunal Supremo nombrado por su Sala de gobierno, un magistrado de la Audiencia de Madrid nombrado también por su Sala de gobierno, un catedrático de derecho de la Universidad Central nombrado por el gobierno, dos abogados del Colegio de Madrid nombrados por su Junta de gobierno y un oficial del Ministerio de Gracia y Justicia nombrado por el Gobierno, que debía hacer las veces de secretario sin voto.

143 Salvo un cupo reservado al Rey por mor del mandato del artículo 94 de la Constitución de 1869.

144 Para tal fin se había de formar el denominado 'Cuerpo de aspirantes a la Judicatura'. Cfr. Título II, capitulo $1^{\circ}$, arts. 80-108. El sistema de ingreso fue uno de los campos de batalla en los que se habían de medir las fuerzas del ejecutivo y el judicial y, por tanto, objeto de gran controversia. El Informe que el Ilustre Colegio de Abogados de Burgos emitió inmediatamente después de la promulgación de la LOPJ por exigencias legales (citado en nota $\mathrm{n}^{\circ}$ 106, pp. 7-8), considera que la primera reforma que se debe acometer afecta a este cuerpo de aspirantes a la judicatura, pues entienden que “... esta institución, completamente desconocida en nuestro país, no ha de producir más efecto que avivar en la juventud los deseos de formar parte en el ejército inmenso de los empleados públicos, con tanta más razón cuanto que vincula en esa clase la única puerta legal que se deja abierta para ingresar en la judicatura". Pero, en cambio, defienden a capa 
preparación de los aspirantes como la obstrucción a cualquier intento de cooptación por parte del resto de poderes del estado. La resolución de la inamovilidad fue más compleja a pesar de que la normativa no fue parca ${ }^{145}$.

Pedro Gómez de la Serna, justo cuando la Ley Orgánica del Poder Judicial cumple su primer año de vida, en su condición de presidente del Tribunal Supremo, pronunciará el correspondiente discurso con motivo del acto formal de apertura del nuevo año judicial ${ }^{146}$. Y comienza su disertación con una doble felicitación: por un lado, porque por primera vez un evento de estas características se desarrollara bajo el amparo de una marco normativo claro, homogéneo y completo $\mathrm{y}$, por otro, porque con la ley recién estrenada se conseguía limitar la actuación del poder ejecutivo ${ }^{147}$.

No obstante, a pesar de la alegria que le invade y la congratulación por el notable progreso ${ }^{148}$ que, en general, se puede afirmar que se ha ido experimentando a lo largo del siglo ${ }^{149}$, en seguida exterioriza que, en realidad, es

y espada por ser "más económico, y sobre todo de resultados más conocidos" el sistema de oposiciones. Que debe ser completado por unas "propuestas en terna, igual o parecido al que se ha observado, por espacio de muchos años en la provisión de las Relatorias...”. Mediante esta vía, desde su punto de vista, se garantizan los conocimientos teóricos que deben ser completados con otros de carácter prácticos adquiridos mediante una "asistencia continua a las sesiones públicas de una Audiencia, hecha constar por certificación de su Presidente...".

145 Para garantizar ésta se desglosan los apartados de las destituciones (capítulo II del Título IV), las suspensiones (capitulo III del Título IV), los traslados (capítulo IV del Título IV) y las jubilaciones (capítulo V del Título IV), cuyos supuestos se van desarrollando de manera pormenorizada.

146 "Estado lamentable de la administración de justicia en lo criminal y reformas que imperiosamente reclama. Discurso leido por el Exmo. e Ilmo. Señor Don Pedro Gómez de la Serna, Presidente del Tribunal Supremo, en la solemne apertura de los Tribunales, celebrada en 15 de Setiembre de 1871", RGLJ, n 39, 1871, pp. 314-337.

147 "Estado lamentable de la administración de justicia en lo criminal y reformas que imperiosamente reclama. Discurso leido por el Exmo. e Ilmo. Señor Don Pedro Gómez de la Serna, Presidente del Tribunal Supremo, en la solemne apertura de los Tribunales, celebrada en 15 de Setiembre de 1871", op. cit., p. 314: "La inauguración solemne del año judicial se celebra por primera vez en virtud de una ley. Hasta ahora a falta de disposiciones legislativas referentes a este acto, se consideraba autorizado el Gobierno para suplir su silencio, usando de las atribuciones que por regla general le correspondian... La ley orgánica del Poder judicial... ha limitado en éste, como en otros puntos importantes, las atribuciones del Poder ejecutivo, el cual en adelante no podrá por sí modificar la regla hoy establecida siendo necesaria una nueva ley para cualquier reforma que quiera introducir...".

148 "Estado lamentable de la administración de justicia en lo criminal y reformas que imperiosamente reclama. Discurso leido por el Exmo. e Ilmo. Señor Don Pedro Gómez de la Serna, Presidente del Tribunal Supremo, en la solemne apertura de los Tribunales, celebrada en 15 de Setiembre de 1871”, op. cit., p. 318: “... Podrá, sin duda, ser problemática la conveniencia de algunas alteraciones introducidas en nuestro derecho moderno, pero no creo que haya quien pueda desconocer que el espíritu que lo domina ha sido constantemente progresivo...”.

149 "Estado lamentable de la administración de justicia en lo criminal y reformas que imperiosamente reclama. Discurso leido por el Exmo. e Ilmo. Señor Don Pedro Gómez de la Serna, Presidente del Tribunal Supremo, en la solemne apertura de los Tribunales, celebrada en 15 de Setiembre de 1871", op. cit., p. 318: "Creo, señores, que participareis de mi opinión: fijad si no la vista en lo que era nuestra administración de justicia al comenzar el Gobierno representativo, y lo que es hoy; y puesta la mano sobre el corazón, decid si no han sido en general dignas de aplauso las reformas que en la organización judicial y en los procedimientos, tanto civiles como criminales, se han hecho en los treinta y seis años que han transcurrido desde la publicación del 
un regocijo fugaz pues son innumerables las quejas que todavía se pueden elevar por el "estado lamentable en que se encuentra la administración de justicia". Curiosamente su lamento no se centra en las posibles interferencias del gobierno en la labor del judicial, como hasta ahora venía siendo tradicional ${ }^{150}$, y sí, en cambio, en la falta de actuación del ejecutivo y del legislativo en el ámbito criminal, que lo considera abandonado y falto de actualización, así como por no promover de manera perentoria una legislación en el ámbito procedimental, tanto criminal como civil, así como un código sobre esta última parcela, reglamentación que entiende inaplazable ${ }^{151}$.

Montero Ríos, a la altura de 1872 y de nuevo en Gracia y Justicia tras un anterior paso efimero por el Ministerio, en el correspondiente discurso de apertura de los tribunales, en cambio insiste en la reivindicación de que la judicatura es un "poder en la Constitución del Estado" y una "gran fuerza en la vida social". El primero en la medida que garantiza todos los derechos y la segunda en cuanto da eficacia a todos los deberes ${ }^{152}$.

Partiendo de este posicionamiento entiende que la manera en que la justicia es elevada a la categoría de poder es "por medio de la organización vigorosa de las instituciones que hayan de administrarla, y por las prerrogativas y garantias otorgadas para el digno desempeño de sus funciones, a los Magistrados que las representan". De ahí que el grueso de su hilo discursivo lo centre en la enérgica defensa que de la inamovilidad de los jueces proclama la nueva ley a la vez que subraya la importancia de las nuevas disposiciones que se han debido promulgar para completarla pues la nueva ley ha resultado insuficiente ${ }^{153}$.

reglamento provisional para la administración de justicia, por más que a algunos les parecieran precipitadas, y poco dispuesto el país para recibirlas"

150 M. Torres Campos, Cómo se administra justicia, op. cit., pp. 7-8, en la que se queja de que a pesar del nuevo marco normativo persiste el predominio "del Poder administrativo sobre el judicial". La razón fundamental que, desde su punto de vista, avala tan categórica afirmación se resume sucintamente en que "... a él corresponde el nombramiento, la traslación y la separación de los funcionarios judiciales". En ese sentido "claro está que puede haber uno y muchos ministros que se conduzcan dignamente; pero puede haber también otros, que traten por estos medios de influir en la resolución de determinados asuntos, y hasta que vendan los cargos. El Ministerio de Gracia y Justicia, -es-... en realidad -el que- está al frente del poder judicial, puesto que su organización de él depende...”

151 "Estado lamentable de la administración de justicia en lo criminal y reformas que imperiosamente reclama. Discurso leído por el Exmo. e Ilmo. Señor Don Pedro Gómez de la Serna, Presidente del Tribunal Supremo, en la solemne apertura de los Tribunales, celebrada en 15 de Setiembre de 1871”, op. cit., p. 316: “... Por espacio de más de un tercio de siglo se han creado multitud de Comisiones, ya para la formación de Códigos determinados, ya para la de todos ellos. En estas Comisiones han turnado los Jurisconsultos más notables del país, que con desinterés, con celo, con noble abnegación han trabajado afanosamente para contribuir a la gran obra de la Codificación española ¿Qué se ha hecho de estos trabajos? Depositarlos en los archivos, sin que apenas haya quien sepa la existencia de alguno ni quien los haya examinado...".

152 E. Montero Ríos, Discurso leído por el Excmo. Sr. D..., Ministro de Gracia y Justicia en la solemne apertura de los tribunales celebrada en 15 de setiembre de 1872, Madrid, Imprenta del Ministerio de Gracia y Justicia, 1872, p. 7: "Como poder, corre a vuestro cargo la integridad de la Constitución y de las leyes. Como fuerza social, respondéis ante la conciencia pública del estado moral de la Nación".

153 E. Montero Ríos, Discurso leído por el Excmo. Sr. D..., Ministro de Gracia y Justicia en la solemne apertura de los tribunales celebrada en 15 de setiembre de 1872, op. cit., p. 8: "Así se explica por qué la inamovilidad judicial necesitó el vivificante calor de la libertad política para 
Una normativa que, a los cinco años de la entrada en vigor de la Ley Orgánica y a juicio de Cirilo Álvarez, presidente del Tribunal Supremo, todavía resulta pacata pues no deja pasar la ocasión que le brinda el tradicional acto de apertura de los tribunales para reclamar la "verdadera inamovilidad de los Magistrados y Jueces establecida sobre bases inquebrantables"154.

El año 1876 trae aires politicos completamente diferentes. Aparece un texto constitucional con el que formalmente se pone fin a un proceso revolucionario que durante varios años ha intentado soluciones diversas: desde la monárquica con renovación dinástica incluida hasta la republicana con distintos perfiles. Superadas las discrepantes tentativas y con la jefatura del estado encarnada en Alfonso XII el giro conservador es manifiesto. Al apostarse por una linea continuista en sintonía con la desarrollada durante el reinado de Isabel II se intentarán podar aquellas innovaciones demasiado temerarias a los ojos de los nuevos rectores políticos. Y el orden judicial está en el punto de mira. El nuevo depositario de la cartera ministerial de justicia, Cristóbal Martín de Herrera, sostiene que para que ésta se considere que ha alcanzado un lugar significado entre las instituciones del estado debe haber, como mínimo, una buena organización de los tribunales y una óptima legislación en los ámbitos civil y procesal civil y penal. Y denuncia que "en España hoy estos cuatro importantes órdenes de leyes se encuentran en lamentable estado"155. Admitida la urgencia en poner fin a esta situación, especialmente por lo que se refiere a la ausencia de un cuerpo de leyes tipo codificador en dichas materias ${ }^{156}$, centra sus criticas en la Ley Orgánica.

germinar y florecer entre los pueblos modernos. Aragón fue quizá el primero de Europa que reclamó ya en 1442 la estabilidad de sus Jueces; Inglaterra, aleccionada por una dolorosa experiencia, se apresuró en 1688 a proclamar la inamovilidad de los suyos; también fue consignada en todas las Constituciones que España se dio desde 1812 hasta 1869, pero bien sabéis, cuan escaso respeto obtuvo hasta la promulgación en 15 de Setiembre de 1870 de la Ley orgánica del poder que dignamente estamos desempeñando. Desde entonces, aun cuando el acatamiento a esta ley hiciese imposible la continuación de todos los azares por que la Magistratura española había pasado en anteriores épocas, fue necesario, sin embargo, publicar en 27 de junio último nuevas disposiciones, que diesen mayor seguridad y firmeza al principio de la inamovilidad...".

154 Discurso leído por el Excmo. Sr. D. Cirilo Álvarez presidente del Tribunal Supremo en la solemne apertura de los tribunales celebrada en 15 de setiembre de 1875, Madrid, Imprenta del Ministerio de Gracia y Justicia, 1875, p. 4.

155 C. Martín de Herrera, "Estado de la legislación en España y sus reformas más urgentes. Discurso leído por el Exmo. Sr...., Ministro de Gracia y Justicia en la apertura de los Tribunales, solemnizada con la presencia de S.M. el Rey D. Alfonso XII, el día 15 de Setiembre de 1876", RGLJ, $\mathrm{n}^{\circ} 49,1876$, p. 146.

156 C. Martín de Herrera, "Estado de la legislación en España y sus reformas más urgentes. Discurso leído por el Exmo. Sr...., Ministro de Gracia y Justicia en la apertura de los Tribunales, solemnizada con la presencia de S.M. el Rey D. Alfonso XII, el dia 15 de Setiembre de 1876", op. cit., p. 147: "La educación moral y religiosa del pueblo, la propagación de las luces en todas las esferas y grados de la ciencia, el estímulo del trabajo nacional, el fomento de todas las fuentes de riqueza, la reorganización política y administrativa del país, el arreglo de la Hacienda, medios precarios son para llegar al fin apetecido; pero insuficientes si no van acompañados de las reformas definitivas de la organización judicial, de los procedimientos civiles y criminales y del Código penal, y si no se emprende con tesón a la vez que con prudencia, la unificación del derecho civil en toda la Monarquía, tanto tiempo ha intentada, tan adelantada en su preparación y por tan largos años abandonada después...". 
Elogia su oportunidad y su finalidad ${ }^{157}$ pero la considera un fracaso sin paliativos. Denuncia su inaplicación y censura la falta de medios que la han condenado a que sea irrealizable en numerosos aspectos:

“... por no haber tenido en cuenta la escasez de recursos del Tesoro, que visiblemente imposibilitaba tan costosa organización de Tribunales, nació muerta en esta parte y muerta sigue al cabo de seis años; espectáculo poco edificante, porque perjudica al prestigio del derecho e introduce confusión"158.

Pero su desaprobación va más allá y no finaliza con esta invectiva. En realidad este argumento es sólo una cortina de humo que envuelve otra serie de reproches con los que apunta directamente a las cotas de independencia que con la ley vigente puede conseguir el orden judicial. El desplazamiento ideológico que revela el estrenado gobierno alfonsino en la persona de su ministro de justicia es tan ostensible que públicamente defiende la necesidad de primar la responsabilidad, las correcciones disciplinarias de jueces y magistrados, sobre su inamovilidad:

“... la oposición por sí sola, no descubre la existencia de todas las condiciones que exige el dificil cargo del Juez; que los turnos rigurosos en los ascensos no permiten estimar debidamente interesantes motivos de preferencia; que la inamovilidad pugna con el carácter propio del Ministerio fiscal; que la responsabilidad no puede compensar suficientemente la inamovilidad, si no está muy asegurada y no va acompañada de un sistema rígido y eficaz de correcciones disciplinarias; y que el sometimiento de los negocios contenciosos de la administración a la jurisdicción de los Tribunales, al paso que distrae la atención de estos a materias poco propias de su competencia, perjudica a la independencia mutua de las diferentes funciones del Poder público, en cuya división y armonía descansa muy principalmente el Gobierno representativo".

$\mathrm{Y}$, sin serle suficientes estas consideraciones, dedicará el resto de su extenso discurso a reivindicar, sin cortapisas, la supremacía del ejecutivo sobre el judicial ${ }^{159}$.

157 C. Martín de Herrera, "Estado de la legislación en España y sus reformas más urgentes. Discurso leído por el Exmo. Sr...., Ministro de Gracia y Justicia en la apertura de los Tribunales, solemnizada con la presencia de S.M. el Rey D. Alfonso XII, el dia 15 de Setiembre de 1876”, op. cit., p. 147: "A buenos principios generalmente admitidos por la ciencia y seguidos en las naciones más cultas obedeció la formación de la (en más o menos) vigente Ley orgánica del poder judicial, que trató de realizar aspiraciones en vano hasta entonces consignadas en todas nuestras constituciones politicas...”.

${ }^{158}$ C. Martín de Herrera, "Estado de la legislación en España y sus reformas más urgentes. Discurso leido por el Exmo. Sr...., Ministro de Gracia y Justicia en la apertura de los Tribunales, solemnizada con la presencia de S.M. el Rey D. Alfonso XII, el dia 15 de Setiembre de 1876”, op. cit., p. 148.

159 C. Martín de Herrera, "Estado de la legislación en España y sus reformas más urgentes. Discurso leído por el Exmo. Sr...., Ministro de Gracia y Justicia en la apertura de los Tribunales, solemnizada con la presencia de S.M. el Rey D. Alfonso XII, el dia 15 de Setiembre de 1876", op. cit., pp. 148-149: "Reducir la reforma en cuanto a la planta y organización de los Tribunales a lo absolutamente preciso para establecer el juicio oral y única instancia ante el Tribunal colegiado 
Visión radicalmente diferente es la de Vicente Romero Girón, Ministro de Gracia y Justicia en $1883^{160}$. La situación politica va evolucionando y tiene su reflejo en la consideración del orden judicial. Para él la inamovilidad es vital: “... puede afirmarse que por doquiera se enaltece la inamovilidad judicial como garantía positiva de independencia, lo mismo para los justiciables que para el poder". Pero considera que no es suficiente para garantizarla con que se establezca por ley que los miembros de la judicatura sólo pueden perder su destino en virtud de expediente o sentencia siempre que medie causa pública y justificada ${ }^{161}$. No. Para él hay otros riesgos que inciden directamente en el desempeño de la labor judicial. Especialmente la posibilidad que tiene el ejecutivo de conceder premios en forma de ascensos:

“... desde el punto en que el Gobierno, a quien se otorga el derecho de nombrar y sobre todo la facultad de ascender, dispone de muy espacioso margen en las categorias, grados y turnos, para convertirse en dispensador casi arbitrario de mercedes y distinciones, poco conformes, a mi ver, con la idea de justicia y la dignidad de sus sacerdotes. Y si a esto agregamos el espíritu de partido, la ingerencia (sic) malsana y creciente de la politica en la justicia, padecimiento crónico del cual ninguno hemos logrado escapar, y el peligro, por desgracia demasiado probable, de que el mismo Cuerpo judicial, presa de inevitable flaqueza porque con hombres se constituye, se sienta aguijoneado ante la perspectiva del ascenso de modo fácil y expedito y llegue a olvidar alguna vez su austeridad en que debe cifrar su gloria, para hacerse instrumento de intereses y tendencias poco conciliables con la misión augusta del juzgador, convengamos honradamente en que la tan ponderada inamovilidad judicial se resiente de profundos decaimientos y acusa vicios radicales que la desvirtúan y menoscaban...".

en los asuntos criminales, separando en lo posible estas materias de las civiles para la más rápida represión de los delitos, tan necesaria en este país perturbado por antiguas y recientes desgracias; mantener, sí, como principio general el ingreso en la carrera judicial por oposición, mas regulando este procedimiento de manera que vaya acompañado de un período de prueba en funciones análogas a las estrictamente judiciales para que se demuestre, no sólo la ciencia, sino también el juicio, el carácter, la probidad y todas las demás dificiles cualidades que en el Juez deben concurrir; establecer, respecto a los ascensos, la marcha lenta y ordenada de los funcionarios por los diversos grados de la escala; admitir en algunos de estos la concurrencia de notorias y distinguidas capacidades de fuera, y dar un lugar muy amplio a la colocación de los cesantes; pero sin reducir la adjudicación de los ascensos a una especie de operación algebraica, en cuyo resultado, que muchas veces sorprende al mismo favorecido, tiene escasa parte la apreciación del Ministro encargado de velar por la recta administración de justicia; colocar la inamovilidad en un terreno propio, racional, en que no choque con las más evidentes exigencias de la realidad, amparando este alto principio con un buen sistema de responsabilidad penal y disciplinaria; y devolver definitivamente al alto Cuerpo consultivo de la Administración del Estado la jurisdicción retenida, la aplicación de las leyes y disposiciones administrativas, dejando sólo a los Tribunales la de las civiles y penales, que es su verdadero instituto; tales son, Señor, las modificaciones que el Gobierno de V.M. procurará ir introduciendo, a medida que las circunstancias lo consientan...".

160 “Discurso leido por el Excmo. Sr. D. Vicente Romero y Girón, Ministro de Gracia y Justicia, en la solemne apertura de los Tribunales, celebrada en 15 de Setiembre de 1883", RGLJ n 63, 1883, pp. 193-245.

161 “... la inamovilidad asi establecida y practicada es puro artificio...”. 
Un año después el fiscal del Tribunal Supremo, Ruiz y Capdepón ${ }^{162}$, insiste en la importancia de la inamovilidad:

\begin{abstract}
"Ha llegado ya la hora de que la Magistratura española tenga la inamovilidad que exige de consuno la ciencia y los más altos intereses jurídicos y sociales. Confiesa el infrascripto, con satisfacción, que aún aquellos partidos, que no aceptan entre sus dogmas políticos ese importante principio, en la práctica, con sus hechos, han prestado cierto culto al mismo, y que las corrientes de opinión que a todos empujan, imponen a los gobiernos el respeto debido a la inamovilidad judicial".
\end{abstract}

Como se puede comprobar la inamovilidad fue un asunto candente que mantuvo en vilo a jueces y magistrados durante toda la centuria, especialmente en su último tercio ${ }^{163}$, y que, sin embargo, no logró solucionarse de manera eficaz, como defiende Aparicio ${ }^{164}$, hasta que los cuerpos de funcionarios de la administración acabasen de formarse, siendo fruto no tanto de una normativa específica como del proceso de estabilización funcionarial en su conjunto, cuestión dilatada en el tiempo ${ }^{165}$.

\title{
4.3.2. La institución del jurado ${ }^{166}$
}

Coincide la doctrina ${ }^{167}$ en señalar que en España los orígenes del jurado hay que buscarlos en el Estatuto de Bayona de 1808168. Se trata de una

162 "Exposición que dirige al Gobierno de S.M. el fiscal del Tribunal Supremo en doce de setiembre de 1883”, RGLJ n ${ }^{\circ}$ 64, 1884, p. 93.

163 De hecho la ley fue completada en este apartado por varias disposiciones. Vid. al respecto M. Lorente Sariñena; F. Martínez Pérez; M.J. Solla Sastre, Historia legal de la justicia en España (1810-1978), op. cit., pp. 425 y ss.

164 M.A. Aparicio, El status del poder judicial en el constitucionalismo español (1808-1936), op. cit., p. 157.

165 Vid. al respecto la voz 'Funcionario público' en Enciclopedia Jurídica Española, s.f., pp. 864988 y la voz 'Empleado público' en M. Martínez Alcubilla, Diccionario de la Administración española, Madrid, 1917, pp. 595-667.

166 Sobre el concepto y sus fundamentos vid. J.A. Alejandre García, La justicia popular en España. Análisis de una experiencia histórica: los Tribunales de Jurados, Madrid, 1981, especialmente, pp. 17-75.

167 Vid., entre otros, R. Gibert, "El juicio por jurados en España”, Revista de la Facultad de Derecho de la Universidad Complutense de Madrid, XV, n ${ }^{\circ}$ 42, 1971, pp. 559-572; del mismo autor, "El juicio por jurado", Rvdimentos Legales. Revista de Historia del Derecho, n 2, $2000, \mathrm{pp}$. 13-61; J.A. Alejandre García, "Los Tribunales populares en España", Historia 16, n⿳ 101 , sept. 1984, pp. 7-14; del mismo autor, "Introducción histórica al Jurado español" en AAVV, Jornadas conmemorativas del Centenario de la Ley del Jurado, Madrid 1988, pp. 3-18; del mismo autor, "La ley del Jurado de 1888, cien años después”, Historia 16, n 146, 1988, pp. 12-16; del mismo autor, "La experiencia histórica sobre las competencias atribuibles a los tribunales de jurados", Anuario Jurídico y Económico Escurialense, $\mathrm{n}^{\circ}$ 21, 1989, pp. 181-194; del mismo autor, "El restablecimiento de un sistema histórico de Administración de Justicia: el juicio por jurados”, en La aplicación del Derecho a lo largo de la Historia. I Jornadas de Historia del Derecho. Universidad de Jaén, Jaén, 1996, pp. 13-29; R. Gómez Rivero, El Tribunal del Jurado en Albacete (1888-1936), Albacete, 1999; F. Martinez Pérez, Entre confianza y responsabilidad. La justicia del primer 
institución básica para permitir la participación popular en la administración de justicia. Y la Constitución de 1812, que estaba por la labor, lo faculta por medio del art. 307:

"Si con el tiempo creyeren las Cortes que conviene haya distinción entre los jueces del hecho y del derecho, la establecerán en la forma que juzguen conducente"169.

Cien años después de que esta disposición viera la luz el jurado estaba vigente. Una herencia gaditana indiscutible. Pero que estuviera en uso no significa que durante un siglo hubiera tenido una existencia pacífica e ininterrumpida. La frustración casi inmediata de la puesta en práctica de los preceptos constitucionales por el regreso de Fernando VII a España y a su política absolutista obliga a aguardar al Trienio Liberal, concretamente a la Ley de imprenta de 22 de octubre de $1820^{170}$, para que tenga lugar el pistoletazo de salida en su aciago recorrido. Con esta disposición por primera vez se pone a prueba en la práctica ${ }^{171}$. Un corto recorrido porque de nuevo el proceder regresivo del monarca abortará su trayectoria ${ }^{172}$.

Habrá de esperarse a un nuevo escenario político para que el jurado pudiera retomar su senda. El 17 de octubre de 1836, superados los sucesos de La Granja y restablecida la Constitución de 1812, se recupera la legislación de imprenta promulgada durante la etapa del Trienio Liberal. En palabras de Pérez Juan ${ }^{173}$ : "From that moment, the Jury regained its validity in Spain in accordance with the model and legal framework established during the first Spanish Constitutionalism".

La Constitución de 1837 decidió seguir esa línea. Su artículo 2 remitía expresamente y en exclusiva a los jurados "la calificación de los delitos de

constitucionalismo español (1810-1823), op. cit., pp. 508-534; VVAA, Juicio por Jurados: experiencia y revisión, Madrid, 2007; J.A. Pérez Juan, "Legal Framework for the Jury in the first Spanish Constitutionalim" en I. Czeguhn; A. Sánchez Aranda (Hg,), Vom Diener des Fürsten zum Diener des Rechts, Regensburg, 2011, pp. 119-133; del mismo autor, "Marco legal del jurado en el primer constitucionalismo español" en Historia Iuris. Estudios dedicados al profesor Santos M. Coronas González, II, Oviedo, 2014, pp. 1169-1188.

168 Art. 106: "El proceso criminal será público. En las primeras Cortes se tratará de si se establecerá o no el proceso por jurados". Vid. I. Fernández Sarasola, La Constitución de Bayona (1808), Madrid, 2007.

169 Sobre el papel de la institución en el marco constitucional vid. B. Clavero Salvador, "Códigos y jueces (las puertas y los porteros de la ley)" en AAVV, Jornadas sobre el poder judicial en el Bicentenario de la Revolución Francesa, op. cit., pp. 69-89.

170 Título VI, arts. 36 a 68.

${ }^{171}$ Esta disposición fue modificada poco después por la Ley adicional de 12 de febrero de 1822 y por la de 22 de julio de 1823, aunque esta última sin efectos prácticos. Vid., al respecto, J.A. Pérez Juan, "Marco legal del jurado en el primer constitucionalismo español", op. cit., pp. 1182 y ss.

172 J.A. Alejandre, La justicia popular en España. Análisis de una experiencia histórica: los Tribunales de Jurados, op. cit., p. 92: "La experiencia jurídica fue demasiado breve como para emitir, en consideración a ella, un juicio certero sobre la eficacia de la institución".

173 J. A. Pérez Juan, “The jury in Spain 1833-1843”, en prensa, cortesía del autor. 
imprenta". Subraya Alejandre ${ }^{174}$ que la razón de que se circunscribiera únicamente a estos delitos y no a todos se debía a un cierto recelo, a que no se consideraba "aún llegado el momento de reconocer la madurez social necesaria para su establecimiento" ${ }^{175}$. De ahí que se recuperase la ley de imprenta del trienio que, sin embargo, tuvo una vigencia exigua, pues el acceso de los moderados al poder anunciaba cambios radicales. Primero con el Decreto de 10 de abril de 1844 que afectaba especialmente a la composición del jurado, convirtiéndolo en una institución "más selecta o clasista"176 y, posteriormente, con la Constitución de 1845, pues, al no mencionarlo expresamente, propició el Decreto de 6 de julio de 1845 que lo suprimía directamente.

A partir de ese momento, sufre continuos vaivenes, una vorágine de recuperación-supresión ${ }^{177}$, ligados siempre a la esfera de los delitos de imprenta hasta la revolución septembrina que cambiará la línea argumental en un doble sentido: por un lado, tratando de asentar la exigencia de su implantación y, por otro, su carácter lato ${ }^{178}$. Respecto a la primera cuestión fracasa momentáneamente pues aunque recobrada por la legislación revolucionaria nuevamente, a comienzos de 1875 se suprime. No obstante, al poco tiempo, es rescatada otra vez, en concreto en 1888, por medio de una Ley de 20 de abril.

174 J.A. Alejandre, La justicia popular en España. Análisis de una experiencia histórica: los Tribunales de Jurados, op. cit., p. 103.

175 De hecho en el artículo $1^{\circ}$ adicional del texto constitucional se establece que: "Las leyes determinarán la época y el modo, en que se ha de establecer el juicio por jurados para toda clase de delitos".

176 J.A. Alejandre, La justicia popular en España. Análisis de una experiencia histórica: los Tribunales de Jurados, op. cit., pp. 104-105.

177 J.A. Alejandre, La justicia popular en España. Análisis de una experiencia histórica: los Tribunales de Jurados, op. cit., pp. 106-109: “... Ocho años después, un nuevo decreto restauraría el Jurado para los delitos de imprenta, con ciertos límites restrictivos en su composición y en su competencia. El entonces presidente del Consejo de Ministros, Juan Bravo Murillo, presentó a la Reina el proyecto de decreto, que sería sancionado el día 2 de abril de 1852, por el que se creaba el Jurado integrado por siete jueces de hecho sacados de una lista de los mayores contribuyentes, que en cada capital de provincia formaria el gobernador civil. La inestabilidad de la institución y su dependencia de la situación política son paradigmáticas en estos años centrales del siglo. Vive un año, desaparece al siguiente, renace al iniciarse el bienio y una ley de 21 de diciembre de 1855 confirma su competencia respecto de los delitos de imprenta. En 1856, el Acta adicional a la Constitución de 1845 subsanaría el olvido en que ésta tuvo al Jurado, declarando en su artículo $1^{\circ}$ que 'la calificación de los delitos de imprenta corresponde a los Jurados, salvas las excepciones que determinen las leyes', reconocimiento tardío de lo que ya de hecho existía, pero que ahora tendría un valor efimero, puesto que aquel mismo año un Real decreto dejó sin efecto dicha Acta y ordenó que sólo rigiera y se observase la ley constitucional de la Monarquía de $1845 \ldots$ La serie de derogaciones, restablecimientos y reformas en la regulación de la ley de imprenta había creado una notable inseguridad sobre qué jurisdicción debía entender y en qué casos sobre los delitos de imprenta.... La esperada ley de imprenta, fundamento del Jurado, estaría en vigor desde 1864 a $1867 "$.

178 Así, el art. 93 de la Constitución de 1869 indica que: "Se establecerá el juicio por jurados para todos los delitos políticos, y para los comunes que determine la Ley. La Ley determinará también las condiciones necesarias para desempeñar el cargo de jurado". Disposición que se concretará con la Ley Orgánica del Poder Judicial de 1870 (especialmente art. 276) y, sobre todo, con la Ley de Enjuiciamiento Criminal de 1872 (arts. 658 a 786). Vid. al respecto J.A. Alejandre, La justicia popular en España. Análisis de una experiencia histórica: los Tribunales de Jurados, op. cit., pp. 111 y ss. 
Comienza el nuevo siglo, el del centenario de la Constitución de 1812 y su vigencia resulta indiscutida.

En cuanto al segundo punto, la extensión de su competencia, hay que subrayar que ahora se ensancha sobremanera. Ya no queda restringida a los delitos de imprenta. Los jurados conocerán de las causas en las que se juzguen delitos de ${ }^{179}$ :

- traición;

- contra las Cortes y sus individuos y contra el Consejo de Ministros;

- contra las formas de gobierno;

- de los particulares con ocasión del ejercicio de los derechos individuales garantizados por la Constitución;

- de los funcionarios públicos contra el ejercicio de los derechos individuales garantizados por la Constitución;

- relativos al ejercicio de cultos;

- rebelión;

- sedición;

- falsificación de la firma o estampilla Real, firmas de los Ministros, sellos y marcas;

- falsificación de moneda;

-falsificación de billetes de banco, documentos de crédito, papel sellado, sellos de Telégrafos y Correos y demás efectos timbrados, cuya expedición estuviera reservada al Estado;

- falsificación de documentos públicos, oficiales y de comercio y de los despachos telegráficos;

- falsificación de documentos privados;

- abusos contra la honestidad, cometidos por funcionarios públicos;

- cohecho;

- malversación de caudales públicos;

- parricidio;

- asesinato;

- homicidio;

- infanticidio;

- aborto;

- lesiones producidas por castración o mutilación o cuando de sus resultas quedare el ofendido imbécil, impotente o ciego;

- duelo;

- violación; 
- abusos deshonestos;

- corrupción de menores;

- rapto;

- detenciones ilegales;

- sustracción de menores;

- robos;

- incendios;

- imprudencia punible, cuando si hubiere mediado malicia el hecho constituiria alguno de los delitos anteriores

- los cometidos por medio de imprenta, grabado u otro medio mecánico de publicación, exceptuando los delitos de lesa majestad y los de injurias y calumnias.

\subsubsection{La conciliación y el arbitraje.}

La Constitución de 1812 apostaba por instituciones donde la participación popular era decisiva para el desenlace del proceso. Así, el arbitraje ${ }^{180}$, que permitía el recurso a mediadores elegidos de entre el propio vecindario ${ }^{181} \mathrm{e}$, incluso, aunque de forma más indirecta, la conciliación ${ }^{182}$, que era una ruta obligatoria antes de acudir a los tribunales donde los alcaldes, elegidos por medio de votación pública, tenían un papel destacado ${ }^{183}$.

El arbitraje tenía honda raigambre en la práctica jurídica peninsular. Como señala Merchán ya desde el derecho visigodo del Liber "se inicia una tradición judicialista del arbitraje como regla general" 184 . Uso que tiene continuidad con los textos alfonsinos y que llegará hasta la etapa codificadora donde se regulará detalladamente en textos normativos como la Ley de enjuiciamiento sobre los

180 Art. 280: "No se podrá privar a ningún español del derecho de terminar sus diferencias por medio de jueces árbitros, elegidos por ambas partes". Art. 281: "La sentencia que dieren los árbitros, se ejecutará, si las partes al hacer el compromiso no se hubieren reservado el derecho de apelar".

181 Vid al respecto A. Merchán Álvarez, El arbitraje. Estudio histórico-jurídico, Sevilla, 1981, especialmente pp. 38-41.

182 Art. 282: "El alcalde de cada pueblo ejercerá en él el oficio de conciliador; y el que tenga que demandar por negocios civiles o por injurias, deberá presentarse a él con este objeto". Art. 283: "El alcalde con dos hombres buenos, nombrados uno por cada parte, oirá al demandante y al demandado, se enterará de las razones en que respectivamente apoyen su intención; y tomará, oído el dictamen de los dos asociados, la providencia que le parezca propia para el fin de terminar el litigio sin más progresos, como se terminará en efecto, si las partes se aquietan con esta decisión extrajudicial". Art. 284: "Sin hacer constar que se ha intentado el medio de la conciliación, no se entablará pleito ninguno".

183 Vid al respecto J. Montero Aroca, "Bosquejo histórico de la conciliación hasta la Ley de enjuiciamiento civil de 1855", Revista de Derecho Procesal Iberoamericana, $\mathrm{n}^{\circ}$ 4, 1971, pp. 857907. En p. 860 la define como "solución amigable de los litigios tendente a evitar o terminar el proceso".

184 A. Merchán Álvarez, El arbitraje. Estudio histórico-juridico, op. cit., p. 39. 
negocios y causas de comercio de 24 de julio de $1830^{185}$ o la Ley de Enjuiciamiento civil de 5 de octubre de $1855^{186}$

En cuanto a la conciliación tampoco nace con la Constitución de 1812 pues su origen está directamente relacionado con el proceso mercantil medieval; concretamente "en las ordenanzas que desarrollaban el proceso ante los consulados"187. Pero en cambio, con el texto constitucional se generaliza y se establece "por primera vez en nuestro Derecho como actividad previa de carácter obligatorio para todo tipo de procesos, tanto civiles como mercantiles"188. Las disposiciones constitucionales fueron objeto de desarrollado normativo por el ya citado Reglamento de las Audiencias y Juzgados de primera instancia de $1812^{189}$. Pero por poco tiempo. La recuperación de las riendas de gobierno por Fernando VII en su versión absolutista trajo consigo la derogación de la obra gaditana y esta disposición no iba a ser ajena a sus drásticas medidas. Esporádicamente se tratan de rescatar las directrices constitucionales durante el trienio (Ley de 18 de mayo de 1821) pero otra vez de forma breve pues a comienzos del mes de octubre de 1823 el recuperado marco normativo liberal queda derogado. Así pues, la conciliación queda circunscrita al ámbito mercantil, limitación confirmada con la aprobación del Código de Comercio de 1829190 y su correlativa norma procedimental, la Ley de enjuiciamiento sobre los negocios y causas de comercio de 24 de julio de $1830^{191}$.

Para que la intervención de la autoridad municipal se recupere en la esfera civil se habrá de esperar al Reglamento para la administración de justicia en lo respectivo a la jurisdicción ordinaria de $1835^{192}$. Como señala Montero con esta disposición "y a pesar de la terminología empleada, se instaura, ahora ya definitivamente, el juicio de conciliación, recogiendo la legislación liberal derogada"193.

Pero esta norma daba un paso más. Que los alcaldes constitucionales estuvieran contemplados en el texto constitucional del 12 como cualificados

185 Especialmente en su Título VI: 'Del juicio arbitral'. El Código de Comercio de 1829 remitirá expresamente a ésta.

186 Especialmente en su Título XV: 'Del juicio arbitral' y XVI: 'Del juicio de amigables componedores'.

187 J. Montero Aroca, "Bosquejo histórico de la conciliación hasta la Ley de enjuiciamiento civil de 1855”, op. cit., p. 863.

188 J. Montero Aroca, "Bosquejo histórico de la conciliación hasta la Ley de enjuiciamiento civil de 1855” op. cit., p. 869.

189 Especialmente en su Capitulo II (art. XIII) y III (arts. I a IV).

190 Art. 1205.

191 Especialmente en su Título I: 'De la comparecencia ante los jueces avenidores'.

192 Especialmente en su Capítulo II: 'De los jueces y juicios de paz o actos de conciliación, y de los alcaldes de los pueblos como jueces ordinarios'.

193 J. Montero Aroca, "Bosquejo histórico de la conciliación hasta la Ley de enjuiciamiento civil de 1855”, op. cit., p. 885. Vid., entre otros, J. Guasp Delgado, "Significación teórica de la justicia municipal” en AAVV., La justicia municipal en sus aspectos histórico y científico, Madrid, 1946, pp. 75-100; R. Cobos Gavala, El juez de paz en la ordenación jurisdiccional española, Madrid, 1989, especialmente, pp. 51 y ss. 
agentes gubernativos ${ }^{194}$, figuras de marcado carácter politico, no se vislumbraba como un obstáculo para que participaran, de alguna manera, en la impartición de justicia. Que intervinieran en tareas conciliatorias se podia justificar en la medida en que, precisamente, se trataba de aliviar la labor de los verdaderos profesionales de la justicia, de jueces y magistrados. Era, simplemente una exigencia previa. Así, la municipal, como subraya Sáinz Guerra, quedaba "en cierta medida, al margen de la Administración de justicia"195.

El problema, sin embargo, se tornaba harto complejo cuando los alcaldes asumian, además de éstas, otras tareas consideradas más estrictamente judiciales, esto es, cuando el Reglamento trató de hacer realidad mandatos como el del art. 275196. Éste preveía que en todos los pueblos se establecieran alcaldes con facultades "así en lo contencioso como en lo económico"197. Esta vía abría la posibilidad a que, por un lado, impartieran justicia los jueces y magistrados, que eran quienes verdaderamente personificaban al tercer poder y que debian ser nombrados por el Rey tras un proceso, más o menos riguroso, de selección participado por el Consejo Real, y los alcaldes constitucionales que, en cambio, eran elegidos periódicamente por los ciudadanos y, además, controlados por el poder ejecutivo central ${ }^{198}$. La estricta separación de poderes quedaba algo tocada ${ }^{199}$.

194 Art. 309: "Para el gobierno interior de los pueblos habrá ayuntamientos compuestos de alcalde o alcaldes...". Art. 323: "Los ayuntamientos desempeñarán todos estos encargos bajo la inspección de la diputación provincial...". Art. 324: "El gobierno político de las provincias residirá en el jefe superior, nombrado por el Rey...". Art. 325: "En cada provincia habrá una diputación llamada provincial... presidida por el jefe superior".

195 J. Sáinz Guerra, La administración de justicia en España (1810-11870), op.cit., p. 252.

196 Este artículo aparece incluido en el título V: "De los tribunales y de la Administración de Justicia en lo civil y criminal"; la normativa sobre los alcaldes y los ayuntamientos en el texto constitucional gaditano se concentraba principalmente en el Título VI que llevaba el significativo rótulo de: "Del gobierno interior de las provincias y de los pueblos". Junto a estas disposiciones de rango constitucional aparecerán una serie de normas de desarrollo tales como el Decreto CCI, de 9 de octubre de 1812 (Reglamento de las Audiencias y Juzgados de Primera Instancia), el Decreto CCXLIV, de 24 de marzo de 1813 (Reglas para que se haga efectiva la responsabilidad de los empleados públicos) y el Decreto LV, de 13 de marzo de 1814 (Reglamento del Tribunal Supremo de Justicia); normas a las que se sumaron con posterioridad otras tales como la Instrucción para dirimir las competencias de jurisdicción entre las autoridades judiciales, de 19 de abril de 1813 , Decretos de 11 de agosto de 1820, Ley de 3 de junio de 1821 e Instrucción para el gobierno económico politico de las provincias, de 3 de febrero de 1823 (legislación restablecida con fecha de 30 de agosto de 1836 al par de la recuperación del texto constitucional).

197 Un artículo que, curiosamente, salvo "ligeras reflexiones sobre la palabra contencioso" fue aprobado sin discusión. Así lo recuerda J. Montero Aroca, J., "La justicia municipal”, Revista de Derecho Judicial, XIII, n ${ }^{\circ}$ 51-52, 1972, p. 87. Y eso, a pesar de que como señala J. Sáinz Guerra, La administración de justicia en España (1810-11870), op.cit., p. 252, su presencia era perturbadora al constituir "un elemento contradictorio en la organización judicial que nacía en ese momento".

198 Sobre esta cuestión, pueden verse, entre otros, F. Martínez Pérez, Entre confianza y responsabilidad. La justicia del primer constitucionalismo español (1810-1823), op. cit., especialmente pp. 430 y ss. En ese sentido defiende que: “... Lo extraño no era atribuir funciones de juez al alcalde, sino pretender que sólo se dedicase a las tan nuevas competencias relacionadas con la policía, el gobierno y la administración de los pueblos".

199 Vid., entre otros, C. De Castro, La revolución liberal y los municipios españoles: 1812-1868, Madrid, 1979; C. Vĩnes Millet, El municipio en España. Su evolución histórica, Granada, 1995; E. 
Así, el Reglamento de 1835 prescribe en su articulado que "los alcaldes y tenientes de alcalde son además jueces ordinarios en sus respectivos pueblos..." 200 . Una decisión que fue objeto de severas críticas ${ }^{201}$ y que originó constantes protestas, especialmente, de los jueces, que defendian que su experiencia les demostraba reiteradamente las perturbaciones que tal opción generaba ${ }^{202}$. En su lucha por apartarlos de tan delicada tarea no estaban solos pues también desde el foro se levantaban voces de protesta. Juristas como Manresa y Navarro 203, Pedro I. Miquel204 o Gómez de la Serna ${ }^{205}$, entre otros muchos, denunciarán la falta de preparación de los alcaldes, la connivencia a que eran propensos, la intermediación de sus luchas políticas, las constantes disputas por la jurisdicción o la falta de garantías sobre su imparcialidad ${ }^{206}$. Argumentos como estos no sirvieron, de momento, para que la justicia se librara de tan molestos compañeros de viaje. La maniobra sustitutoria culminará

Orduña Rebollo, Historia del municipalismo español, Madrid, 2005; J. Gay Armenteros, Politica y administración en los comienzos de la España contemporánea, Granada, 2007.

200 Art. 31.

201 M.A. Morales Payán, "Los alcaldes al servicio de la justicia decimonónica: una propuesta discutida”, op. cit., especialmente, pp. 49 y ss.

202 E. Montero Ríos, "Breves indicaciones acerca de las nuevas leyes relativas al Derecho penal y organización del poder judicial. Idea sobre la alta misión del Magistrado”, RGLJ, n ${ }^{\circ}$ 37, 1870, pp. 241-250, en su calidad de Ministro de Gracia y Justicia en la solemne apertura de los Tribunales celebrada en 15 de setiembre de 1870 reconocerá que: "A pesar de las grandes novedades introducidas desde 1835, con el fin de separar la justicia de la administración, todavía hasta hoy han conservado los Alcaldes su carácter de funcionarios judiciales...".

203 “¿Quién debe sustituir a los jueces de primera instancia en casos de ausencia o impedimento, o de vacante de juzgado?”, RGLJ, $\mathrm{n}^{\circ}$ 7, 1855, pp. 304-309. Se plantea que ante una ausencia de un juez, mientras la audiencia no le nombra el suplente, debe hacerse cargo del juzgado el alcalde constitucional y, en su defecto, el abogado más antiguo del partido judicial y para él "lamentables son las consecuencias que de aquí se siguen. En el uno o en el otro caso se administra la justicia por quien carece de facultades para ellos, por quien no tiene jurisdicción, por persona incompetente, por un intruso que se dice Juez sin serlo...".

204 "Observaciones sobre el proyecto de arreglo de tribunales, redactado por el Mmo. Sr. D. Manuel García Gallardo”, RGLJ, n 4, 1854, pp. 7-34: “... y en verdad sentimos que estos dependientes de la administración ejerzan funciones judiciales, ni aún las más insignificantes porque, generalmente hablando, carecen de instrucción necesaria y no están libres de pasiones mezquinas; en contacto por lo regular desde su niñez con sus convecinos, han llegado a halagar en su corazón afecciones de parentesco y de amistad; han llegado a sentir el combate de la rivalidad y del odio; han llegado a beber en la fuente de los partidos la ponzoña de la parcialidad y de la injusticia... Nosotros siempre clamaremos porque los alcaldes tengan las menos atribuciones judiciales que sean posibles; nos inspiran miedo los alcaldes como jueces...”.

205 “De los jueces de paz”, RGLJ, no 9, 1857, p. 101: “... con ella -alude a la institución de los jueces de paz- queda realizada en todo a lo que los negocios civiles se refiere, la separación de funcionarios de la administración y del orden judicial...”.

206 P.M., "Observaciones al proyecto de ley constitutiva sobre organización de tribunales de fuero común, leido por el Excmo. Sr. Ministro de Gracia y Justicia en la sesión del Congreso de señores Diputados del dia 21 de noviembre de 1853", op. cit., p. 460: “Acerca de las facultades que se conceden a los alcaldes y tenientes de alcaldes como jueces pedáneos, sólo nos corresponde decir, que un juez, llamado como se halla en cualquiera de sus actos, a decidir de los intereses, de la honra y hasta de la vida de los hombres, para que llene su misión sublime como es debido, es menester que se coloque a mayor altura que las flaquezas vulgares, de manera que no alcance hasta él el rudo embate de las pasiones; y desgraciadamente en muchos pueblos los alcaldes y los tenientes son la pasión personificada, porque han bebido en el choque de los bandos de la ponzoña de la rivalidad y del odio...". 
bastantes años después. Primero, en el ámbito civil, con la introducción de la figura de los jueces de paz ${ }^{207}$, a través de la ley de Enjuiciamiento civil en 5 de Octubre de $1855^{208}$ y poco más tarde, en el ámbito criminal ${ }^{209}$, con la Ley de Organización del poder judicial de 15 de Setiembre de 1870 y la de Enjuiciamiento criminal de 22 de Diciembre de $1872^{210}$. Precisamente aquélla, la civil, será la que no obstante el apartamiento de los alcaldes de las tareas judiciales, afiance la institución conciliatoria en cuanto talli1.

207 Hay que precisar, como hace J. Montero Aroca, J., “La justicia municipal”, op. cit., p. 99, que el nacimiento de los jueces de paz fue turbulento. Por una serie de consideraciones de índole politica su inicial caminar fue un fracaso. Así, el R.D. de 22 de octubre de 1855 y la R.O. de 12 de noviembre del mismo año facilitaron cierta dependencia de los jueces de paz a los alcaldes; poco después la R.O. de 2 de enero de 1856 deja sin efecto el nombramiento de jueces de paz y encomienda a los alcaldes el despacho de todos los asuntos que, según la Ley de Enjuiciamiento criminal, debian despachar aquéllos, tarea de la que serán apartados por un nuevo R.D., de 28 de noviembre del mismo año, que organizaba de nuevo los juzgados de paz y el nombramiento de sus titulares. No obstante esta reaparición, el R.D. de 22 de octubre de 1858 preveía que los alcaldes fuesen suplentes de los jueces de paz.

208 La introducción de éstos y, más tarde, de los jueces municipales aliviará algo la tensión pero no será una solución ideal. Al respecto, por ejemplo, Vicente Romero Girón, "Discurso leído por el Excmo. Sr. D. Vicente Romero y Girón, Ministro de Gracia y Justicia, en la solemne apertura de los Tribunales, celebrada en 15 de Setiembre de 1883”, op. cit., p. 204, señala: “... Si numerosos y graves son los inconvenientes de la posible ingerencia (sic) política en la administración de justicia, cuando los Jueces y Tribunales se trata, sube de punto el mal en los Jueces municipales: si alli cabe temer o presumir la acción del poder o de otras influencias, penetra aquí como plaga devastadora otro factor más temible y pertinaz: el caciquismo local...". En la misma línea, G. Ossorio y Pizarro, "Nuevas observaciones acerca de la ley sobre organización del poder judicial", RGLJ, $n^{\circ}$ 54, 1879, p. 415: "Que la institución de los Jueces municipales deja mucho que desear... extremo es sobre el cual insistiremos un día y otro...".

209 E. Montero Ríos, "Breves indicaciones acerca de las nuevas leyes relativas al Derecho penal y organización del poder judicial. Idea sobre la alta misión del Magistrado", op. cit., p. 241: "A pesar de las grandes novedades introducidas desde 1835, con el fin de separar la justicia de la administración, todavía hasta hoy han conservado los Alcaldes su carácter de funcionarios judiciales...".

210 Entre tanto, distintas disposiciones trataron de arrojar algo de luz al marasmo organizativo creado, tales como el R.D. de 21 de abril de 1834, para que los alcaldes ordinarios de todos los pueblos cesaran en el ejercicio del poder judicial; el R.D. de 23 de junio de 1835 que posibilitó que conocieran de pleitos civiles cuya cuantía no excediera de 200 reales; el Reglamento provisional para la administración de justicia de 26 de septiembre de 1835 que amplió sus competencias; la R.O. de 1 de julio de 1848 resolviendo dudas sobre la inteligencia de la regla $3^{\mathrm{a}}$ de la ley provisional para la aplicación del Código Penal; la R.O. de 28 de octubre de 1848 para que los alcaldes y sus tenientes en la cabeza de partido puedan conocer en juicio verbal de los negocios que no excedan de la cantidad de 200 reales; el R.D. de 4 de junio de 1848 para dirimir las competencias de jurisdicción y atribuciones entre las autoridades judiciales y administrativas; o el R.D. de 26 de septiembre de 1851 sobre ejercicio de la jurisdicción de los alcaldes y sus tenientes.

211 J. Montero Aroca, "Bosquejo histórico de la conciliación hasta la Ley de enjuiciamiento civil de 1855”, op. cit., p. 889, destaca, además de ésta, la importancia de otros textos normativos como la R.O. de 5 de noviembre de 1838, la R.O. de 31 de marzo de 1839, las Ordenes de 12 y 20 de julio de 1841, la R.O. de 8 de diciembre de 1845, el R.D. de 22 de mayo de 1846 y la R.O. de 1 de enero de 1847 . 


\section{OPINIONES CRÍTICAS}

Llegando al final de la centuria decimonónica, habiendo cambiado el escenario constitucional pero no el texto marco de referencia, la Ley Orgánica del Poder Judicial, la preocupación por el estado de la justicia persiste. Un folleto de la época cuyo autor se esconde bajo las iniciales A y P. se queja enérgicamente de la desconsideración con la que se trata a la administración de justicia ${ }^{212}$. A su modo de ver diversas causas contribuyen a este descrédito. Unas serían de carácter general, de entre las que sobresale, como más grave, la negación, o cuando menos, la puesta en entredicho del principio de autoridad, hecho que, por otra parte, afecta por igual a otros ámbitos del estado 213 .

Otras, más específicas, se hayan circunscritas a la organización judicial vigente de la que denuncia unos defectos evidentes. Realmente, el escrito no es que más que un ejercicio de reivindicación de una igualdad de trato entre la audiencia madrileña y la barcelonesa. No obstante, al hilo expositivo del agravio exige una serie de mejoras que ayudan a dibujar el estado de la justicia. Así, urge la creación de una policía judicial ${ }^{214}$, insta a que el control de los establecimientos penitenciarios pase a manos del Ministerio de Gracia y Justicia abandonándose la intervención del de Gobernación, compele a la corrección del, a su juicio, desacierto en el diseño territorial de los juzgados y tribunales así como su categorización (especialmente respecto de las audiencias), apremia a aumentar tanto el bajísimo número de servidores en los mismos como su exigua remuneración y, finalmente, lanza un exhorto para mitigar la desconfianza hacia la labor de jueces y magistrados que, según su punto de vista, se desprende de la

212 El hecho y el derecho, o necesidad de algunas reformas en la administración de justicia, especialmente en Cataluña, Barcelona, Establecimiento tipográfico de L. Domenech, 1879, p. 6: “... Hoy, sin embargo -no hay por qué ocultarlo- tan puro sentimiento ha visiblemente decaido, se mira con desvio, sino con indiferencia, la administración de justicia, se lanzan censuras y propalan hasta voces de difamación contra ella, que acaban de entibiar la fe y el respeto a los Tribunales, tan necesario en toda sociedad bien organizada, y a tal punto han llegado las cosas, que la contienda judicial verdaderamente asusta, y no se la considera ya como el medio justo y decoroso de resolver las dudas legales o dar solución a las cuestiones nacidas de la pugna de opuestos derechos, cuando no ha sido dable conjurarlas por medio de una transacción razonable, sino que únicamente se apela a ella como recurso extremo y desesperado cuando la oposición de derechos y choque de intereses, tomando gravísimas proporciones, ha revestido ya el carácter de un serio conflicto, en detrimento de la paz de las familias y desprestigio del buen orden social...".

213 El hecho y el derecho, o necesidad de algunas reformas en la administración de justicia, especialmente en Cataluña, op. cit., p. 7: “... cuando la razón humana todo lo analiza y discute, cuando el sentimiento moral decae, la indiferencia religiosa crece, los vínculos sociales se enervan y las tendencias de la época plantean a cada paso pavorosos problemas sobre cuánto hay de más fundamental en el orden civil y hasta en el religioso, no es de estrañar (sic) que la administración de justicia, como alta y fundamental institución que representa la autoridad, el derecho y el orden en la sociedad, se haya quebrantado más o menos a impulsos de las corrientes del siglo en que vivimos...".

214 El hecho y el derecho, o necesidad de algunas reformas en la administración de justicia, especialmente en Cataluña, op. cit., p. 38: "Pues esto es lo que falta al poder jurídico de nuestra patria: la organización de la policía judicial; pero una policía, no compuesta de los elementos que hoy forman las rondas de orden público, guardia municipal o urbana, ni policía secreta de la autoridad administrativa o militar, sino una policía ilustrada, hábil, discreta, dotada de finura en las maneras, recta en las formas, astuta en la investigación, constituyendo una verdadera carrera bien retribuida...". 
Ley Orgánica de la que no tiene una opinión muy favorable ${ }^{215}$. Como él hay numerosos juristas que desconfian de la provisional ley organizativa.

Pero este sentir negativo habria que matizarlo pues, en realidad, como señala González Alonso ${ }^{216}$, fueron, probablemente, "la inestabilidad política, los crecidos gastos que habría ocasionado adaptar a su articulado la organización judicial existente $\mathrm{y}$, de manera especial, el rápido regreso al poder de los conservadores monárquicos" las causas que impidieron su inmediata aplicación en los términos exactos en que había sido promulgada. Y aunque esas circunstancias acabaran en el descrédito del texto normativo es, sin embargo, "en estos años cuando la justicia adquiere la contextura que ha perdurado hasta fechas muy recientes". No hay que perder de vista que esta disposición de 1870, con ligeros retoques, acabará aplicándose en coordinación con otras que fueron aprobadas con posterioridad, especialmente, la Ley de Enjuiciamiento civil de 3 de febrero de 1881 y la Ley de Enjuiciamiento criminal de 14 de septiembre de 1882, vigentes en el momento de conmemorar el centenario de la Constitución de 1812.

En esa línea de crítica hacia el estado de la administración de justicia se puede sumar otra publicación de 1890, también impresa en Barcelona, y que llevaba por título "La administración de justicia ante la opinión". Cuenta con una participación de más de una treintena de autores a los que hay que sumar la Junta de gobierno del Colegio de Abogados de La Coruña a través de un informe y la Academia de Derecho de Barcelona por medio de un dictamen.

El prologuista y a su vez impulsor de la obra fue un prestigioso magistrado de la época, Vicente Amat y Furió ${ }^{217}$. Con afirmaciones tan rotundas como que "sin la administración de justicia no se concibe la sociedad" 218 o que ésta es "la institución que más eficazmente contribuye al sostenimiento del orden social"219

215 Así, se queja especialmente de la redacción del art. 234 que obliga al traslado forzoso de jueces y magistrados cuando lleven ocho años de residencia en una misma población.

216 B. González Alonso, “La justicia...”, op. cit., p. 412.

217 Datos obtenidos en http://petreraldia.com/reportajes/vicente-amat-furio-1857-1943-sucontribucion-a-la-historia-de-petrer.html, donde se extracta el artículo publicado en la revista Festa (2012) por Perceval Verdú, E. y Rico Navarro, M $^{a}$ C. Nacido en Petrer en 1857, con veintiún años se licenció en Derecho Civil y Canónico pasando a ejercer seguidamente como abogado en Valencia. A los pocos años abandonó el ejercicio para actuar como secretario de Sala de la Audiencia de Valencia en sustitución de su padre. Con veintisiete años ganó la plaza de relator propietario de Sala de la misma ciudad. No llegaba a la treintena cuando se trasladó a Barcelona, a su Audiencia, para ocupar una plaza similar a la que dejaba. En 1890 sería nombrado magistrado de Audiencia de lo criminal. Sería cuestión de tiempo el que diese el salto que lo llevaría hasta el Tribunal Supremo del que llegó a ser secretario de sala. Ocasional colaborador en prensa (La Vanguardia) durante su recorrido profesional fueron frecuentes sus publicaciones de carácter técnico. Así, además de la que nos ocupa en este trabajo se pueden mencionar: Cuadro de los términos judiciales en lo criminal; El Juicio oral en materia civil; Estudio práctico del enjuiciamiento criminal; Manual de Derecho para los aspirantes al cargo de procurador en Audiencia territorial; Juzgados de Primera instancia...

218 La administración de justicia ante la opinión, op. cit., p. 3.

219 Sus razonamientos son de gran actualidad. Así, en p. 4 señala que: "Los que movidos de generosos sentimientos y por nobilísimos impulsos trabajan por la paz y el desarme universal, en vano buscarán un código internacional que abarque todos los casos, prevea todas las contingencias y ofrezca siempre soluciones, y sólo podrán lograr sus deseos el día en que consigan organizar un gran Tribunal al que todas las naciones rindan acatamiento y cuyas decisiones estén todos dispuestos a sostener contra aquel que las contrarie. ¿Sería posible la constitución de semejante Tribunal en condiciones de imparcialidad y justicia? No me atrevo a 
confiesa que su experiencia profesional le ha mostrado profusos defectos en el funcionamiento y diseño de la administración de justicia que podian y debían ser corregidos. Con tal motivo, años antes, publicó una obra titulada El juicio oral en materia civil. Apuntes para la reorganización de los tribunales y la reforma de la ley procesal, donde detallaba las que, a su juicio, debian ser reformas irrenunciables en el ámbito judicial que no admitían dilación en su ejecución. Pero, consciente del escaso eco que tuvieron sus demandas por la debilidad de su posición ${ }^{220}$, decidió dar un paso al frente y reunir un elenco de personalidades para que mostrasen su opinión sobre el estado de la justicia y pusiesen de relieve las mejoras que, desde sus respectivos puntos de vista, debian adoptarse ${ }^{221}$. A pesar de la diversidad de criterios de los participantes había un nexo de unión que no admitía discusión:

\begin{abstract}
"Dedicado el presente libro a estudiar los medios de mejorar en nuestra patria la Administración de justicia en materia civil, era natural, y así ha sucedido, que sus autores comenzaran su obra por el estudio del estado actual de aquélla. Y en este punto, forzoso, aunque sensible me es consignar aquí, que el veredicto le ha sido muy desfavorable... Hallará aquí el lector opiniones contrarias acerca de la bondad de cada sistema procesal; encontrará partidarios de la apelación o de la instancia única; defensores del Tribunal colegiado o del unipersonal; indicaciones diversas acerca de otros problemas de la organización y del procedimiento; tan sólo ha habido unanimidad, pero unanimidad abrumadora, en la apreciación del actual estado de la Administración de justicia. Todos la consideran defectuosa por unas $u$ otras causas, todos eligen los colores más subidos de su paleta para pintar sus deplorables efectos; todos convienen en que el actual estado de cosas no puede continuar sin grave riesgo..."222.
\end{abstract}

Las páginas dedicadas a la presentación de la obra son aprovechadas por el magistrado para recordar algunas de las lacras que ya venía denunciando desde tiempo atrás tales como la lentitud con la que la justicia se desenvolvía ${ }^{223}$, su

afirmarlo; pero sí aseguro con întima convicción que poco tiempo después de constituido las armas enmohecidas se convertirán en instrumentos de labor y los ejércitos de exterminio en ejércitos de trabajo, de producción y de progreso. ¡La justicia es la madre de la paz!”.

220 La administración de justicia ante la opinión, op. cit., p. 5: “Comprendí como realidad innegable que mi voz humildísima había de perderse en el vacío, y al considerar que lejos de desvanecerse de igual modo, habian de ser escuchadas atentamente las de aquellas personas que por su saber y experiencia representaran la opinión ilustrada, la opinión científica, la opinión sana del país, concebí el proyecto de acudir a ellas para que dictaminaran en tan controvertido asunto...".

221 La administración de justicia ante la opinión, op. cit., p. 6: "Estaba la tierra tan bien preparada, son tan notorios los males que afligen a la Administración de justicia, es tan necesario y urgente el remedio, se siente por todos tan vivamente esta necesidad, que mi osadia al dirigirme, sin título alguno personal, a los jurisconsultos más eminentes, a los más altos magistrados, a los estadistas más eximios, no pudo estrellarse contra la indiferencia y fue acogida en todas partes con simpatia y hasta con entusiasmo, dando por resultado el presente libro...”.

${ }^{222}$ La administración de justicia ante la opinión, op. cit., pp. 7-8.

${ }^{223}$ La administración de justicia ante la opinión, op. cit., p. 10: "Hoy se vive deprisa; se viaja y se cambian los productos con el auxilio del vapor; se habla y se contrata por medio de la electricidad; y no es posible que se administre justicia a paso de galera acelerada. Y a este paso se 
carestía o la falta, a menudo, de garantías para los demandantes de la misma ${ }^{224}$. Concede que se han dado algunos pasos en pos de una cierta mejora pero piensa que, en general, el camino elegido ha sido errado ${ }^{225}$. Y el mayor error, el fracaso más sonado, lo focaliza en el tema de la independencia del orden judicial. Precisamente, cuando termina de hacer un breve resumen del contenido de la obra, enumerando el elenco de participantes y sus respectivos trabajos, lanza una proclama profundamente reveladora:

"Pido, ante todo y sobre todo -y esto no es un secreto- separación completa de la politica y la justicia, llegando a solicitar, para conseguirlo, la independencia absoluta del Poder judicial"226.

A los efectos de este trabajo, de los más de treinta artículos que recoge, sobresale el de Antonio Aguilar que lleva por título "Tribunales $y$ Procedimientos"227. Por supuesto que, como el resto de participantes en la obra colectiva, eleva su lamento por el mal estado de la justicia: "varias causas han descubierto y han recrudecido, en los presentes dias, el mal de que la Administración de la Justicia ya se quejaba..."228. Pero, en concreto, merece la pena detenerse en los dos primeros apartados englobados bajo el título de " $E l$ Poder Judicial". Principia el primero con una dura crítica al modelo de organización política vigente. Denuncia cómo el caciquismo ${ }^{229}$ campa a sus

administra, porque la organización judicial y las leyes de procedimiento civiles son substancialmente las mismas de la época en que se viajaba en estos vehículos”.

${ }^{224}$ La administración de justicia ante la opinión, op. cit., p. 11: "la Administración de justicia... es cara y no ofrece las necesarias garantías a la defensa de los derechos que está llamada a amparar... El procedimiento escrito con la duplicidad de instancias ha de ser forzosamente lento, caro y falto de garantías...".

${ }^{225}$ La administración de justicia ante la opinión, op. cit., p. 12: "En cuanto al procedimiento se refiere, se han ordenado cuidadosamente sus disposiciones por las dos leyes de enjuiciamiento publicadas; se ha procurado abreviar los trámites, reglamentar los juicios, combatir la mala fe, dificultar el uso de los recursos como arma de mala ley; se han hecho laudables esfuerzos, pero se ha equivocado el camino y los resultados no han correspondido a los buenos deseos, ni a los trabajos realizados..."

${ }^{226}$ La administración de justicia ante la opinión, op. cit., p. 18.

227 Aguilar será un jurista que se distinguirá por su combatividad a la hora de preservar la independencia del poder judicial y su denodada lucha contra las injerencias del ejecutivo especialmente. No se limita a este escrito. Hay otros como Los Tribunales y el Ministro, Justicia para la justicia o Justicia y política, aunque, en la misma línea argumental más renombradas si cabe fueron sus conferencias impartidas en el Ateneo madrileño que se conservan impresas: Independencia del poder judicial”, conferencias pronunciadas en el Ateneo científico, literario $y$ artístico de Madrid, en las noches del 15 y del 22 de abril de 1891, Madrid, Librería de Fernando $\mathrm{Fe}, 1891$. En las mismas se preguntará, entre otras cuestiones, si “... visto así, tal como es en realidad, el alcance de la misión confiada a los Tribunales, ¿podrá cumplirla el poder ejecutivo? ¿Tiene, para este caso, aptitud especial, organismo bien conformado, naturaleza adecuada?” para responderse de forma taxativa que no, que “... el poder ejecutivo nunca cumplirá bien funciones que son muy semejantes a las que, en el organismo humano, cumple la conciencia...”.

${ }^{228}$ La administración de justicia ante la opinión, op. cit., p. 38.

229 La administración de justicia ante la opinión, op. cit., p. 38: “... Este sistema despertó ambiciones, trocó en groseros materialistas a los hijos de rancios liberales que de extremo de 
anchas advirtiendo que “... los elementos políticos, -cuya importancia y necesidad nadie desconoce-, serán siempre de dañosísima influencia en la Administración de la Justicia, si a su alcance la tienen".

En la segunda, parte de la evidencia de que "hay, en primer término, una aspiración general: la de que se asegure a los Tribunales su independencia y no llegue jamás hasta ellos el interés de partido o de bando y la acción de los hombres politicos...". En tal sentido, reconoce que el principio de inamovilidad judicial es indispensable. Aunque no suficiente. Si el mismo "se asegura y se practica con buena fe; si el funcionario no puede sentir temor ni esperanza, porque no depende, como hoy, del arbitrio ministerial, entonces tal vez habrá quienes digan que se ha llegado al punto apetecido. Y no obstante, ni aún así obtendriamos las condiciones y garantias necesarias" 230 . Junto a éste, paralelamente, defiende la inexcusable necesidad de exigir responsabilidad a los jueces y magistrados en el ámbito de su actuación: "La independencia que se pide no se puede separar de la responsabilidad..."231.

Sentadas estas premisas, se centra en la necesidad de mejorar la imagen que de la justicia tiene el ciudadano. Una visión de libertad limitada o vigilada que puede derivar de situaciones muy diversas. Así, por ejemplo, apunta a la figura del fiscal. Advierte que la opinión pública lo percibe como un peón al servicio del ministro de turno y no como un servidor de la sociedad. Para romper con esa asociación de ideas reclama al gobierno que sea escrupuloso en sus relaciones con el mismo y manifieste un profundo respeto en el desempeño de sus tareas.

Igualmente problemática resulta reducir la cuestión de los ascensos en el seno del cuerpo de jueces y magistrados a tan sólo dos opciones: o la vía de la antigüedad pura y dura, injusta intrínsecamente, o la senda de premiar según méritos acumulados, que se convierte en una puerta abierta a la arbitrariedad más recalcitrante. Obligatorio es, a su juicio, arbitrar otro régimen que permita combinar la valía personal con la dedicación sin que quede ningún resquicio para que el ejecutivo premie lealtades.

En tercer lugar alude al tema del ingreso en la carrera judicial. Reconoce su complejidad. Se decanta claramente por el modelo de 'oposiciones', vigente en el momento, aunque entiende que es manifiestamente mejorable. Pero sobre todo reivindica el descarte definitivo de cualquier ruta que posibilite el nombramiento de personas que no hayan mostrado su capacidad y que, sin embargo, gocen de apoyo político:

"O se prescinde de verdaderas ilustraciones que puedan llevar su acción a la obra de los Tribunales, honrando la magistratura y favoreciendo los intereses de la Justicia, o se da entrada a magistrados con precedentes y compromisos

virtud pararon en extremo de candidez, y creó, en fin, vigoroso, potente y temible el caciquismo de salón y de campanario que hoy se combate destruyendo todos los organismos de la Administración...".

230 La administración de justicia ante la opinión, op. cit., p. 42.

${ }^{231}$ La administración de justicia ante la opinión, op. cit., p. 44. 
en la política, y a los ineptos para la carrera, aunque muy hábiles como intrigantes" 232 .

Por lo que hace a la cuestión de la responsabilidad de jueces y magistrados, aunque se declara defensor impenitente advierte cómo puede utilizarse para desprestigiar a quien resulte un engorro. La cautela, avisa, es ineludible:

“... en el vulgo vivirá con facilidad el recelo, y quizá se ha de atribuir a innobles venganzas o a malas artes para llegar a fin ilícito, lo que fue exigencia de sabia Administración y principio de justicia”233.

Finalmente, acusa la existencia de una tradicional desconfianza, incluso hostilidad, del ciudadano hacia la justicia. Y desde su punto de vista el problema se ha de centrar, ante todo, en que "nos empeñamos en resolver como cuestión de forma la que es cuestión substantiva; que pretendemos, sin darnos cuenta del contrasentido, organizar Tribunales independientes antes de organizar el Poder Judicial"234. Y aquí reside la clave:

"En tanto que la independencia no exista de acción a acción, de Poder a Poder, será delirio pensar en que el Gobierno, la representación de la política, no influya y pese con peso abrumador en el Tribunal, la representación del derecho" 235 .

Concede que está pasada de moda la discusión de si la justicia ha de ser considerada como un verdadero poder o es una mera extensión del ejecutivo pues el tiempo la ha superado. Pero exige que se pase de las grandilocuentes declaraciones a los hechos prácticos:

“... ahora, digo, es ocasión oportuna como no hubo otra, para organizar un Poder al que se confie en toda su pureza la Administración de la Justicia, y que se consagre a ella, alentado por la santidad de su misión contenido únicamente por severísimos cánones que aseguren su responsabilidad, como garantía del individuo y del Estado"236.

De casi final del siglo es una publicación de Lorenzo Barrio y Morayta, abogado del colegio madrileño, que lleva por título: '¿Por qué no hay pleitos? Reformas necesarias en la administración de justicia' ${ }^{237}$. Su contenido refleja la

\footnotetext{
232 La administración de justicia ante la opinión, op. cit., p. 43.

${ }^{233}$ La administración de justicia ante la opinión, op. cit., p. 44.

${ }^{234}$ La administración de justicia ante la opinión, op. cit., p. 44.

235 La administración de justicia ante la opinión, op. cit., p. 44.

${ }^{236}$ La administración de justicia ante la opinión, op. cit., p. 45.

237 Madrid, Imprenta de Ezequiel Solís, 1896.
} 
realidad de los inmediatos años precedentes dado que se trata de una recopilación de artículos publicados en un noticiero jurídico, el Heraldo de los Tribunales. Se suma a la larga lista de juristas que se quejan del mal funcionamiento de la justicia:

“... lo cierto es que la administración de justicia se encuentra hoy en un estado tan lamentable, que todo el poder milagroso que se le atribuye a Jesús no bastaría para levantar a este Lázaro con toga" 238 .

De entre el largo inventario de disfunciones enfatiza su desazón en el ámbito del personal que sirve en la misma. Curiosamente, como regla general salva a los jueces: "la generalidad de los jueces son personas dignísimas y peritas". Aunque no lo hace de todo el colectivo pues conviene que hay un cierto porcentaje que no merecen tal condición:

“... dentro de la misma carrera judicial hay, por desgracia, bastantes individuos que no deben el puesto que ocupan a haber acreditado su suficiencia por medio de oposición, sino que por la asimilación de que gozan algunos destinos del Estado y por otras circunstancias entre las que figura, no pocas veces, la influencia política, han logrado ser incluidos en el escalafón..."239.

Persisten, según su punto de vista, colocaciones por intermediación de la clase politica que pone en entredicho la independencia del poder judicial240. A la necesidad de poner fin a esta situación, suma otras demandas entre las que sobresale la de reformar las disposiciones relativas a la responsabilidad de los jueces. Pues es una vía alternativa interesante para corregir los errores (intencionados o no) de ese personal "falto de formación". De modo especial exige que las quejas derivadas de los extravios en sus actuaciones sean revisadas por unos tribunales independientes, donde no haya lugar a una posible decisión basada en una falsa solidaridad derivada de pertenecer al mismo cuerpo ${ }^{241}$.

238 ¿Por qué no hay pleitos? Reformas necesarias en la administración de justicia, op. cit., p. 4.

239 ¿Por qué no hay pleitos? Reformas necesarias en la administración de justicia, op. cit., pp. 6-7.

240 En otro plano, aunque intimamente relacionado, critica que el exceso de trabajo al que están sometidos les lleva a delegar muchas tareas en personal subalterno del que ya no le inspira tanta confianza: “... se vea en la necesidad de delegar en los Escribanos de su Juzgado, los cuales dicho sea aunque sean también personas dignísimas y todo lo honradas que se quiera, carecen de las condiciones y conocimientos que se hacen concurrir en los jueces. Y aún no sería del todo malo que la cosa parase ahí, sino que siéndole también imposible al Escribano el despachar por sí mismo los asuntos de su cargo, delega a su vez en su Oficial, muy buen muchacho por lo común, pero que, en general, no pasa de ser un escribiente, y casi siempre con muy mala letra. De todo esto resulta que especialmente en las grandes poblaciones la administración de justicia se encuentra en la práctica encomendada en la mayoría de los casos a personas inexpertas...”

${ }^{241}$ ¿Por qué no hay pleitos? Reformas necesarias en la administración de justicia, op. cit., p. 12: "Es notoriamente insuficiente la legislación actual por lo que se refiere a la responsabilidad judicial; la experiencia nos lo enseña, y recientemente se han dado casos de gran resonancia que confirman la insuficiencia que señalamos. La mayoría de las veces resulta un mito en la práctica la responsabilidad de jueces y magistrados que casi nunca llega a hacerse efectiva; lo cual 
Incluso propone que las penas a imponer, en caso de ser exigible responsabilidad, sean más duras que las vigentes en ese preciso momento ${ }^{242}$.

Y, entre crítica y crítica, llegamos a 1912, el año del centenario de la Pepa. Con las debidas licencias eclesiásticas, ve la luz un parco volumen firmado por el padre Juan María Solá243 con el expresivo título de ¡Cien años de desdichas! (1812-1912). Estudio crítico de la Constitución de Cádiz ${ }^{244}$.

depende a nuestro modo de ver de la clase del tribunal que ha de juzgarlos, compuesto por sus superiores gerárquicos (sic), amigos la mayoría de las veces y compañeros siempre. Este sentimiento, el de compañerismo y un mal entendido amor al prestigio de clase, perjudica sobremanera al que se ve en la triste necesidad de tener que entablar un expediente de responsabilidad contra un funcionario del orden judicial. Todos sabemos que las reprensiones y los apercibimientos es lo que más abunda, con excasear (sic) también; pero con eso nada consigue el interesado ni se le indemniza del perjuicio causado. Se necesita, pues, un castigo más enérgico y un tribunal más independiente para fallar esta clase de asuntos y estimamos que siempre que se ventile una cuestión de hecho, a nadie mejor que al jurado ordinario podrian someterse y si se tratase de una cuestión esencialmente jurídica a un jurado también elegido al azar en la misma forma que hoy se viene haciendo, pero entre personas que a los requisitos ordinarios reuniesen ciertas condiciones de pericia o conocimientos técnicos que presupongan capacidad bastante para obrar en justicia y a sabiendas de lo que se hace, cuyos jurados podrían muy bien elegirse entre los abogados, notarios, catedráticos de derecho y demás profesiones análogas...".

242 Prosigue su exposición formulando una retahíla de reivindicaciones que escapan ya al objetivo de este trabajo. Nos limitamos pues simplemente a mencionarlas superficialmente. En este sentido cabe subrayar la petición del aumento del personal en la administración de justicia, el que se tomen las medidas oportunas para, una vez dictada una sentencia, se aplique en la práctica y la conveniencia de rebajar las costas procesales así como el acortamiento de plazos en el desarrollo del proceso.

243 Barcelona, Tipografía Católica, Calle del Pino, núm. 9, 1912.

244 Por supuesto que no sería el único libro que con motivo del centenario viera la luz. Hubo numerosas publicaciones de todo tipo. Justo antes y con posterioridad, de carácter laudatorio y bastante críticas. Entre estas últimas la de Solá sobresale por su crudeza. Sin ánimo exhaustivo se pueden mencionar: M. Alba; R. de Puga (eds.), La Constitución de 1812 en la Nueva España, México, Publicaciones del Archivo General de la Nación, 1912-1913; P. de Angelis, Ramón Power, primer diputado a Cortes por Puerto Rico, Madrid, 1912; J. Argüelles, Biografia de los diputados asturianos de las Cortes de Cádiz, Oviedo, 1912; J. Belda y R.M. de Labra y Martínez, Las Cortes de Cádiz en el Oratorio de San Felipe, Madrid, Imprenta de Fontanet, 1912; A. de Castro Rossi, Cortes de Cádiz. Complementos de las sesiones verificadas en la Isla de León y en Cádiz. Extractos, datos, noticias, documentos y discursos publicados en periódicos y folletos de la época, Madrid, Imprenta de Prudencio Pérez de Velasco, 1913, volúmenes I y II; R. Comenge, Antología de las Cortes de Cádiz, Madrid, Establecimiento Tipográfico Hijos de J. A. García, 1909; A. Flores y Caamaño, D. José Mejia Lequerica en las Cortes de Cádiz de 1810 a 1813, o sea, el principal defensor de los intereses de la América española en la más grande Asamblea de la Peninsula, Barcelona, 1913; J. Gallardo y De Font, Apertura de las Cortes en 24 de septiembre de 1810, (artículos publicados en el Adelantado de Segovia en septiembre de 1910), Segovia, Imprenta de "E1 Adelantado", 1910; J. Gómez Bardají; J. Gómez Bardají; J. Ortíz Burgos, Crónica del centenario de la instalación de las Cortes Generales y Extraordinarias llamadas de Cádiz, Madrid, $1912 ; \mathrm{R}$. Gómez de Villafranca, Los extremeños de las Cortes de Cádiz, Badajoz, 1912; L. González Obregón (dir.), La Constitución de 1812 en la Nueva España, México, Archivo General de la Nación, 1912/1913, volúmenes I y II; A. Martínez de Salazar, Apuntes biográficos de los diputados gallegos doceañistas, Santiago de Compostela, 1912; F.J. de Moya y Jiménez, 1812-1912: Centenario de las Cortes y sitio de Cádiz. Los doceañistas Canarios (Apuntes histórico-biográficos), 1912; V. Pérez González, Álbum politico: recuerdo del primer centenario de la Constitución de Cádiz, Madrid, Imprenta de Gabriel López del Horno, 1912; F. Rahola y Tremols, Los Diputados por Cataluña en las Cortes de Cádiz, Barcelona, Imprenta de la Casa Provincial de Caridad, 1912; R. Salillas, En las Cortes de Cádiz (Revelaciones acerca del estado politico y social), Madrid, 1910; E. del Valle 
Parte su autor de la siguiente premisa: "esto es cabalmente lo que intentaba el liberalismo: acabar con la Religión y con la patria"245. En consecuencia, rechaza de plano la Constitución de 1812 en cuanto signo identitario de aquél. Por supuesto, desde su punto de vista, no tiene cabida ningún acto de celebración por su centenario.

La animadversión que exhibe en su escrito contra el texto doceañista le lleva al extremo de silenciar, por ejemplo, lo que de positivo para el catolicismo trajo consigo éste, como el monopolio religioso que implantó, prerrogativa que, por ejemplo, no recogía la constitución entonces vigente ${ }^{246}$. Prefiere, en cambio, reunir una pródiga lista de razones por las que la constitución gaditana debía ser objeto de inequívoco rechazo. Unas, tan livianas como que hasta "el cielo estaba contra ella", desencadenando el cólera y una climatología adversa ${ }^{247}$ y, otras, de un contenido algo más sustancioso, como aquéllas en las que tacha a las Cortes, simbolo inequívoco del proyecto liberal, de perjuras, pérfidas, ingratas ${ }^{248}$, regicidas $^{249}$, cismáticas $^{250}$, impias $^{251}$, opresoras, hostiles ${ }^{252}$, de rapacidad insaciable ${ }^{253}$, hipócritas ${ }^{254}$ y antipopulares ${ }^{255}$.

Iberlucea, Los Diputados de Buenos Aires en las Cortes de Cádiz y el nuevo sistema de gobierno económico de América, Buenos Aires, Martín García, 1912; G.M. Vergara, Los diputados eclesiásticos en las Cortes de Cádiz, Madrid, 1912; Vipegón, Memorándum político: recuerdo del primer centenario de la Constitución de Cádiz, Madrid, Imprenta de A. Marzo, 1912; VV. AA., Velada en honor y memoria de los diputados doceañistas, Cádiz, Academia Hispanoamericana de Cádiz, 1910.

245 J.M. Solá, ¡Cien años de desdichas! (1812-1912). Estudio critico de la Constitución de Cádiz, op. cit., p. 34.

246 La Constitución de 1876 aunque en su artículo 11 instauraba a la católica como religión del estado también establecía que "nadie sería molestado en territorio español por sus opiniones religiosas, ni por el ejercicio de su respectivo culto, salvo el respeto debido a la moral cristiana...". Al respecto señala J.M. Cuenca Toribio, "El Catolicismo español en la Restauración (1875-1931)", op. cit., p. 278, que: "Sin embargo, las esperanzas de que la monarquía alfonsina consagrase, a la manera de los moderados de 1845, la unidad religiosa de la nación, haciendo caso omiso de la tolerancia propugnada por algunas voces desde la tribuna y la prensa, quedaron defraudadas. Las leyes y fórmulas legales por las que se regirian las relaciones entre la Iglesia y el Estado durante la Restauración se inspirarían en el mismo clima espiritual que informaría toda la obra de Cánovas del Castillo: la ausencia de cualquier exclusivismo y la solución de la vía media para todos los problemas. El artículo -en el que se recogian y amalgamaban los términos de los textos constitucionales de 1854 y 1869 , y que fue uno de los más discutidos de la Constitución dada al país en 1876- sancionaba de manera explícita la tolerancia".

247 También recalcará la alegria que, según él, se vivió en Cádiz por la vuelta de Fernando VII a partir del 17 de abril de 1814.

248 Entre otras cosas porque "por la mañana juran al rey por soberano, y a la tarde se adjudican a sí la soberanía. Ellos se declaran la Nación, ellos reyes, ellos soberanos, y en su orgullo luciferino se arrogan el título y renombre de Su Majestad... Su primer acto fue avasallar a la Regencia. A las ocho de la noche mandan que sus individuos esperen las órdenes de las Cortes... A las once y media de la noche llaman a los cuatro regentes (el quinto, que era el virtuosísimo señor Quevedo, obispo de Orense, no quiso ir), se les exige el juramento de reconocer la soberanía nacional...".

${ }^{249}$ Para certificar esta calificación recurre a la Atalaya de la Mancha, "papel católico de Madrid, en sus números de Abril y Mayo de 1814" que da cuenta de una "Constitución secreta que se fraguó en las logias, de la cual la gaditana era solamente como el primer jalón". El artículo 38 de la misma establecía que "Al paso que esta Constitución (la de Cádiz) se vaya realizando, los miembros de la Convención procurarán ir preparando al pueblo para que se deshaga de su rey". 
El clérigo reniega de las conmemoraciones previstas subrayando que, de haber algo que celebrar, en todo caso, debería ser para ensalzar el levantamiento popular que se produjo contra los invasores franceses. Mientras esta acción es digna de glorificar nada hay que elogiar del texto politico coetáneo:

\begin{abstract}
"Asenté, señores, al principio, que así como el primer centenario de la resistencia gaditana al invasor francés es todo vuestro y debéis con gran júbilo celebrarlo, el otro de la Constitución de 1812 no es, honrados gaditanos, católicos sinceros, buenos españoles, no es vuestro, sino contra vosotros y vuestros más caros intereses" 256.
\end{abstract}

Máxime a la altura de un nuevo siglo recién comenzado que, según el autor del impreso, sigue una senda equivocada, precisamente, labrada por dicha norma:

250 En tres argumentos cimenta su afirmación: que "los caudillos y muñidores" de la Constitución "eran furibundos jansenistas"; que el decreto de 22 de febrero de 1813 procedia a suprimir el tribunal de la Inquisición y que las Cortes no sólo ordenaban la celebración de un Concilio nacional sino que, incluso, establecian las materias a tratar.

251 Considera que en realidad no todos los diputados eran impíos, sino que "fue impía la asamblea, impío el espíritu dominador en ella, impios muchos de sus decretos y encaminados a destruir la piedad y religión en los pechos de los españoles". Su diatriba se centra especialmente en la labor de dos figuras, el secretario de la Junta Central, Manuel Quintana y el secretario de las Cortes Bartolomé Gallardo, a los que juzga muy duramente al par que cuestiona la libertad de imprenta, el que se protegiera "con su sombra y autoridad los escritos y autores que combatían más sañudamente la Religión católica", el "multiplicar los escritos contra la disciplina general de la Iglesia" y, finalmente, "la persecución a mano armada de todo escrito que se opusiese a las nuevas doctrinas".

252 Son 'opresoras' del Episcopado español y 'hostiles' al clero y pueblo de Cádiz. Para justificarlo cita varios casos de persecuciones y hostigamientos a obispos, como los de Orense, Santander, Oviedo y un largo etcétera. Está convencido que "la convención de Cádiz iba siguiendo, aunque de lejos y pesadamente, las huellas de la convención francesa".

253 Las considera insaciables en su tarea de apoderamiento 'sacrílego' de los bienes de la Iglesia y del pueblo.

254 Una hipocresía que según el prelado procedía desde el mismo momento de su constitución: "Vedles el día 24 de septiembre a las diez de la mañana, hincadas las rodillas ante el altar, prestando muy devotos el juramento de fidelidad a la corona; ved cómo encabezan la ley constitucional: 'En nombre del Padre y del Hijo y del Espíritu Santo'; ved a Villanueva, acabado modelo de afectaciones jansenísticas, que propone en la sesión de 3 de Noviembre de 1810, que para alejar de España los efectos de la ira divina se haga en todas las provincias penitencia general y pública, con tres dias de rogativas, comulgando en uno de ellos todos los señores diputados. 'Los volterianos soltaron la carcajada y El Conciso, en su número 39, burlóse (sic) generosamente del orador y de su propuesta ¡Singular destino de los clérigos liberales! Ni el cielo ni el infierno los quieren'... La mayor parte de ellos procedian, no lo dudo, con sinceridad; pero los muñidores de las Cortes eran volterianos redomados, y querian con ese anzuelo de piedad y religión atraer a los incautos y encubrir con esa máscara sus malvadas intenciones".

255Entiende que numerosos diputados alardeaban de poseer exquisita formación cultural cuando, en realidad, según él era escasa y, en la mayoría de los casos, confusa, especialmente por haber utilizado fuentes erróneas y perturbadoras en su formación política.

256 J.M. Solá, ¡Cien años de desdichas! (1812-1912). Estudio crítico de la Constitución de Cádiz, op. cit., p. 3. 
"Yo me explico que en los albores de la pasada centuria y recién fraguado este flamante código, hubiera españoles que o halagados por la novedad, o seducidos por el ruin ejemplo, o alentados por la esperanza de medros personales, abrazasen incautamente aquellas reformas y las defendiesen a capa y espada, como si en ellas se hallasen los gérmenes de nuestra grandeza y nacional prosperidad. Pero que después de cien años de frutos amarguísimos, de funestas experiencias, de guerras intestinas, de bancarrotas escandalosas, de perdimentos sucesivos de todo nuestro imperio de ultramar; que después de cien años de asoladora decadencia en letras y en las armas, en la politica interior y en la politica internacional, en las ciencias y en las artes; que después de cien años de llagas sobre llagas (que sólo Dios sabe y puede remediar) en las costumbres públicas y privadas, en la vida doméstica y social, en las clases altas, bajas y medianas, que han quedado, en virtud de esas reformas y principios quebrantas, desunidas, enconadas las unas contra las otras, a punto de enseñorearse de este pueblo infeliz el socialismo y la anarquía, haya todavía quien admire la Constitución del año 12, madre y engendradora de todas las demás que han turbado y despedazado a España, eso, señores, no acabo de entenderlo..."257.

Partiendo de la base de que el genuino espiritu del pueblo español es ajeno al liberalismo, al cual considera una frivola importación del extranjero que lleva al país por mal camino, rechaza todas las constituciones decimonónicas, a las que tacha de "antipatrióticas y anticristianas" y reclama un gobierno "a la española", un "vivir a la española" y un "resucitar y aun sobrepujar las gloriosas hazañas de nuestros dorados siglos" pues, concluye, "el liberalismo constitucional de 1812 nos ha empobrecido, deshonrado, envilecido..."258.

\section{A MODO DE CONCLUSIÓN}

Varela Suanzes-Carpegna ${ }^{259}$ asevera que La Pepa fue un texto que, a pesar de sus notables defectos ${ }^{260}$, ejerció un gran atractivo entre "los demócratas españoles del siglo XIX"261. La clave de su seducción quizá radicase en que a él se

257 J.M. Solá, ¡Cien años de desdichas! (1812-1912). Estudio crítico de la Constitución de Cádiz, op. cit., pp. 3-4.

258 J.M. Solá, ¡Cien años de desdichas! (1812-1912). Estudio crítico de la Constitución de Cádiz, op. cit., pp. 35 y ss.

259 J. Varela Suanzes-Carpegna, Politica y Constitución en España (1808-1978), op. cit., pp. 103 y ss.

260 Como el hecho de no reconocer el sufragio directo ni auténticamente universal, no garantizar los derechos de reunión y asociación, consagrar un estado fuertemente centralizado o mantener la confesionalidad del Estado y la intolerancia religiosa.

261 J. Varela Suanzes-Carpegna, Politica y Constitución en España (1808-1978), op. cit., pp. 103 y ss.: "Se comprende, ciertamente, esta admiración de los demócratas españoles del pasado siglo por el liberalismo doceañista y la Constitución de Cádiz... Pero el hecho indiscutible es que esta Constitución consagraba una 'monarquía moderada', en la que se concedía a la Corona importantísimas atribuciones en el orden ejecutivo; no reconocía el sufragio directo ni auténticamente universal al excluir no sólo a las mujeres de toda clase y condición, cosa común al constitucionalismo español del XIX, sino también a los sirvientes domésticos; no garantizaba tampoco los derechos de reunión y asociación, indisolublemente ligados a los principios democráticos de participación y pluralismo. Esta Constitución, además, si bien permitía una 
le debía: “... sobre todo, el progreso innegable de las libertades públicas, prestigio de los pueblos modernos..."262. Por lo que hace al ámbito de la organización de justicia no hay duda de que sienta los principios que regirán en las centurias siguientes. Aunque, su desarrollo efectivo lo harán diversos textos jurídicos posteriores. Especialmente significativos tanto el Reglamento provisional para la administración de justicia de 1835 como la Ley Orgánica del Poder Judicial de $1870^{263}$. No serán las únicas disposiciones normativas pues cien años de vaivenes políticos ${ }^{264}$ habian traído una maraña normativa compleja y a menudo contradictoria. Pero el zigzagueo legislativo no logró impedir la consolidación de sus principios en el curso en el que se le homenajeaba. Así lo reconocía expresamente el diario ABC en su crónica de loa a su centenario:

“... Código tan recio, verdaderamente tan fundamento y estribo de nuestro Estado moderno, que a él se debe -con la reforma de los tiempos- el Poder judicial -declarado con toda independencia, sin función delegada...".

Fecha de envio / Submission Date: 21/04/2016

Fecha de aceptación / Acceptance Date: 19/05/2016

autonomía en el ámbito municipal, consagraba un Estado fuertemente centralizado, que reforzaba las tendencias administrativas centripetas que, tanto en la Península como en América, había iniciado la monarquía borbónica desde la entronización de Felipe V. Por último, pero no lo menos importante, la Constitución de Cádiz mantenía la confesionalidad del Estado y la intolerancia religiosa... A pesar de lo dicho, tanto el liberalismo doceañista como la Constitución de Cádiz era lógico que ejerciesen un gran atractivo en los demócratas españoles del siglo XIX”.

262 ABC de 19 de marzo de 1912.

263 No comparte esta afirmación A. Carretero Pérez, "La administración de justicia desde 1808 a 1833 y de 1833 a 1868", op. cit., p. 83 para quien si bien "el principio politico fue realmente implantado en la Constitución de 1812" su desarrollo real se debió a "las demás Constituciones y las leyes ordinarias desde 1833 a 1868, de manera que la Ley Orgánica casi nada innovó que no se hallara antes ya establecido".

264 Vid., entre otros, M. Ballbé, "La justicia española en la historia constitucional, desde 1812 a 1978: una justicia civil teórica versus una justicia militar dominante” en J. M. Scholz (ed.), El tercer poder. Hacia una comprensión histórica de la justicia contemporánea en España, op. cit., pp. 381394. 